\title{
Molecular characterisation of Sitobion avenae F. clones and their interaction with different host plants
}

\author{
Dissertation \\ to obtain the Ph. D. degree \\ presented by \\ Hussein Alkhedir \\ born in Albab, Syria
}

in the Faculty of Agricultural Sciences,

Georg-August-University Göttingen, Germany

Göttingen, October 2009 
D7

1. Name of referee: Prof. Dr. Stefan Vidal

2. Name of co-referee: Prof. Dr. Petr Karlovsky

Date of dissertation: 21.10 .2008 
Contents

page

Abstract (English) $\quad 6$

$\begin{array}{ll}\text { Abstract (Deutsch) } & 7\end{array}$

Introduction $\quad 8$

$\begin{array}{lr}\text { Chapter } 1 & 12\end{array}$

Diversity of bacterial symbionts and host plant performance in clones of the English Grain Aphid Sitobion avenae F. (Insecta: Homoptera)

Abstract

1-1Introduction 14

1-2 Material and methods $\quad 15$

1-2-1 Aphid cultures

1-2-2 culturing of host plants

1-2-3 Microsatellite genotyping

1-2-4 Detection of bacterial endosymbionts and assessment of their diversity

1-2-5 Molecular phylogenetic analysis

1-2-6 Clonal performance of Sitobion avenae

1-2-7 Statistic analysis:

1-3 Results

1-3-1 DGGE profiles and phylogenetic diversity of Sitobion clones

1-3-2 Clonal performance of Sitobion avenae

1-4 Discussion

1-4-1 Endosymbiontic bacteria of Sitobion avenae clones

1-4-2 Clonal performance of Sitobion avenae clones

Chapter 2

Effect of sugar proportion and aphid endosymbionts on grain aphid (Sitobion avenae F.) specialisation on cocksfoot cultivars

Abstract

2-1 Introduction

2-2 Material and methods

2-2-1 Host plants used in experiments

2-2-2 Aphid cultures and rearing procedures

2-2-3 Experimental procedures

2-2-4 Clonal performance on cocksfoot

2-2-4-1 Performance of selected clones 1-10 on ten cocksfoot cultivars

2-2-4-2 Performance of all collected clones on cultivar Amba 
2-2-4-3 Performance of clone 5 on wheat with advanced feeding on cultivar Amba 2-2-4 Statistic analysis

2-3 Results

2-3-1 Performance of selected clones 1-10 on ten cocksfoot cultivars

2-3-2 Performance of all collected clones on cultivar Amba

2-3-3 Performance of clone 5 on wheat with advanced feeding on cultivar Amba

2-4 Discussion

2-4-1 Impact of host origin on performance and specialisation

2-4-2 Influence of WSC on S. avenae performance and specialization on cocksfoot 2-4-3 Influence of secondary bacterial endosymbionts on tolerance of $S$.avenae clones to WSC and host specialisation of S. avenae

Chapter 3

Host plants use, performance and fitness of grain aphid Sitobion avenae F. clones in central Germany

Abstract

3-1 Introduction

3-2 Material and methods

3-2-1 culturing of host plants

3-2-2 Aphid cultures

3-2-3 Experimental set up

3-2-4 Statistics

3-3 Results

3-3-1 Genetic variability, variation in life history traits, bacterial endosymbionts and clonal performance

3-3-1-1 Production of offspring

3-3-1-2 Fresh weight (host plants utilization or fitness)

3-3-1-3 Alatae production

3-3-1-4 Survival

3-3-2 Genetic Stability of S. avenae clones

3-4 Discussion

3-4-1 Genetic stability, variation in life history traits and host adaptability of S. avenae clones

3-4-2 Secondary bacterial endosymbionts of Sitobion avenae clones

3-4-3 Common and clones of Sitobion avenae

Chapter 4 
The effect of light intensity on the colour morph formation and performance in grain aphid clones (Sitobion avenae F.) (Homoptera: Aphididae)

Abstract

4-1 Introduction

4-2 Material and methods

4-2-1 Aphid cultures and determination of light intensity

4-2-2 Determination colour of Sitobion avenae on host plants

4-2-3 Determination colour of Sitobion avenae Clone 9 reared in petri dishes

4-2-4 Determination colour of clone 6 reared on one seedling in transparent culture

4-2-5 Performance of all tested $S$. avenae clones under different light intensities

4-2-6 Carotenoides analysis of Sitobion clones

4-2-7 Statistic analysis

4-3- Results

4-3-1 Colour morphs under different light intensities on different host plants

4-3-2 Colour morphs of clone 9

4-3-3 Colour change of clone 6

4-3-4 Effect of light intensities on clonal Performance of Sitobion avenae clones

4-3-4-1 Population size of aphid

4-3-4-2 Fresh weight

4-3-4-3 Alate production

4-3-5 Performance of different colour morphs of Sitobion avenae

4-3-6 Carotenoides of Sitobion avenae clones

4-4 Discussion

4-4-1 Impact of light intensity on colour formation S. avenae clones

4-4-2 Impact of light intensity on clonal performance of $S$. avenae clones

4-4-3 Selective advantages of colour in Sitobion avenae clones

Discussion

References

Acknowledgments

Publication

Curriculum vita 


\section{Abstract (English)}

The English grain aphid, Sitobion avenae (F.), is an important pest in agricultural ecosystems, especially in temperate climates on the northern and southern hemisphere. We studied the specialization and adaptability of $10 \mathrm{~S}$. avenae clones in relation to the presence of symbiotic bacteria on different host plants in response to different light regimes. The clones used in the study and their symbiotic bacteria were genetically characterized; eight of them are common in Germany; nine of them have secondary bacterial endosymbionts. We hypothesized that genetic diversity of the clones, their endosymbiotic bacteria, variation in life history traits, light intensity, and water soluble carbohydrates, respectively mediate the interactions between $S$. avenae clones and their host plants. We found that colour morphs of Sitobion avenae clones are genetically determined and expressed by light intensity. Furthermore light intensity affects the performance of Sitobion avenae clones. Also, we found that water soluble carbohydrates of cocksfoot trigger the specialization in Sitobion avenae clones and the adaptation. Finally we argue that the specialization of Sitobion avenae clones result from interactions between the clones and the host plants, mediated by the specific endosymbiotic bacteria. 


\section{Zusammenfassung (Deutsch)}

Die Große Getreideblattlaus, Sitobion avenae (F.), ist ein wichtiger Schädling in Agrar- Ökosystemen, besonders in gemäßigten Klimazonen auf der nördlichen und südlichen Hemisphäre. Wir untersuchten die Spezialisierung und Adaptation von $10 \mathrm{~S}$. avenae- Klonen in Bezug auf das Vorhandensein von symbiotischen Bakterien auf verschiedenen Wirtspflanzen und in Bezug auf verschiedene Licht-Regime. Die Klone in dieser Studie und ihre symbiotischen Bakterien wurden genetisch charakterisiert; acht von innen sind häufig in Deutschland; neun von ihnen haben sekundäre bakterielle Endosymbionten. Wir postulieren, dass die genetische Variabilität der Klone, bedingt durch ihre endosymbiotischen Bakterien, ihre Polymorphismus, und die Lichtintensität und die in der Pflanze vorhandenen wasserlöslichen Kohlehydrate die Interaktionen zwischen den S. avenae Klonen und ihren Wirtspflanzen vermitteln. Wir haben festgestellt, dass die Farbe des Sitobion avenae Klone genetisch festgelegt ist und durch die Lichtintensität beeinflusst wird., Die Lichtintensität wirkt sich ausserdem auf die Performance der S. avenae Klone aus. Wir haben weiterhin gefunden, dass die wasserlöslichen Kohlehydrate des Knäuelgrases (Dactylis glomerata) Auslöser der Spezialisierung der S. avenae Klone sind. Die Adaptation und Spezialisierung der S. avenae Klone ist Ergebnis der Interaktionen zwischen den Klonen und den Wirtspflanzen und wird durch die spezifischen endosymbiotischen Bakterien vermittelt. 


\section{Introduction}

Aphids are a species rich gropu of herbivorous insects including about 4700 species worldwide; 100 of them are economically important (Eastop \& Blackmann, 2007). Aphids have a very remarkable life cycle as compared to other animal groups; they comprise parthenogenetic and sexual generations, exhibit polymorphism, obligately shift between unrelated host plant taxa, have a short generation time (about 10 days on average), and telescoping generations where granddaughters begin to develop directly within the daughters which are themselves not yet born (Dixon, 1985). So far 50\% of the known insect biotypes with cyclic parthenogenetic generations on agricultural crops showing host plant specialization are aphids (Saxena \& Barrion, 1987).

Moreover, aphids show colour polymorphisms (Blackman and Estop, 1984; Dixon, 1998) which may have selective advantages given certain conditions. For instance, colour polymorphisms may positively influence the escape behaviour of aphids from their predators (Braendle \& Weisser, 2001) , may impact foraging behavior of coccinellid species (Harmon et al., 1998), may effect the performance of aphids (Weber, 1985) and is regarded to be involved in resistance to aphid parasitoids (Ankersmit, 1981 \& 1986). The abiotic factors causing colour polymorphisms, such as light intensity, photoperiods and temperature affect not only the colour formation of aphids but also they fecundity of aphid (Markkula et al., 1965, 1967) and at the same time the quality of its host plants.

Almost all aphids harbour the obligate bacterial endosymbiont Buchnera aphidicola (Buchner 1965) which provides aphids with essential amino acids (Douglas, 1998; Dixon, 1998).

Buchnera produces abundant amounts of a specific protein named symbionin which is involved in the transmission of viruses (Van den Heuvel et al., 1994 \& 1997). In addition to Buchnera, aphid may harbour secondary bacterial endosymbionts (Buchner, 1965; Chen et al., 1996 \& 2000; Fukatsu \& Ishikawa, 1993; Fukatsu et al., 1998, 2000, 2001 \& 2002; Sandström et al., 2001), which have been abbreviated with PAUS, PABS and PASS, but which have been identified in the meantime as Regiella insecticola (U type), Hamiltonella defensa ( $T$ type) and Serratia symbiotica ( $R$ type), respectively. Secondary bacterial endosymbionts interact with different aphid traits, such as host-plant range and specialization (Chen et al., 2000; Tsuchida et al., 2004) or thermal tolerance (Montllor et al., 2002; Russell \& Moran, 2006). They are also involved in improvement of fitness of aphid species on specific host plants (Leonardo et al., 2003; Tsuchida et al., 2004) and 
may confer resistance to parasitoids and fungal pathogens (Oliver et al., 2003 \& 2005; Ferrari et al., 2004; Scarborough et al., 2005).

Food primary and secondary compounds mediate the interaction between insects and their host plants, and shape the relationship between plants and insect herbivorous; at the same time the quality of food can directly affect the potential fecundity of herbivores insect. Compounds of the plant sap, such as nitrogen compounds, carbohydrates, amino acids and many other compounds modulate the relationship between insects and their host plants (Awmack et al., 2002) Water soluble carbohydrates (WSC) are food compounds known as good indicators for drought or salt tolerance in wheat (Kerepesi \& Galiba, 2000). In rye grass WSC is also known as an indicator of production and contribute to an increased milk production (Smith et al., 1997; Mayland et al., 2001; Miller et al.,2001). So far there is no clear evidence whether WSC in wheat influence resistance of cultivars to S. avenae (Ciepiela et al., 1999).

The English grain aphid, Sitobion avenae (F.), is an important pest in agricultural systems, especially in temperate climates on the northern and southern hemisphere (Blackman \& Eastop, 1984; Vickerman \& Wratten, 1979). It was reported as a vector of BYDV in Africa, Europe, Asia, Japan, Indonesia, Taiwan (Province of China), and North \& South America, respectively (FAO, 2002). The grain aphid is present on grasses of the family Gramineae, including cereals throughout the year; this species can be considered to be autoecious and restricted to Gramineae. Cocksfoot (Dactylis glomerata L.) is one of the common weeds in cereal fields, furthermore some cultivars are used as foraging grass and are known as a host plants of S. avenae.

Surveys of the population structure of $S$. avenae revealed genetic variability in $S$. avenae populations, a spatial and temporal variation and the existence of predominant cyclic parthenogenetic clones (Sunnucks et al., 1997; Simon et al., 1999; Haack et al., 2000; Papura et al., 2003, Reimer, 2005). In central Germany several common genotypes were found on wheat from 2001 to 2003 (Reimer, 2005), and these common genotypes differed in colour.

Moreover, there is evidence for host-based genotypes or specialized clones on Dactylis glomerata (De Barro et al. 1995 a; Sunnucks et al., 1997).

The existence of host based genotypes was inferred from host plant collections and performance on D. glomerata in addition to molecular indicators. Clonal performance on 
cocksfoot alone was not sufficient to explain the specialization of $S$. avenae on this grass species.

The colour morphs of S. avenae F. differ from green to red-brown to pink (Phillips, 1916; Müller, 1961; Markkula et al., 1963, 1965, 1967; Jenkins et al., 1991\& 1999). Colour polymorphism of $S$. avenae results mainly from differences of carotenoide proportions (Jenkins et al., 1991, 1999). However, the mechanisms determining the induction of colour morphs in S. avenae is still not understood in detail.

Up the now no secondary symbiotic bacteria were recorded from S. avenae clones, thus their contribution to fitness parameters or specialization are not known.

We have collected several common clones (related to different genotypes and different colour morphs) on wheat, D. glomerata and other graminoid grasses in central Germany; in order to understand the interaction between these grasses and other potential host plants in addition to factors mediating these interaction and responsible for the occurrence of the common clones.

We hypothesized that

1- The endosymbiotic bacteria contribute to the adaptability and fitness of Sitobion avenae clones, hence to their distribution. (chapter 1)

2- Water soluble carbohydrate proportions in Dactylis glomerata trigger the resistance of Sitobion avenae clones and that bacterial endosymbionts may play a role in this process (chapter 2).

3- The genetic diversity and variation in life history traits affect the abundance of the common Sitobion avenae clones and that the secondary bacterial endosymbionts contribute to performance of the common clones on their agricultural host plants, thus contribute to their distribution (chapter 3 ).

4- Sitobion avenae clones are influenced by light intensity, which in turn affects the fecundity, fitness, alate production in addition to colour formation (chapter 4).

The interaction between Sitobion avenae clones and their host plants mediated by the parameters mentioned above result in host plant-based clones, most commonly found under prevailing environemental conditions in central Germany. 
To test these hypotheses we first genetically characterized the clones. Thereafter we screened these clones for their secondary bacterial endosymbionts. We then studied the clonal performance of $S$. avenae clones on wheat, bluegrass and ryegrass during three successive generations in addition to 10 Dactylis glomerata cultivars differing in their WSC levels. In these cases we regarded clonal polymorphisms and bacterial endosymbionts contributing to performance, adaptability and fitness of Sitobion avenae clones. Finally we tested the performance, fitness, and colour formation of Sitobion avenae clones on wheat using different light regimes to understand the interaction between light intensity and genetic factors on these parameters. 


\section{Chapter 1}

Diversity of bacterial symbionts and host plant performance in clones of the English Grain Aphid Sitobion avenae F. (Insecta: Homoptera)

Hussein Alkhedir ${ }^{1}$, Petr Karlovsky ${ }^{2}$, Stefan Vidal ${ }^{3}$

${ }^{1,3}$ Agricultural Entomology and ${ }^{2}$ Molecular Phytopathology and Mycotoxin Research, Georg-August University Goettingen, Grisebachstrasse 6, 37077 Goettingen, Germany

Keywords : Sitobion avenae, Regiella insecticola, Hamiltonella defensa, DGGE, Endosymbionts

Corresponding author:

Hussein Alkhedir

Agricultural Entomology

Georg-August University Goettingen

Grisebachstrasse 6

37077 Goettingen, Germany

Tel +49551393728

Fax +495513912105

email: halkhed@gwdg.de

Running title: Bacterial endosymbionts of Sitobion avenae 


\begin{abstract}
Primary and secondary endosymbionts of aphids affect their performance on host plants and other traits. The genetic diversity of both aphid and their bacterial endosymbionts is known to modulate these affects. Sitobion avenae is one of common cereal aphids, but neither the diversity of its primary endosymbionts has been studied nor have secondary bacterial endosymbionts of $S$. avenae been reported. We investigated the endosymbionts in Sitobion avenae by characterizing all bacterial endosymbionts in ten genetically defined $S$. avenae clones, eight of which are wide-spread in Germany, by denaturing gradient gel electrophoresis (DGGE). Furthermore, we sequenced 16S RNA genes of the primary endosymbiont Buchnera aphidicola and secondary endosymbionts Regiella insecticola and Hamiltonella defensa, respectively from these clones. While the divergence of $16 \mathrm{~S}$ sequences of $B$. aphidicola within $S$. avenae was the lowest among the three endosymbionts $(0.11 \%$ compared to $0.32 \%$ and $0.70 \%$ for Hamiltonella defensa and Regiella insecticola, respectively), the distance between $B$. aphidicola sequences from $S$. avenae and other aphid species (up to $7 \%$ ) indicated that the host specialization in $B$. aphidicola reached the speciation stage. Secondary endosymbionts were found in nine of the ten clones investigated: four clones harboured Hamiltonella defensa while five clones contained Regiella insecticola. We compared the clonal performance of the clones on four host plants. The performance varied significantly between clones and was affected by both the plant species and bacterial endosymbionts. Our results showed that the clonal performance of $S$. avenae is affected by a complex of factors including the genotype, bacterial endosymbionts, the host plant species and the interaction among all three factors.
\end{abstract}




\section{Introduction}

Almost all aphids harbour the obligate bacterial endosymbiont Buchnera aphidicola (Buchner 1965) providing aphids with essential amino acids (Douglas 1998; Dixon 1998). In the absence of $B$. aphidicola, aphids suffer from sterility or mortality (Houk \& Griffiths1980; Ohtaka \& Ishikawa 1991). B. aphidicola produces abundant amounts of a specific protein named symbionin which is a homologue of the GroEL protein of Escherichia coli (Baumann et al. 1995; Filichkin et al.1997) which functions in protein folding, translocation across membranes, and recovery from stress (Baumann et al. 1995). Moreover, symbionin is involved in the transmission of viruses (Van den Heuvel et al.1994 \&1997). In addition to B. aphidicola, aphids may harbour secondary bacterial endosymbionts (Buchner 1965; Chen et al.196, 2000; Fukatsu \& Ishikawa1993; Fukatsu et al.1998, 2000, 2001, 2002; Sandström et al. 2001), which have been previously named as PAUS, PABS and PASS, later on identified as Regiella insecticola (U type), Hamiltonella defensa ( $T$ type) and Serratia symbiotica ( $R$ type), respectively. Secondary bacterial endosymbionts interact with different aphid traits, such as host-plant specialization (Chen et al. 2000; Tsuchida et al. 2004) and thermal tolerance (Montllor et al. 2002; Russell \& Moran 2006). They are also involved in the improvement of fitness of aphids on specific host plants (Leonardo et al. 2003; Tsuchida et al. 2004) and may confer resistance to parasitoids and fungal pathogens (Oliver et al. 2003 \& 2005; Ferrari et al. 2004; Scarborough et al. 2005).

The English grain aphid, Sitobion avenae ( $F$.$) , is an important pest in agricultural systems,$ especially in temperate climates on the northern and southern hemisphere (Wangai et al. 2000) and is regarded a major aphid pest on cereals in Germany (Weber 1985).

Virtually nothing is known about the diversity of the primary endosymbionts (B. aphidicola) in this species and no secondary bacterial endosymbionts has been reported in $S$. avenae so far.

The elimination of Buchnera $s p$. from Sitobion avenae caused a weight reduction and delay in larval development as other aphid species (Caillaud et al. 1999). On the molecular level only the GroEL gene from B. aphidicola is sequenced from S. avenae (Ohtaka et al. 1992; Filichkin et al.1997)

In this study we investigated the diversity of primary and secondary bacterial endosymbionts of Sitobion avenae and the impact of endosymbionts on the performance of aphids on different plants. 


\section{1-2Material and methods}

\section{1-2-1Aphid cultures}

We collected 65 Sitobion avenae clones from different regions in central Germany, Goettingen, Kassel and Giessen, respectively, in 2004 by sweep-net sampling from wheat (Triticum aestivum), cocksfoot (Dactylis glomerata) and graminoid grasses. Clones were established from single aphids kept on wheat seedlings (winter wheat cultivar "Bussard"; Lochow Petkus company, Germany) grown in pots with a diameter of $11 \mathrm{~cm}$, filled with a 2:1 mixture of soil (Fruhstorfer Typ P) and sand, and covered with transparent ventilated cylindrical tubes of $10 \mathrm{~cm} \times 30 \mathrm{~cm}$ size. Aphids were transferred to new plants every second week and the cultures were kept at $20 \mathrm{C}^{\circ}$ and 16:8 light/dark hour conditions, 60$80 \%$ humidity in rearing cabinets; water was applied twice a week. Given these conditions all clones reproduced parthenogenetically. The 10 clones used in this study were selected based on five microsatellite loci as described by Reimer (2005) representing 6 common genotypes regularly occurring in central Germany (Table1 and 2). A clone of Acyrthosiphon pisum (Harris), known to harbour Serratia symbiotica, originally collected on the campus site of the university and reared under constant conditions in the institute for many generations, and a clone of Aphis fabae fabae, also originating from the campus and known to harbour no secondary bacterial endosymbionts, were used for outgroup comparisons.

\section{1-2-2Culturing of host plants}

These 10 clones were tested on several grass species. Seeds of Dactylis glomerata cv." Prairial" were obtained from the National Agricultural Research Center for Hokkaido Region, seeds of Phalaris arundinacea (culture form), Elymus repens (syn = Agropyron $r$.) and Holcus lanatus (wild type form) were obtained from Appels Wilde Samen Company, Germany. These seeds were germinated in the greenhouse in trays filled with a mixture 2:1 of soil (Fruhstorfer Typ P) and transplanted to pots with a diameter of $11 \mathrm{~cm}$, filled with the same soil mixture. These seedlings were used for the experiments when being 4 weeks old.

\section{1-2-3Microsatellite genotyping}

DNA was extracted from individual aphids following the 'salting out' protocol of Sunnucks \& Hales (1996). Genotypes were determined at five microsatellite loci: Sm10, Sm11, Sm17 (Sunnucks et al. 1996), Sa4 $\Sigma$ (Simon et al. 1999) and S16b (Wilson et al. 2004). Sm11 is linked to the X-chromosome (Wilson et al. 1997), whereas all the others are autosomal (Simon et al.1999). Polymerase chain reactions (PCRs) were performed in 10 $\mu$ l volumes containing 0.5 units of recombinant Taq (rTaq TAKARA BIO INC, Japan) polymerase, 
$\mathrm{Mg}^{2+}$-free reaction buffer, $200 \mu \mathrm{M}$ dNTPs (TAKARA), $5 \mathrm{pmol}$ of each primer (ROTH), $10 \%$ DMSO, $2 \mathrm{mM} \mathrm{Mg}^{2+}$ (as $\mathrm{MgCl}_{2}$ ) and $2 \mu \mathrm{l}$ of the ten fold diluted DNA extract (approx. $2-10$ $\mathrm{ng}$ ) for Sm17 and $2.5 \mathrm{mM} \mathrm{Mg}^{2+}$ and $5.8 \mu$ of DNA extract (5.8 $-29 \mathrm{ng}$ ) for all other loci. All PCRs were performed in a BIOMETRA gradient thermocycler with an initial denaturation at $94{ }^{\circ} \mathrm{C}$ for $2 \mathrm{~min}$. This was followed by five touch-down cycles (first cycle $7^{\circ} \mathrm{C}$ higher than final annealing temperature) and 29 cycles with denaturation at $94{ }^{\circ} \mathrm{C}$ for $15 \mathrm{sec}$., and annealing of primers at $55^{\circ} \mathrm{C}$ (30 sec) for $\mathrm{Sm} 17$ and Sm10, $47^{\circ} \mathrm{C}$ for $\mathrm{Sm} 11$, or $60^{\circ} \mathrm{C}$ for $\mathrm{S} 16 \mathrm{~b}$ and Sa4 respectively. Elongation took place at $72^{\circ} \mathrm{C}$, ending with a $10 \mathrm{~min}$ termination step at $72^{\circ} \mathrm{C}$. Gel electrophoresis in $6 \%$ denaturating polyacrylamide and silver staining was performed as described in Llewellyn et al. (2003). Allele sizes were estimated using a sequencing size ladder, prepared by sequencing the pGEM-3Zf $(+)$ vector (PROMEGA) using the 'Thermo Sequenase Cycle Sequencing Kit' (USB, USA). Gels were documented using a digital camera. Image analysis was performed with the Digitrace software package (IMATEC Elektronische Bildanalysesysteme $\mathrm{GmbH}$, Germany).

\section{1-2-4Detection of bacterial endosymbionts and assessment of their diversity}

DNA was extracted from aphids using the salting-out protocol of Sunnucks et al. (1996). Bacterial 16S rDNA was amplified using two pairs of primers (Table 3) which amplified two different parts of $16 \mathrm{~S}$ rDNA. The first pair F-968-GC and 1401R-GC are general primers used to amplify bacterial $16 \mathrm{~S}$ rDNA (Nübel et al. 1996). The PCR was conducted as follows: The reaction mixture contained 1X PCR puffer (Bioline, U.K.), $3 \mathrm{mM} \mathrm{MgCl}, 0.2$ $\mathrm{mM}$ dNTP, $0.8 \mu \mathrm{M}$ each primer, and $0.5 \mathrm{U}$ Taq polymerase (Bioline, U.K.) in a total volume of 25 I. PCR was performed in a gradient thermocycler (Biometra, Germany) with an initial denaturation temperature at $94{ }^{\circ} \mathrm{C}$ for $3 \mathrm{~min}$ followed by 13 touch-down cycles (denaturation $1 \mathrm{~min}$ at $94^{\circ} \mathrm{C}$, annealing $30 \mathrm{~s}$ from $67^{\circ} \mathrm{C}$ to $50^{\circ} \mathrm{C}$, elongation $1 \mathrm{~min}$ at $72^{\circ} \mathrm{C}$ ) and 25 cycles with annealing for $30 \mathrm{~s}$ at $55^{\circ} \mathrm{C}$ and the same denaturation and elongation parts. The final extension was carried out for $5 \mathrm{~min}$ at $72.5^{\circ} \mathrm{C}$. The second primer pair used was Buch 16S rDNA forward and Buch 16S rDNA reverse primers, which amplified only 16S rDNA of Buchnera aphidicola (Fukatsu 2001). The PCR reaction mixture contained $1 \mathrm{X}$ PCR puffer, $2 \mathrm{mM} \mathrm{MgCl}$, $0.2 \mathrm{mM}$ dNTP, $1 \mu \mathrm{M}$ each primer, $0.25 \mathrm{U}$ Taq (Bioline, U.K.) in a 25 I reaction. PCR were performed with 30 cycles of a denaturation temperature at $94 \mathrm{C}^{\circ}$ for $1 \mathrm{~min}$, annealing at $58 \mathrm{C}^{\circ}$ for $1 \mathrm{~min}$, and elongation at $72 \mathrm{C}^{\circ}$ for $2 \mathrm{~min}$; terminal extension was performed for $5 \mathrm{~min}$ at $72 \mathrm{C}^{\circ}$. Both amplified products were approximately 400 bp long. PCR products were analyzed on $1.7 \%$ agarose gel after separation at $10 \mathrm{~V} / \mathrm{cm}$ for $60 \mathrm{~min}$. 
The diversity of bacterial endosymbionts was analysed by denaturing gradient gel electrophoresis (DGGE) (Muyzer et al.1993). DGGE was performed with the INGENY phorU system (INGENY international BV, The Netherlands). PCR products were applied onto $7.5 \%$ (wt/vol) polyacrylamide gels in $0.5 x$ TAE buffer $(20 \mathrm{mM}$ Tris acetate, $10 \mathrm{mM}$ sodium acetate, $0.5 \mathrm{mM}$ Na2EDTA, $\mathrm{pH}$ 7.4). The gradients were formed with $7.5 \%$ (wt/vol) acrylamide stock solutions (Acrylamide-N,N'-methylenebisacrylamide, 37.5:1) containing 35 - 65\% denaturant (5.6 M Urea and $32 \%$ (vol/vol) deionised formamide). Electrophoresis was performed at a constant voltage of $120 \mathrm{~V}$ and a temperature of $60^{\circ} \mathrm{C}$ for 16 hours. After electrophoresis, the gels were silver-stained as described by Llewellyn et al. (2003). Band patterns were recorded using a flatbad scanner (Scan Jet 5300C, hp) with a resolution of $150 \times 150 \mathrm{dpi}$.

DNA bands were cut from the gels and incubated overnight in $100 \mu$ listilled water; thereafter $6 \mu \mathrm{l}$ were used as a template for the PCR, as described above, however this time without touch down cycles with primers F-968-Sdal/1401r-Notl and Buch 16S rDNA forward-Sdal/Buch 16S rDNA reverse-Notl, which contained recognition sites for restriction endonucleases Sda I and Not I (Table 3). The amplified rDNA fragments were digested with Sdal and Not I (Fermentas, Europe) and inserted into the cloning vector pBluescriptSK- (Short et al. 1988) digested with the same enzymes and ligated using T4 ligase (Fermentas, Europe). Ligation products were transformed into chemical competent E. coli DH5a. The transformed cells were grown on SOC medium for one hour, followed by plating on MacConkey agar plates (Karlovsky 1993) (Difco, Detroit, Michigan, USA) with $100 / \mathrm{ml}$ ampicillin for 16 hours. White colonies were streaked onto LB plates (Sambrook et al. 1989) with $100 \mathrm{~g} / \mathrm{ml}$ ampicillin. Plasmid DNA was prepared using QIAprep Spin Miniprep Kit (QiAGEN, Germany). DNA sequencing was done by Eurofins MWG GmbH (Germany). All sequences of $16 \mathrm{~S}$ rDNA obtained in this study have been submitted to the Gene Bank; their accession numbers are given within the phylogenetic dendrogramms displayed in the Results section.

\section{1-2-5Molecular phylogenetic analysis}

Multiple alignment of $16 \mathrm{~S}$ rDNA sequences was performed using the programmes BioEdit Version 7.0.0 (Hall 1999) and CLUSTAL X 1.83 (Thompson et al.1997). The phylogenetic analyses were conducted in MEGA4 (Tamura et al. 2007) using Maximum Parsimony (MP) and Neighbor-Joining ( $\mathrm{N}-\mathrm{J})$ methods. For the $\mathrm{N}-\mathrm{J}$ method, the pairwise deletion option was selected, which eliminated positions containing alignment gaps and missing data only in pairwise sequence comparisons (not in the multiple aligment). The $\mathrm{N}-\mathrm{J}$ tree was drawn to scale with branch lengths in the same units as the evolutionary distances 
used, which were computed using the Kimura 2-parameter method (Kimura 1980). The evolutionary distances are expressed in the number of base substitutions per site. The rate variation among sites was modelled with gamma distribution (shape parameter $=2$ ). Bootstrap tests were conducted with 1000 replicates (Felsenstein 1985) to determine the support for individual nodes. MP analysis was conducted using the option "using all sites" which treated gaps as missing data. The MP tree was obtained using the Close-NeighborInterchange algorithm (Nei \& Kumar 2000) with search level 3 (Felsenstein 1985) in which the initial trees were obtained with random addition of sequences (100 replicates). The tree was drawn to scale with branch lengths calculated using the average pathway method (Nei \& Kumar 2000). The rate variation was calculated and bootstrapping performed as described above for the $\mathrm{N}-\mathrm{J}$ method.

\section{1-2-6 Clonal performance of Sitobion avenae}

The clonal performance of the 10 Sitobion clones on the four host plant species described above was evaluated by counting the numbers of aphids surviving in each clone after 30 days, initially introducing ten synchronized first stage nymphs on the respective host plants. Rearing of the nymphs followed the protocol described above. The setup for this experiment was replicated six times for the 3 grass species, except for Dactylis glomerata, which was replicated five times.

\section{1-2-7Statistic analysis:}

GLM (General linear model "estimate mode") Repeated Measures was used to analyze the effect of host plants and clone on the performance of Sitobion avenae, using the aphid populations as the dependent factor, and Sitobion clones, host plants and their interactions as independent factors. Host plants and clones were considered as categorical variables. GLM was also used to analyze the effect of bacterial endosymbionts and host plants on the clonal performance, where aphid populations were the dependent factors, while the bacterial endosymbionts, host plants and the interactions of both parameters were regarded independents factors. Again, host plants and bacteria were considered categorical variables. Fisher's LSD adjustment was used to compare the clonal performance on each host plant species. Systat for Windows, version 11.00 .01 (Systat 2004) was used to perform these analyses. 


\section{1-3Results}

\section{1-3-1DGGE profiles and phylogenetic diversity of Sitobion clones}

DGGE profiles of PCR products obtained with $B$. aphidicola specific primers revealed the invariable presence of $B$. aphidicola in all aphid clones tested (Fig. 1). PCR products separated into two bands. While DNA from band A was re-amplified successfully, reamplification of DNA from band $B$ failed in all samples. Re-amplified fragments were cloned into a plasmid vector pBluescript and sequenced. All inserts had a length of $374 \mathrm{bp}$. The amplified fragments of all rDNA sequences from Sitobion avenae and the Aphis fabae sequence were identical. The sequence of Acyrthosiphon pisum differed in two nucleotides. The sequences were compared to those in the data bank NCBI using blastn suite. The 16S rDNA sequences of $B$. aphidicola from German clones of Sitobion avenae, Acyrthosiphon pisum and Aphis fabae proved to be highly similar to 16S rDNA of $B$. aphidicola sequences stored in the Gene Bank. For example, 16S rDNA of $B$. aphidicola from Acyrthosiphon pisum (accession Nr. M27039) was identical with the sequence obtained from Acyrthosiphon pisum and displayed 99\% identity with the sequences from Sitobion avenae and Aphis fabae.

In order to shed light on the relationship of $B$. aphidicola symbionts from $S$. avenae to $B$. aphidicola from Aphis fabae and Acyrthosiphon pisum, we amplified and cloned the complete 16S gene of $B$. aphidicola, from nine Sitobion avenae clones and the Acyrthosiphon pisum clone using Buch16S1F and 16SB1 primers specific for Buchnera (Table 3 ) and determined their sequences. Cloning the $16 \mathrm{~S}$ gene from $A$. fabae and from S. avenae clone No. 3 failed. After removing primer sequences, nucleotides 1395-1412 of

9 sequences from S. avenae (accessions No. FJ357457 - FJ357465), one sequence from A. pisum (accession No. FJ357466) and 14 sequences of $B$. aphidicola 16S RNA from the GeneBank were subjected to phylogenetic analysis using the Neigbor-Joining (N-J) (Fig. 3) and Minimum Parsimony (MP, data not shown) methods. The number of parsimonyinformative sites (at least two different nucleotides, each of them occurring at least twice) in the whole set was 102 . Sequences from S. avenae clones were very similar, possessing only 6 polymorphic sites, two of them being parsimony-informative. B. aphidicola sequences, from S. avenae clones 5 and 8 were identical. Both of $\mathrm{N}-\mathrm{J}$ - and MPdendrogramms of $B$. aphidicola sequences had the same topology. The B. aphidicola clade of Sitobion avenae appears to be monophyletic and its separation from other $B$. aphidicola strains is highly supported by bootstrap test (100\%). The closest clade to Sitobion is Acyrthosiphon pisum. 
The divergence within Sitobion strains of $B$. aphidicola was $0.1 \%$ substitutions per base pair while the distance between $B$. aphidicola from Sitobion and $B$. aphidicola from the other aphid species ranged from 1.15\% (Acyrthosiphon pisum D) to $6.89 \%$ (Pemphigus betae).

DGGE of PCR products produced with the primers F-968-GC/1401r-GC specific for Eubacteria (Table 3) was used to investigate the variability within bacterial associates from aphid clones (Fig. 1). PCR products partitioned into eleven size classes A-K. DNA from all bands was re-amplified using primers with the same sequences homologous to 16S RNA attached to a 5'-sequences containing the recognition sites for restriction endonucleases Not I and Sda I. Re-amplified fragments were cloned into plasmid vector pBluescript (Short et al., 1988) linearized with Not I/Sda I and sequenced. Cloning and/or sequencing of three fragments (K of clone 9, $\mathrm{C}$ of clone 10 and I of $A$. pisum) failed. The length of the sequenced 27 fragments was 400-401 bp. Sequencing results (accessions No. FJ357467 - FJ357490) revealed that Sitobion avenae clones harbour the secondary bacterial endosymbionts $R$. insecticola (clones 1, 2, 3, 7 and 8) and $H$. defensa (clones 4, 5, 9 and 10 ) in addition to the primary bacterial endosymbionts $B$. aphidicola (Table 4).

Amplified $B$. aphidicola 16S gene fragments were separated by DGGE into 7 bands, five of them belonging to Sitobion clones (1, 2, 3, 7 and 8), one to $A$. fabae (level C) and one to $A$. pisum (level E) (Fig. 1). All amplified R. insecticola $16 S$ gene fragments of $S$. avenae clones (1, 2, 3, 7 and 8) formed a single band on the level J. The amplified $H$. defensa $16 \mathrm{~S}$ gene fragments of Sitobion clones $(4,5,9$ and 10) were separated into 11 bands. $H$. defensa fragments of clones 4 and 5 were separated into 2 bands each $(A$ and $H)$; however, the sequences of these fragments were identical (see Discussion). $H$. defensa fragments of clone 9 were separated into 3 bands on levels $A, C$ and $H$; the sequences of fragments of level $\mathrm{A}$ and $\mathrm{H}$ were identical. $\mathrm{H}$. defensa fragments of clone 10 were separated into 4 bands on levels $D, F, G$ and $H$. Sequencing $16 S$ gene fragments of Sitobion clones 4 (accession No. FJ357474) and 5 (accession No. FJ357476) from level C revealed that they were hybrids of $B$. aphidicola and $H$. defensa sequences. These sequences were excluded from further analysis.

We were unable to assign some of the sequences obtained from the Sitobion clones to known endosymbionts of aphids. For example, the sequence of the amplification products of DNA isolated from $A$. pisum which migrated at the level B (accession No. FJ357488) possessed $100 \%$ identity to Staphylococcus sciuri subsp. rodentium 16S RNA (accession Nr. AB233332). 
The sequences of all $16 \mathrm{~S}$ gene fragments (25 sequences) were subjected to phylogenetic analysis by Neighbour-Joining and Maximum Parsimony methods. The number of informative site in the whole set, which included 39 16S rDNA sequences (25 sequences from this study and the 14 further $16 \mathrm{~S}$ sequences from Gene Bank), was 105. $B$. aphidicola, $R$. insecticola and $H$. defensa of $S$. avenae clones proved to be very similar, possessing only 2, 4 and 5 polymorphic sites, respectively. Among these from those polymorphic sites only two were parsimony-informative in $R$. insecticola and $H$. defensa. Both N-J and MP dendrograms of DGGE band sequences had the same topology (see Fig. 2 for the N-J dendrogram), consisting of 4 main clades well-supported by bootstrap analysis (97-99\%). The distance between the $B$. aphidicola clade and other symbionts was $13 \%$ to $14 \%$ while the distance between $H$. defensa and $R$. insecticola clades was $7 \%$.

To understand the relationship among $R$. insecticola and $H$. defensa strains of Sitobion clones and the endosymbionts from the other aphid species tested, we amplified the 16S gene of both $H$. defensa and $R$. insecticola from all Sitobion clones using forward primers $H$. defensa $\mathrm{F}$ and U99F for $H$. defensa and $R$. insecticola, respectively, and a common reverse primer 16SB1 (Table 3). We used the same PCR protocols as for $B$. aphidicola except for the annealing temperature of $55^{\circ} \mathrm{C}$. After removing the primers sequences, the remaining sequence (1415-1416 nt for $H$. defensa and 1417-1438 nt for $R$. insecticola) were subjected to phylogenetic analysis by Neighbour-Joining methods (Figs. 4 and 5) and Maximum Parsimony (data not shown). The number of informative sites in the set of $15 R$. insecticola sequences was 29. Among them, 5 sequences from Sitobion strains (accessions No. FJ357495 - FJ357499) contained 19 polymorphic sites, 10 of them being parsimony-informative. $H$. defensa strains from all aphids were very similar; while the number of informative sites in the whole set of $14 \mathrm{H}$. defensa $16 \mathrm{~S}$ sequences were 9. Among them, four strains from Sitobion (accessions No. FJ357491 - FJ357494) contained 9 polymorphic sites, none of them being parsimony-informative.

Both N-J and MP dendrograms for $R$. insecticola and $H$. defensa had the same topology. The strain of $R$. insecticola closest to Sitobion strains originated from Pemphigus betae. The evolutionary divergence within the $R$. insecticola strains of Sitobion was $0.7 \%$ while the distance between $R$. insecticola from Sitobion and $R$. insecticola from the remaining species varied from $0.52 \%$ (Pemphigus betae) to $2.76 \%$ (Macrosiphoniella ludovicianae). The evolutionary divergence among all $H$. defensa strains was less than $0.5 \% ; H$. defensa strains from Sitobion avenae were even more similar (divergence less than $0.32 \%$ ). Within S. avenae, primary and secondary endosymbionts were well separated on genus level. 
The distance between $B$. aphidicola and secondary endosymbionts was $14 \%$ while $R$. insecticola and $H$. defensa sequences differred in $8 \%$ nucleotides.

13-2Clonal performance of Sitobion avenae

The performance of Sitobion avenae clones significantly differed on the four host plants tested (Table 4). The mean number of offspring produced on E. repens $(182,2 \pm 110,3$ SD) within 30 days was significantly higher as compared to the offspring produced on $\mathrm{H}$. lanatus $(123,7 \pm 179,8), P$. arundinacea $(15,1 \pm 18,0)$ and $D$. glomerata $(8,8 \pm 13,9)$, respectively (Fig. 7A). All aphid clones performed well on E. repens (Fig. 7B); even the clone performing least on this grass species (clone 10) produced more nymphs as compared to the mean number of offspring produced on $P$. arundinacea and $D$. glomerata (Fig. 2C and D). The clones 4, 9 and 10 produced less offspring as compared to the mean number of offspring produced on $\mathrm{H}$. lanatus (Fig. 2E). The coefficient of variation was least in clones kept on $E$. repens $(60,6)$ and highest on clones kept on D. glomerata $(159,4)$. All clones survived and produced offspring on $E$. repens, $H$. lanatus and $P$. arundinacea, whereas only 4 clones survived and produced offspring on $D$. glomerata.

When comparing clonal performance between the 4 grass species tested, no clone preformed equally well on all grasses. For example, clone 6 , harbouring the primary endosymbionts $B$. aphidicola only, performed best on $E$. repens and $H$. lanatus as compared to all other clones, whereas on $P$. arundinacea offspring production was at the level of most other clones; this clone did not survive on $D$. glomerata. On the other hand, clones 7 and 8 , harbouring $R$. insecticola, survived on all grasses; however, the former performed least on $\mathrm{P}$. arundinacea, while both performed best on $D$. glomerata. Clones 4 , 5,9 and 10 , respectively, all harbouring $B$. aphidicola and $H$. defensa performed well on $E$. repens, $P$. arundinacea, and $H$. lanatus, while survival on $D$. glomerata was only found in clone 5 . $H$. defensa symbionts were closely related in clones 4,5 , and 9 (Fig. 5 ), whereas $H$. defensa of clone 10 was only marginally related to the $H$. defensa strains of the former clones.

In general, we found no consistent pattern of clonal offspring production versus host plant performance. All clones significantly differed with regard to host plant performance (Tab. 4), and the interaction between host plant performance and clone being also significant. Clones harbouring either $H$. defensa or $R$. insecticola did not perform better on the host plants tested as compared to clones with not secondary endosymbionts (clone 6).

Clones 5 and 10, distinctly separated by the $16 \mathrm{~S}$ rDNA $R$. insecticola sequences, performed significantly different on $H$. lanatus, whereas clone 9 , related to clones 4 and 5 , performed significantly less on the same grass species. 


\section{1-4Discussion}

\section{1-4-1Endosymbiontic bacteria of Sitobion avenae clones}

Apart from confirming the presence of Buchnera aphidicola in S. avenae (Buchner 1965), secondary endosymbionts Regiella insecticola and Hamiltonella defensa were for the first time detected in this aphid species. Each bacterial 16S RNA-gene fragment amplified from S. avenae and separated by DGGE fell into one of the three species clusters well supported by bootstrapping (Fig. 2), indicating that the inventory of bacterial endosymbionts of $S$. avenae was complete.

Vertical transmission of endosymbiontic bacteria in insects limits the genetic exchange and shapes the genome evolution in endosymbionts (Moran and Mira, 2001). These phenomena can be studied by comparing gene sequences. Although many genes of B. aphidicola and eventually its whole genome were characterized (Shigenobu et al. 2000), the only sequence of a protein-coding gene of $B$. aphidicola from $S$. avenae available so far is groEL (Hasan et al. 1996). It has been hypothesized (Hara et al. 1990; Baumann et al. 1996) and very recently experimentally proven (Huang et al. 2008) that GroEL plays a specific role in the biology of endosymbionts by counteracting destabilizing mutations accumulating due to the limited purifying selection in Buchnera (Moran 1996; Wernegreen et al. 2001), caused by the reduced effective population size of the symbiont (Mira and Moran 2002). We compared the sequence of groEL from B. aphidicola from $S$. avenae with sequences obtained from primary endosymbionts other aphids (Ohtaka et al. 1992; Filichkin et al. 1997). The distance of groEL sequence of S. avenae from homologous sequences from other aphids at nucleotide level varied from 7.8\% (Acyrthosiphon pisum) to $13 \%$ (Schizaphis graminum and Rhopalosiphum sp.) (Fig. 6). The topology of a dendrogram of 16S RNA gene sequences was identical with the topology of the dendrogram of nucleotide sequences of groEL (comp. Figs. 3 and 6), though the divergence was much smaller $(1.4 \%-2.4 \%)$.

The distance between groEL gene from S. avenae from homologous genes of other aphid endosymbionts on amino acid level was larger than the distance on the nucleotide level ( $14.8 \%$ from $A$. pisum and $21.6 \%$ from $S$. graminum), which is typical for vertically transmitted endosymbionts (Moran 1996; Moran et al. 2008). High ratios of nonsynonymous to synonymous substitutions in protein coding genes generally indicate the lack of purifying selection. The analysis of GroEL sequences has shown, however, that the evolution of GroEL in endosymbionts was subjected to both purifying and positive selection (Fares et al. 2002). In this respect, GroEL differs from other protein-coding genes of aphid endosymbionts (Fares et al. 2004). 
Do the relationships among $B$. aphidicola populations from different aphid species reflect phylogenetic relationships among their hosts? Based on 16S RNA sequences, the endosymbiont closest to Buchnera from S. avenae originated from Acyrthosiphon pisum (distance $1.35 \%$ ), which is a non cereal aphid. Surprisingly, B. aphidicola endosymbionts from other cereal aphids such as Schizaphis graminum $(2.12 \%$ distance $)$ and Rhopalosiphum sp. (2.35\% distance) were most distant to $B$. aphidicola from $S$. avenae (Fig. 3). Because B. aphidicola became associated with an aphids ancestor before the radiation of aphid species began, the genome of both organisms as believed to coevolve. Branching patterns of dendrograms constructed from selected gene sequences were indeed shown to be similar (Baumann et al. 1997; Clark et al. 2000). This phenomenon appears to be wide-spread in sap-feeding insects and their endosymbionts (e.g., Thao et al. 2000). We cannot conclusively explain the lack of association between the specialization of aphids to cereals and the relatedness of their $B$. aphidicola endophytes. The speciation and host specialization in aphids might not be fully congruent because domestication of cereals was a recent event on the evolutionary time scale.

The low level of molecular diversity as indicated by $16 S$ sequences of $B$. aphidicola from $S$. avenae confirmed the low level of diversity previously reported for this endosymbiont for Pemphigus obesinymphae host (Abbot and Moran 2002). The strictly vertical transmission of the endosymbiont, which prevents gene exchange among endophytes from different individuals of the host, would normally generate diversifying clonal populations. The lack of diversification in $B$. aphidicola from $S$. avenae clones supports the conclusion that the effective population size of both Buchnera and its host are small (Abbot and Moran 2002), drawn from the observation that molecular polymorphisms were found exclusively in rare alleles. Differences among $B$. aphidicola sequences from different aphid species were low, too. When B. aphidicola was established as a type species for genus Buchnera, Baumann speculated that it might require splitting into several species in future (Baumann et al. 1995). As 14 years passed since this work and no taxonomically significant differences among B. aphidicola populations from different hosts were reported, Buchnera will likely remain a single-species genus in foreseable future.

16S RNA gene sequences of secondary endosymbionts, reported for $S$. avenae for the first time in this work, contained a very low level of polymorphism. The similarity of the situation in primary and secondary endosymbionts corroborates the hypothesis that their low genetic diversity was caused by a low effective population size of the host, which affects primary and secondary endosymbionts in the same way. As compared to free-living bacteria, the evolution of the genome of Buchnera is accelerated by increased fixation rate 
for slightly deleterious mutations (Moran 1996, Wernegreen et al. 2001). At the same time, the nucleotide polymorphism in Buchnera is extremely low (Funk et al. 2001, Abbot and Moran 2002, this work). No information is available about the evolution rate in secondary endosymbionts of $S$. avenae but we reason that periodical bottlenecks in the population of the host, alternating with large-scale dispersals, shaped their evolution in the same way as that of Buchnera. Most population genetic features on $B$. aphidicola can probably be generalized to secondary endosymbionts of $S$. avenae.

Endosymbionts of aphids contain only one copy of 16S RNA gene (Unterman et al. 1989; Bauman et al. 1995). The endosymbionts are transmitted mainly vertically, exhibiting maternal inheritance, with occasional horizontal transfer (Sandström et al. 2001, Russell et al. 2003, Baumann 2005). The mechanism of the horizontal transfer has recently been shown to rely on (Moran and Dunbar 2006). Among the ten S. avenae clones used in this work, eight clones occur frequently in Germany, indicating that they are parthenogenetical. Among them, seven clones contained secondary endosymbionts. Two clones were unique, found only once among about 2500 aphids collected in Germany between 2001 and 2004 (Reimer 2005). This is a strong indication that the clones resulted from sexual reproduction. Both rare clones contained secondary endosymbionts. Interestingly, secondary endosymbionts of each of the frequent clone were indistinguishable by their 16S rRNA fragments on DGGE gels (only one band was amplified from each clone), while both rare clones contained secondary endosymbionts which produced several bands on DGGE. This indicates that secondary endosymbionts of rare clones consisted of several lineages with different 16S rRNA sequences, which can be accounted for by supposed (replace this with a better verb) recent origin of these clones by sexual reproduction.

In their observation of horizontal transmission of endosymbionts by sexual reproduction, Moran and Dubnar (2005) observed the production of doubly infected clones by transmission of a second endosymbionts into an aphid clone already bearing a different endosymbionts. In this work we for the first time demonstrated the presence of several lineages of the same endosymbiont species in a single aphid clone. This phenomenon may counteract the accumulation of deleterious mutations normally accumulating due to strictly vertical transmission in a limited effective population size (Rispe and Moran 2000). Vertical transmission of primary endosymbionts has not been observed and if it does not occur in nature, the accumulation of slightly deleterious mutations by secondary endosymbionts should be slower than in primary endosymbionts. This hypothesis can easily be tested by the analysis of homologous gene sequences from primary and secondary endosymbionts. Finding a higher ratio of silent mutations to amino acid- 
changing mutations in secondary endosymbionts as compared to primary endosymbionts would support our hypothesis.

We found that the phylogenetic analysis of 16S rDNA fragments obtained from DGGE resulted in a dendrogram identical to the one obtained by the analysis of full rDNA sequences, indicating that sequencing $16 \mathrm{~S}$ rDNA fragments from nt968 to nt1401, which possess a length suitable for separation by DGGE (Myzer 1999), is sufficient for the identification of bacterial endosymbionts. However, heteroduplex formation may complicate the interpretation of DGGE patterns. We observed that DNA bands of different mobilities (bands $\mathrm{A}$ and $\mathrm{H}$ from clones 4 and 5 ) contained identical $16 \mathrm{~S}$ sequences. We hypothesize that on of the bands was a heteroduplex of $H$. defensa and $B$. aphidicola sequences, similarly as heteroduplex formation may complicate RAPD patterns (Reineke et al. 1999). Another artifact encountered in DGGE is hybrid formation due to template switching by DNA polymerase (Shafikhani 2002). Amplification of band $C$ from clone 4 with primers F-968-GC and 1401r-GC, which amplify both $H$. defensa and $B$. aphidicola $16 \mathrm{~S}$ sequences, generated a hybrid of the length $312 \mathrm{bp}$ which consisted of sequences originated from both organisms. Similarly, a fragment of $401 \mathrm{bp}$ amplified from clone 5 with by the same primers was found to be a hybrid of $H$. defensa and $B$. aphidicola $16 S$ sequences.

Because 165 sequences were obtained from cloned PCR products, low divergence values among $16 \mathrm{~S}$ RNA sequences $(0.1 \%$ nucleotide divergence among $B$. aphidicola from $\mathrm{S}$. avenae) raises the question whether these patterns can be accounted for by PCR errors alone (Karlovsky 1990). The fact that not a single nucleotide difference was found among ten sub-sequences of a conserved region of the 16S RNA gene (374 bp length) indicates, however, that the error rate of the Taq polymerase (Eckert and Kunkel 1990) in our system was very low and the observed sequence differences were genuine.

\section{1-4-2 Clonal performance of Sitobion avenae clones}

The host plant species $S$. avenae were reared on was the most important parameter effecting the clonal performance in our study (see table 5 and 6); the clonal performance was influenced to a large extend by the interaction of host plants and clone and host plants and bacterial endosymbionts. However, we were not able to investigate the direct effect of interactions between the clones and bacterial endosymbionts on the clonal performance on the tested host plants because we lacked a matrix of different clones with different bacterial endosymbionts. In our sample only one clone was devoid of secondary bacterial endosymbionts. Clones harbouring the same secondary bacterial endosymbionts differed in their performance on different host plants (compare clones 4, 5, 9 and 10). The effect of 
secondary bacterial endosymbionts on the host plants specialization is not clear, where some clones for example on $D$. glomerata: clones 7 and 8 which harbour $R$. insecticola perform twice better than clone 5 which harbour $H$. defensa the other clones 1,2,3 and 4,9,10 which respectively harbour $R$. insecticola and $H$. defensa did not survive on this host.

The impact of bacterial endosymbionts on traits it not known in $S$. avenae but it was described in other aphid species such as $A$. pisum. Genotypes of $A$. pisum which harbour $R$. insecticola have twice better performances on clover than those which have $H$. defensa but they can not survive on alfalfa. On the contrary, genotypes which harbour $H$. defensa do $50 \%$ better on alfalfa (Leonardo et al. 2003). In Japan, pea aphid which has $R$. insecticola showed a higher performance on clover than vetch (Tsuchida et al. 2004). However, no conclusive evidence for a contribution of secondary bacterial endosymbionts to host specialization of $A$. pisum on to its survival on artificial diet was found (Douglas 2006; Leonardo 2004). The authors explained these results by supposedly large genetic variability in both aphids and endosymbionts. Our results show on the contrary that the genetic variability in $R$. insecticola and $H$. defensa is limited, both in the same aphid species and among endosymbionts from different aphid species.

There are two potential factors may effect the performance of Sitobion clones: the density of bacterial endosymbionts and the amino acid density in the host plants; we have not quantified both of them in our study but any way our results indicate the host plant as factor contribute to the effect of secondary bacterial endosymbionts on the performance of aphid, where as Chandler et al. (2007) have been shown that the density of $B$. aphidicola and $R$. insecticola varies with regard to the amino acid content in the diet and indicate the same importance of host plant..

Up to now only one study of the geographical distribution of secondary endosymbionts in aphids was published; Tsuchida et al. (2002) found that $A$. pisum exhibit characteristic geographical distribution of $R$. insecticola. Secondary endosymbionts in $S$. avenae have not been reported so far. We showed that both $R$. insecticola and $H$. defensa are frequent in most abundant S. avenae clones in Germany, Further research is needed to shed light on their geographic distribution and their affect either positive or negative on traits such as tolerance to heat, clonal fitness, host plant specialization and resistance to parasitoids or fungal pathogens. 


\section{Figures legends}

Figure (1) Left side: DGGE analysis of $16 \mathrm{~S}$ rDNA fragments from Buchnera aphidicola from 10 S. avenae clones (1-10), one clone of A. pisum (11) and one A. fabae clone (12) amplified using primers Buch $16 \mathrm{~S}$. Right side: DGGE analysis of amplicons generated from the same DNA samples using universal primers for bacteria F968 and 1401R.

Figure (2) Phylogenetic tree constructed by neighbor-joining algorithm (Saitou and Nei, 1987) from the distance matrix of $16 S$ rDNA partial sequences of bacterial symbionts harboured by Sitobion avenae and other aphid species obtained from DGGE (bootstrap support indicated; see Materials and Methods for details). The final dataset consisted of 403 positions.

Figure (3) Phylogenetic tree constructed by neighbor-joining algorithm (See legend Fig. 2) from the distance matrix of $16 \mathrm{~S}$ rDNA of sequences for Buchnera aphidicola harbored by Sitobion avenae clones and other aphid species.The final dataset consisted of 1439 positions

Figure (4) Phylogenetic tree constructed by neighbor-joining algorithm (See legend Fig. 2) from the distance matrix of $16 \mathrm{~S}$ rDNA of sequences for Candidates Regiella insecticola harbored by Sitobion avenae clones and other aphid species. The final dataset consisted of 1442 positions

Figure (5) Phylogenetic tree constructed by neighbor-joining algorithm (See legend Fig. 2) from the distance matrix of $16 \mathrm{~S}$ rDNA of sequences for Candidates Hamiltonella defensa of Sitobion avenae clones and other aphid species.The final dataset consisted of 1437 positions

Figure (6) Phylogenetic tree constructed by neighbor-joining algorithm (See legend Fig. 2) from the distance matrix of groEL nucleotide sequences of Buchnera aphidicola harbored by Sitobion avenae and other aphid species. The final dataset consisted of 1651 positions. Figure (7) clonal performance of Sitobion avenae (clones 1-10) on four host plants (mean number of aphid \pm standard error). (A) Elymus repens (B) Phalaris arundinacea (C) Dactylis glomerata (D) Holcus lanatus (E) the mean performance of all clones on the four host plants mentioned in $A ; B ; C$ and $D$. 
Table (1) Collection site, host plant, and primary and secondary endosymbionts status of Sitobion avenae clones used in the experiments

\begin{tabular}{|c|c|c|c|c|}
\hline $\begin{array}{l}\text { Clone } \\
\text { number }\end{array}$ & Collection site & Host plant & $\begin{array}{c}\text { Primary } \\
\text { Endosymbionts }\end{array}$ & $\begin{array}{c}\text { Secondary } \\
\text { endosymbionts }\end{array}$ \\
\hline 1 & Goettingen & Wheat & B. aphidicola & R. insecticola \\
\hline 2 & Kassel & Cocksfoot & B. aphidicola & R. insecticola \\
\hline 3 & Kassel & Bromus sp. & B. aphidicola & R. insecticola \\
\hline 4 & Goettingen & Cocksfoot & B. aphidicola & H. defensa \\
\hline 5 & Giessen & Wheat & B. aphidicola* & H. defensa \\
\hline 6 & Kassel & Cocksfoot & B. aphidicola & \\
\hline 7 & Giessen & Wheat & B. aphidicola & R. insecticola \\
\hline 8 & Giessen & Wheat & B. aphidicola* & R. insecticola \\
\hline 9 & Kassel & Cocksfoot & B. aphidicola & H. defensa \\
\hline 10 & Kassel & Cocksfoot & B. aphidicola & H. defensa \\
\hline
\end{tabular}

${ }^{*}$ Identical sequences of $16 \mathrm{~S}$ rDNA 
Table (2) Genotype profiles of S. avenae clones

\begin{tabular}{|c|c|c|c|c|c|c|}
\hline$x$ & Sm10 1 & Sm11 & Sm17 & S16b & $\mathrm{Sa} 4 \Sigma$ & $\begin{array}{l}\text { Number of individuals collected } \\
\qquad 2001-2003\end{array}$ \\
\hline 1-2-3-19- 20 & $164 / 166$ & $144 / 149$ & $178 / 179$ & $209 / 274$ & $168 / 168$ & 194 \\
\hline 7- 11- 13-14 & $152 / 166$ & $144 / 144$ & $178 / 178$ & $173 / 189$ & $156 / 172$ & 115 \\
\hline $4-5-6-29-30-31-32-33-34-35-36$ & $164 / 166$ & $144 / 144$ & $179 / 179$ & $159 / 173$ & $162 / 168$ & 66 \\
\hline 8 & $164 / 166$ & $144 / 148$ & $178 / 178$ & $173 / 173$ & $156 / 162$ & 3 \\
\hline 9 & $164 / 164$ & $144 / 148$ & $178 / 178$ & $179 / 275$ & $162 / 172$ & 0 \\
\hline 10 & $160 / 164$ & $144 / 149$ & $178 / 178$ & - & $162 / 168$ & 0 \\
\hline
\end{tabular}

1: Units (bp). 2: clones which collected only once are not listed except for clone 9 and 10 selected for further experiments. 
Table (3) Primers sequences used to amplify $16 \mathrm{~S}$ (restriction sites and GC clam are underline)

Primer

Buch16S1F-Sdal

Buch16S1F-GC

Buch16S1R- Notl

Buch16S1R-GC

PABSF-Sdal

U99F-Sdal

16SB1-Notl

PASScmp-Notl

16SA1-Sdal

F-968-Sdal

1401r- Notl

F-968-GC

1401r- GC
Sequence

TCGAGTCCTGCAGGGAGCTTGCTCTCTTTGTCGGCAA

CGCCCGGGGCGCGCCCCGGGCGGGGCGGGGGCACGGGGGGGAGCTTGCTCTCTTTGTCGGCAA

ATGCTAGCGGCCGCCTTCTGCGGGTAACGTCACGAA

CGCCCGGGGCGCGCCCCGGGCGGGGCGGGGGCACGGGGGGCTTCTGCGGGTAACGTCACGAA

TCGAGTCCTGCAGGAGCGCAGTTTACTGAGTTCA

TCGAGTCCTGCAGGATCGGGGAGTAGCTTGCTAC

ATGCTAGCGGCCGCTACGGYTACCTTGTTACGACTT

ATGCTAGCGGCCGCGCAATGTCTTATTAACACAT

TCGAGTCCTGCAGGAGAGGTTGATCMTGGCTCAG

AGAGAGAACCTGCAGGAACGCGAAGAACCTTAC

AAGAGAAGCGGCCGCGCGTGTGTACAAGACCC

CGCCCGGGGCGCGCCCCGGGCGGGGCGGGGGCACGGGGGGAACGCGAAGAACCTTAC CGCCCGGGGCGCGCCCCGGGCGGGGCGGGGGCACGGGGGGGCGTGTGTACAAGACCC
Cited in

Fukatsu, 2001

Douglas, 2006

Douglas, 2006 and Fukatsu, 2001

Douglas, 2006

Nübel ,1996 and Agnelli,2004 
Table (4) DNA bands found in DGGE analysis of $16 \mathrm{~S}$ fragments of endosymbitic bacteria from S. avenae amplified with primers 968F/1401R (Fig. 1).

\begin{tabular}{|c|c|c|c|c|}
\hline & & \multicolumn{3}{|c|}{ BLAST search } \\
\hline Band & $\begin{array}{l}\text { Endosymbiont } \\
\text { species }\end{array}$ & Clone & Closest match & Similarity \\
\hline A & H. defensa & $4,5,9$ & Macrosiphum euphorbiae ( accession AY136148) & $100 \%$ \\
\hline $\mathrm{B}$ & Unknown & A. pisum & Staphylococcus sciuri subsp. rodentium (accession Nr. AB233332) & $100 \%$ \\
\hline $\mathrm{C}$ & H. defensa & 9 & Macrosiphum euphorbiae (accession AY136148) & $99 \%$ \\
\hline $\mathrm{C}$ & B. aphhidicola & $1,2,3,7,8$ & Schizaphis graminum ( accession Nr. M63246) & $\begin{array}{l}99 \%(\text { clone 1)- } 100 \% \\
\text { (rest) }\end{array}$ \\
\hline $\mathrm{C}$ & B. aphidicola & A. fabae & Aphis fabae (accession Nr. AY518294) & $100 \%$ \\
\hline $\mathrm{C}$ & & 10 & Cloning failed & \\
\hline $\mathrm{D}$ & H. defensa & 10 & Macrosiphum euphorbiae (accession AY136148) & $99 \%$ \\
\hline$E$ & B. aphidicola & A. pisum & Acyrthosiphon pisum (accession Nr. M27039) & $97 \%$ \\
\hline $\mathrm{F}$ & H. defensa & 10 & Macrosiphum euphorbiae (accession AY136148) & $99 \%$ \\
\hline G & H. defensa & 10 & Macrosiphum euphorbiae (accession AY136148) & $99 \%$ \\
\hline $\mathrm{H}$ & H. defensa & $4,5,9,10$ & Macrosiphum euphorbiae (accession AY136148) & $\begin{array}{l}99 \%(\text { clone } 10)- \\
100 \% \text { (rest) }\end{array}$ \\
\hline I & & A. pisum & PCR re-amplification failed & \\
\hline J & R. insecticola & $1,2,3,7,8$ & Pemphigus betae (accession Nr. AY136154) & $99 \%$ \\
\hline $\mathrm{K}$ & & & PCR re-amplification failed & \\
\hline
\end{tabular}


Table (5) Analysis of Variance (GLM) on the effects of clonal diversity and host plant performance in S. avenae clones

\begin{tabular}{rrrrrr}
\hline Source & Sum-of-Squares & df & Mean-Square & F-ratio & P \\
\hline CLONE & 467045.881 & 9 & 51893.987 & 8.381 & 0.000 \\
HOST & 1241080.002 & 3 & 413693.334 & 66.814 & 0.000 \\
HOST $^{*}$ CLONE & 965903.573 & 27 & 35774.206 & 5.778 & 0.000 \\
Error & 1176425.033 & 190 & 6191.711 & & \\
\hline
\end{tabular}

Table (6) Analysis of Variance (GLM) effect of bacterial endosymbionts and host plants on the performance of $S$.avenae clones

\begin{tabular}{rrrrrr}
\hline Source & Sum-of-Squares & df & Mean-Square & F-ratio & $P$ \\
\hline HOST & 1474157.385 & 3 & 491385.795 & 68.075 & 0.000 \\
Bacteria & 367194.684 & 2 & 183597.342 & 25.435 & 0.000 \\
Bacteria*HOST & 676875.419 & 6 & 112812.570 & 15.629 & 0.000 \\
Error & 1573596.698 & 218 & 7218.333 & & \\
\hline
\end{tabular}


Figure (1)

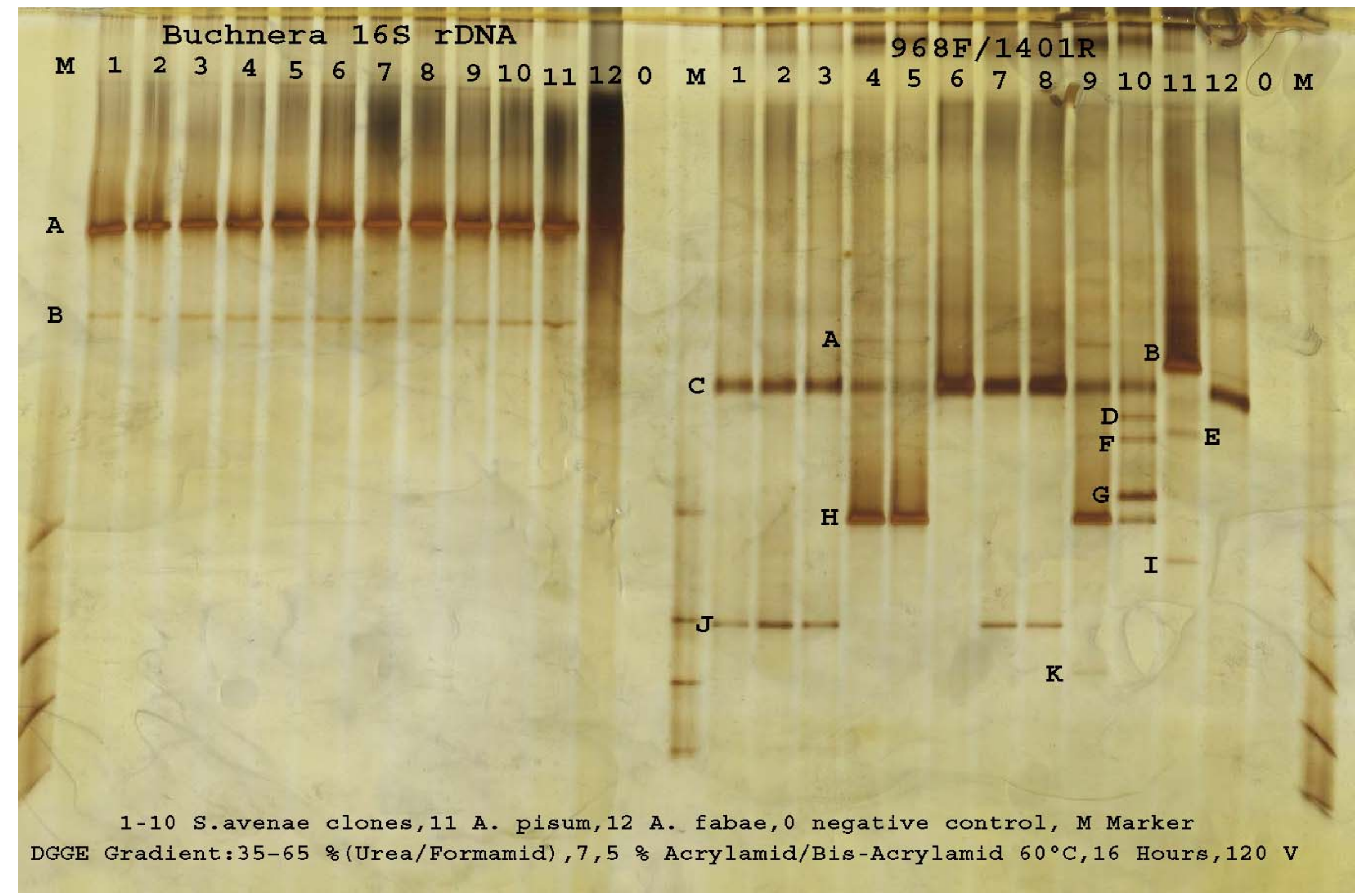


Figure (2)

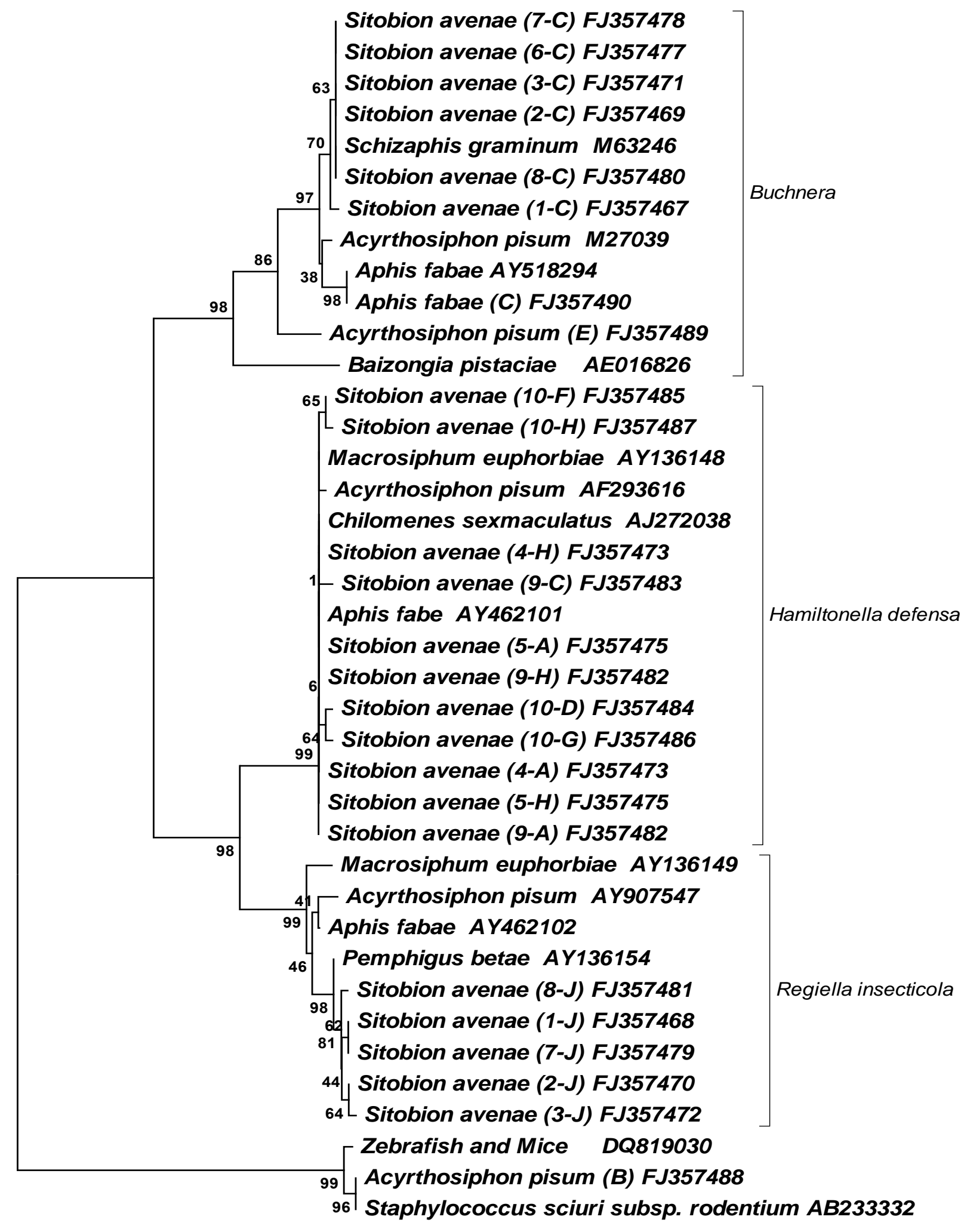

$\stackrel{\longmapsto}{-02}$ 
Figure (3)

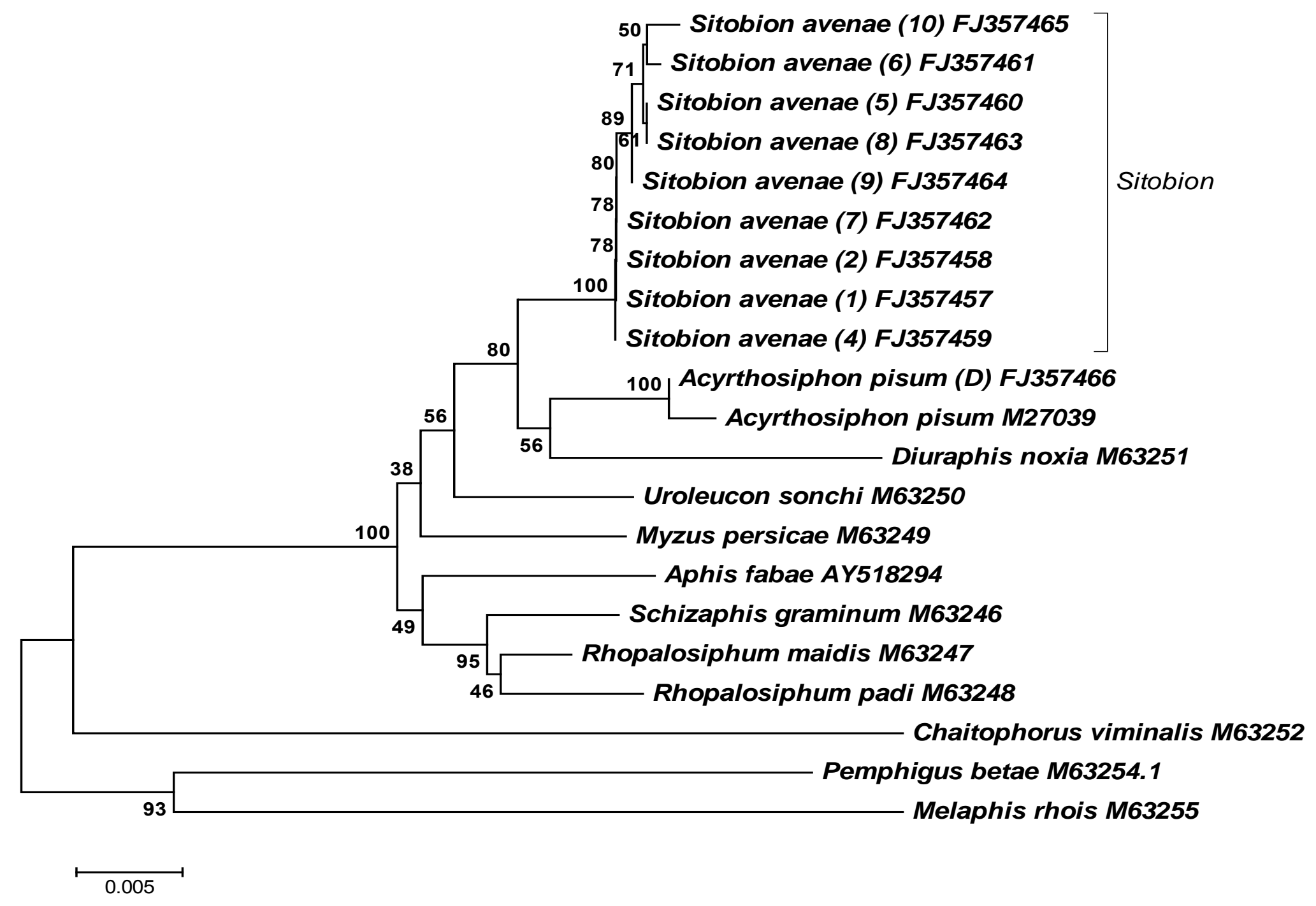


Figure (4)

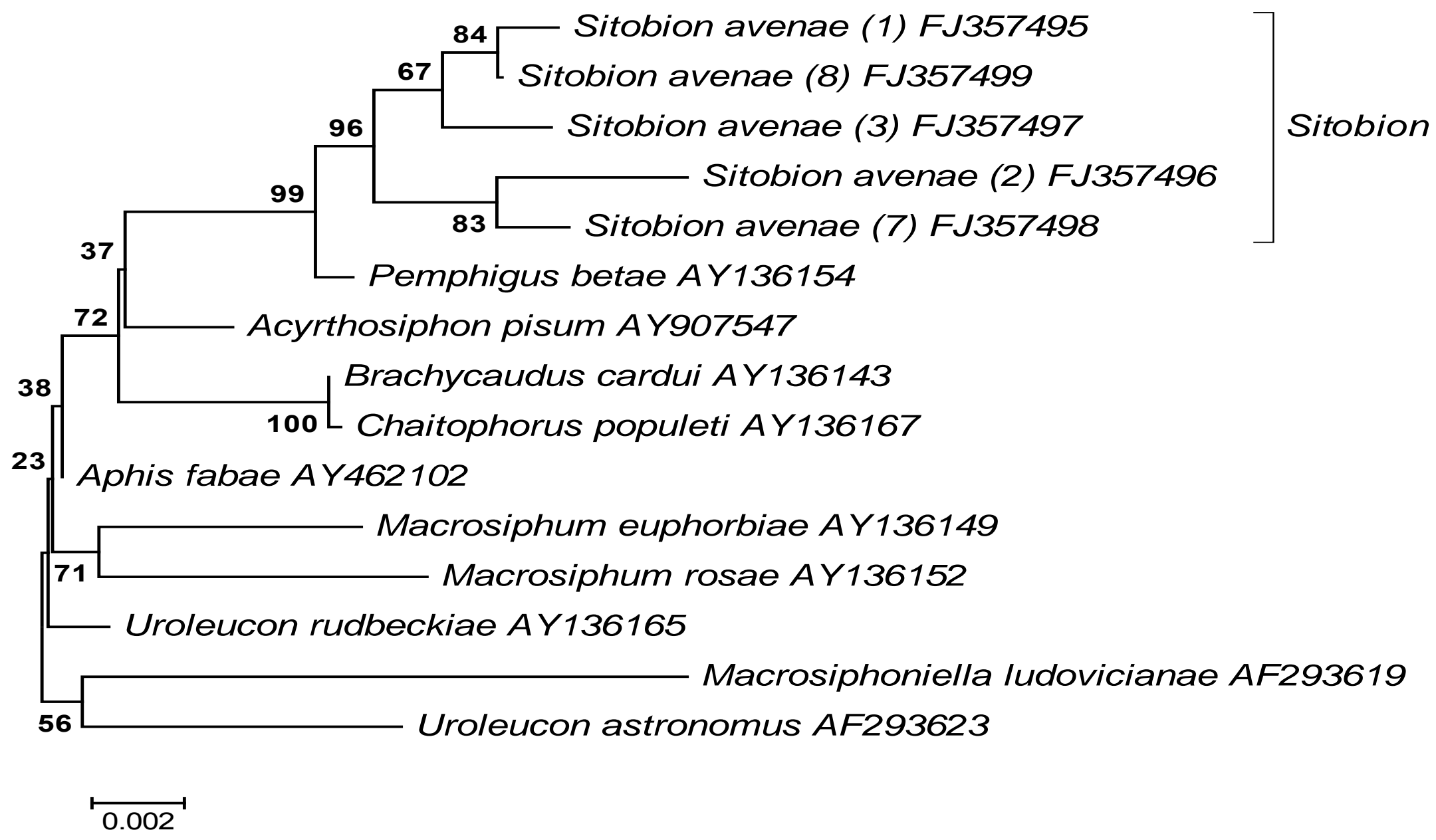


Figure (5)

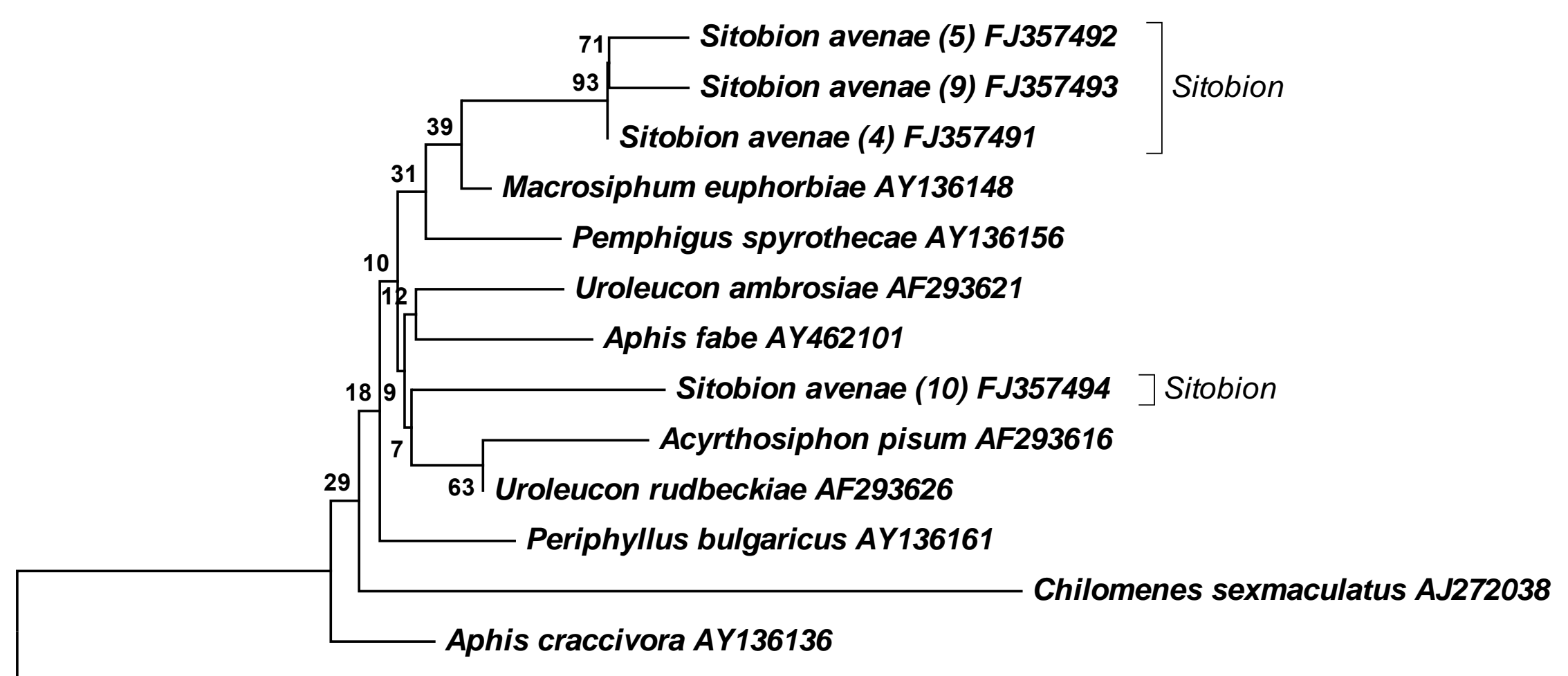


Figure (6)

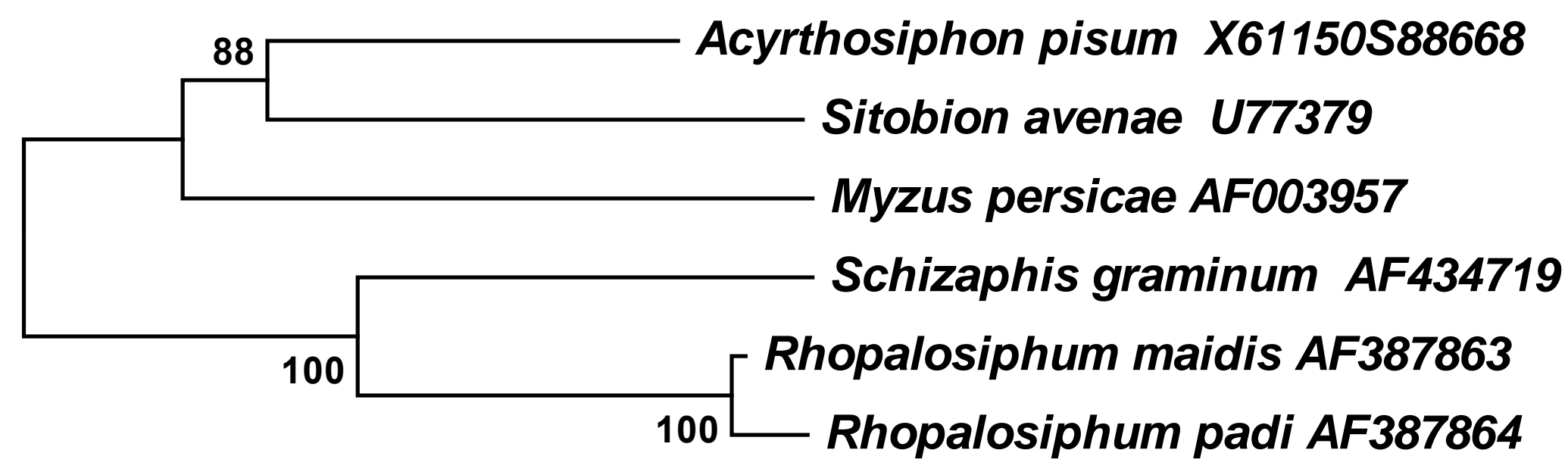

$\stackrel{\vdash}{0.01}$ 
Figure (7)

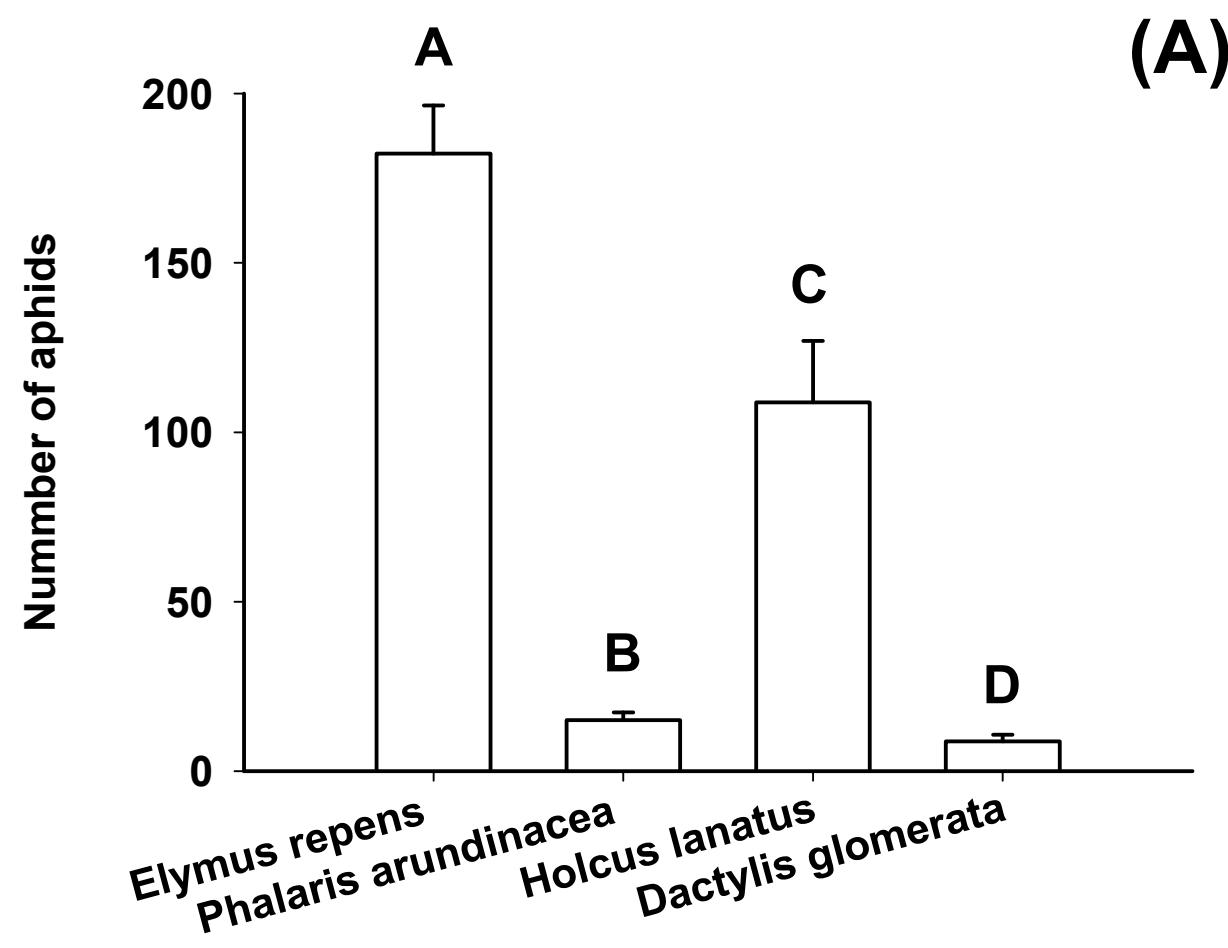

Host 


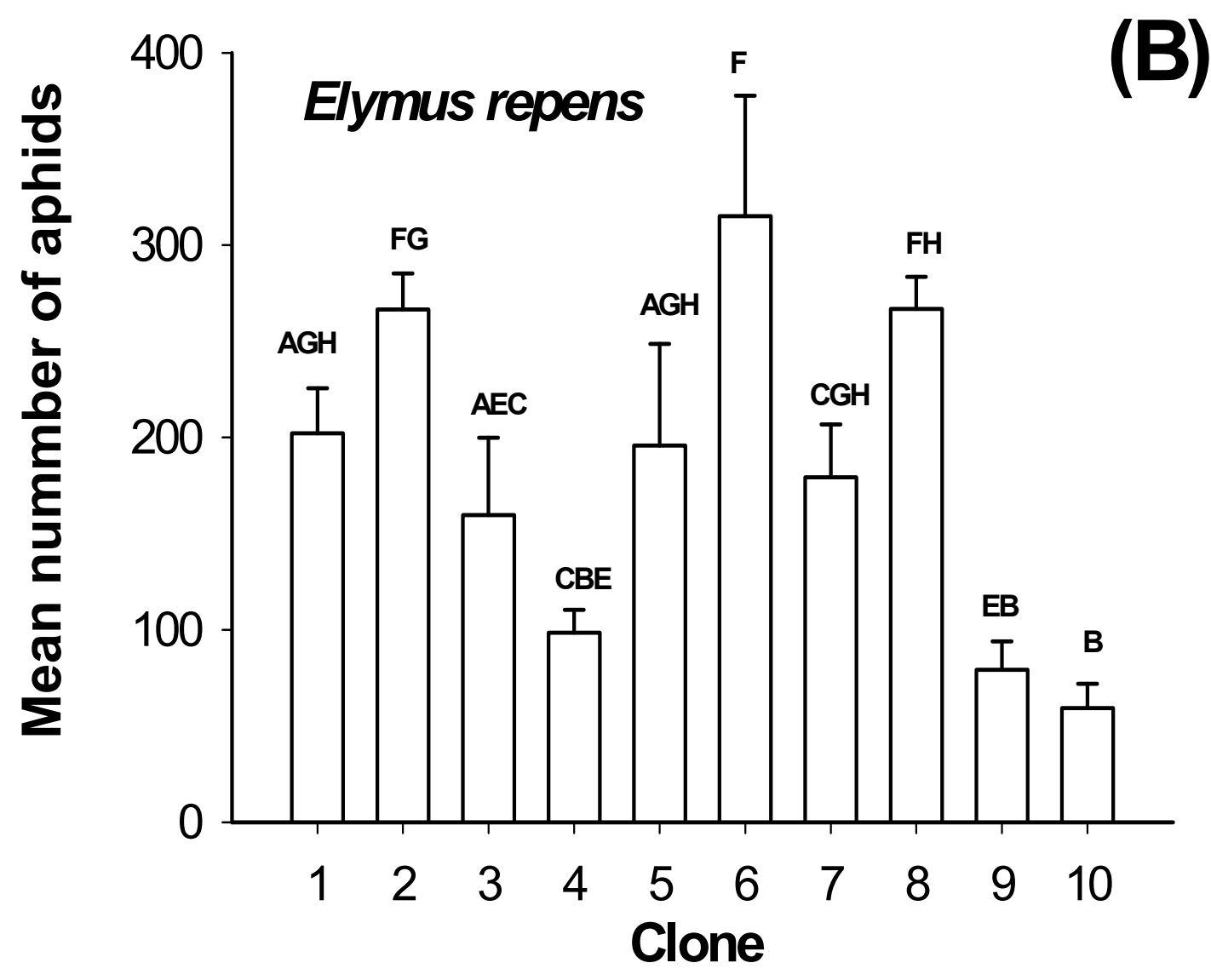



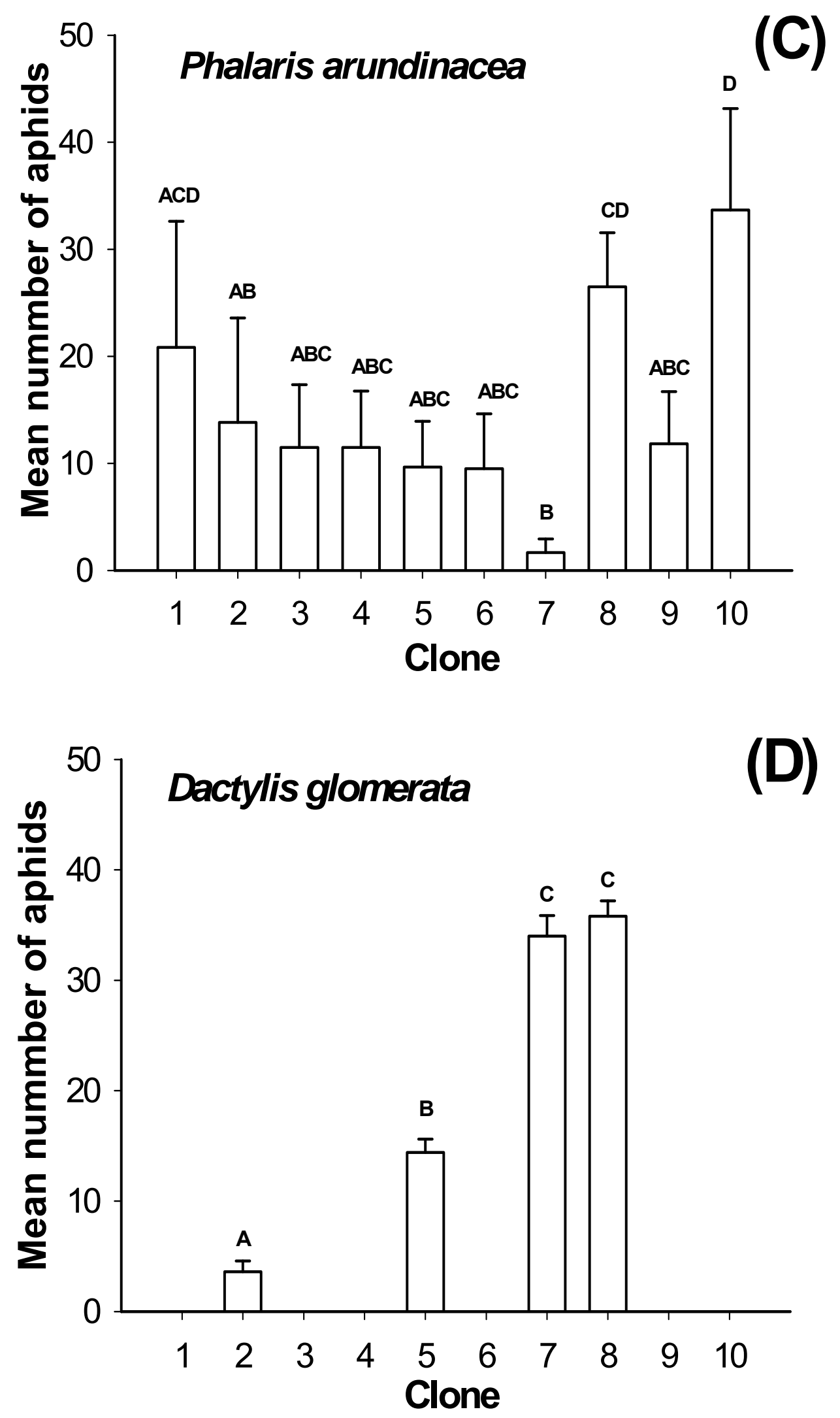


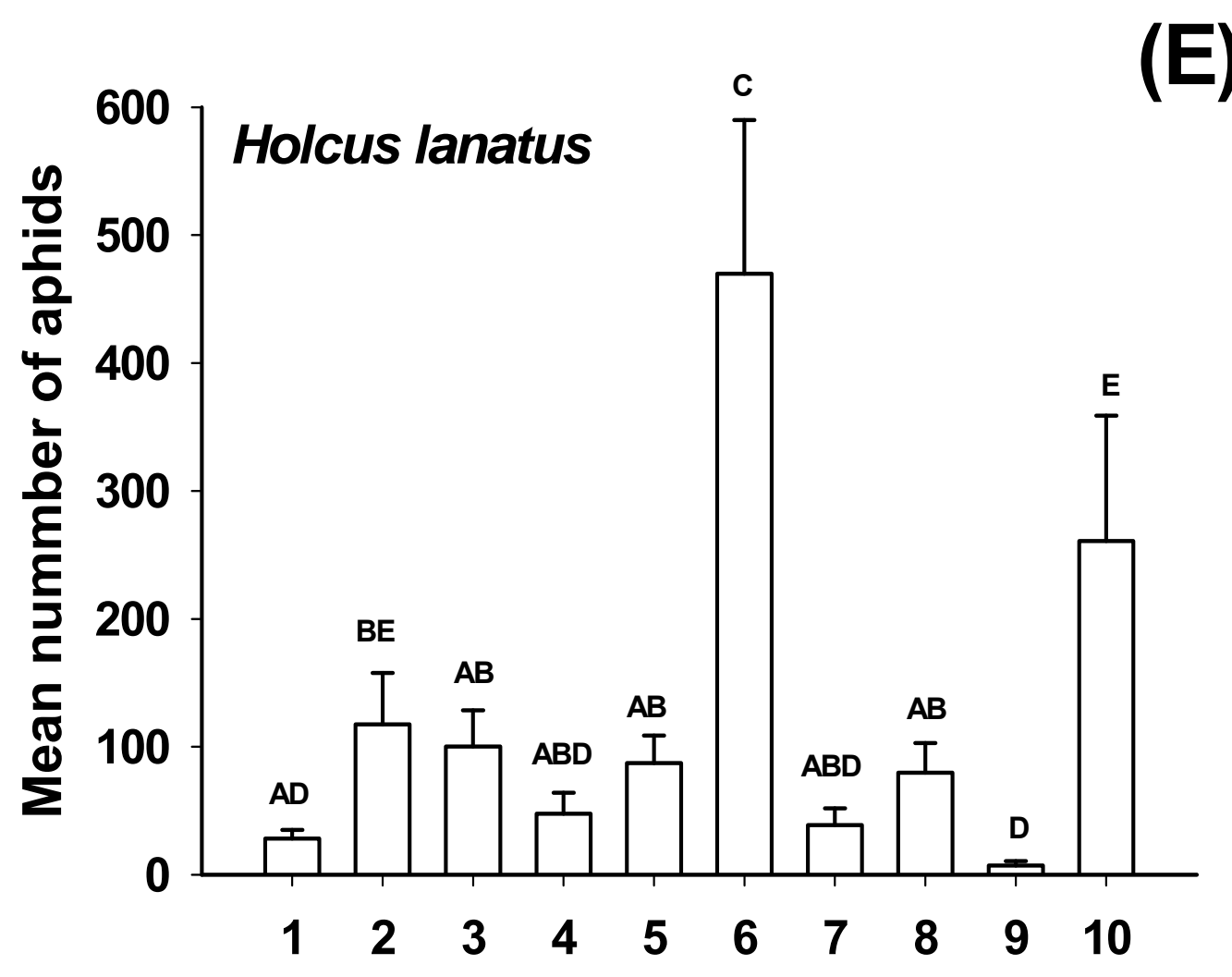

Clone 


\section{Chapter 2}

Effect of sugar proportion and aphid endosymbionts on grain aphid (Sitobion avenae F.) specialisation on cocksfoot cultivars

HUSSEIN ALKHEDIR 1, PETR KARLOVSKY 2 , STEFAN VIDAL 3

1,3Department of Crop Sciences, Agricultural Entomology, Georg-August University

Goettingen, Germany, 2Department of Crop Sciences, Molecular Phytopathology and Mycotoxin Research, Georg-August University Goettingen, Germany.

Corresponding author: Hussein Alkhedir

Department of Crop Sciences, Agricultural Entomology, Georg-August University Goettingen, Germany.

Grisebach Strasse 6 - 37077 Goettingen - Germany

Tel +49 55139 3728, Fax +495513912105, e-mail halkhed@gwdg.de 


\section{ABSTRACT}

Aphid feed on plants sap which rich with sugars maily sucrose and poor with essential amino acids. ). The sugars cause osomatic regulation probleme for aphid, but aphid adapted this fate by hydrolyzation of sugars in their gut the products of the hydrolysis are polymerized into oligosaccharaides and excreted with honeydew. Aphids harbour bacterial endosymbionts supplied them with the essential amino acid needed for surviving but their bacterial endosymbionts are useless when the phloem sap include more than $30 \% \mathrm{~W} / \mathrm{V}$ water soluble carbohydrates (WSC). Aphids harbour other symbionts type, some of them have positive impact of some life traits but it is not known whether they are involved in tolerance to high WSC. The fact that aphids can not survive on artificial diets have more than $34 \% \mathrm{~W} / \mathrm{V}$ may employed in aphid control. In this study we want to apply the knowledge inferred from pervious studies in aphid control and want to test if aphid can survive on host plants with high WSC concentrations and if the secondary endosymbionts of aphid affect the tolerance to WSC. Furthermore we want inspect the factors mediate the specialization of aphid. We test the clonal performance of genetically identified clones of Sitobion avenae F. were collected from different host plants and harbour different bacterial endosymbionts on ten Dactylis glomerata L. cultivars differ in their proportion of water soluble carbohydrate ; D. glomerata is known as wild host for Sitobion avenae and commercially wild planted as forage to domestic animals. Our results indicate that WSC is responsible to resistance to Sitobion avenae, the threshold level trigger the resistance is $1.7 \%{\mathrm{~d} . w t^{-1}}^{-1}$, and cultivars which higher than $1.7 \%$ are absolutely resistance to $S$. avenae. The performance of $\mathrm{S}$, avenae clones on many Dactylis cultivars ranged in their WSC proportion (1-8,3\%) showed trade off between the clone and WSC. We found three clones were specialized on the cultivar which have 1,7\% WSC; two of them harbour Regiella insecticola and perform twice better than third clone which harbour Hamiltonella defensa Also, we found the specialization of Sitobion avenae on dactylis determined by complex of factors but the collection host plants not one of them. 


\section{2-1Introduction}

Aphids and other sucking herbivores adapted to feeding on phloem sap of plants. The composition of phloem sap does not match nutritional requirements of insects in two respects: the content of essential amino acids is insufficient and the concentration of carbohydrates is too high. In aphids, the lack of amino acids is compensated for by an obligatory symbiotic bacterium Buchnera aphidicola, harboured by most of all aphid species, which synthesizes amino acids de novo and secretes them into the bacteriocytes (Douglas, 1998).

The concentration of water-soluble carbohydrates (WSC) in phloem sap may reach over $50 \%(\mathrm{w} / \mathrm{v})$ depending on environmental conditions, plant species and developmental age (Winter et al.,1992; Geiger and Servaites 1994; Kehr et al.,1998). The dominating component of WSC is sucrose (Fisher, 2000), which is the major transported assimilate in plants. The osmotic value of phloem sap exceeds the osmotic value of insect body fluids up to five times (Douglas et al.,2006a). Without protection mechanisms, osmotic pressure exerted by soluble carbohydrate onto the digestive system of aphids would cause the loss of water from body fluids, particularly the haemolymph, leading to fatal dehydratation. Aphids adapted to feeding on phloem sap by a two-step conversion of sucrose to products of low osmotic activity. In the first step, sucrose is hydrolyzed into glucose and fructose (Rhodes et al.,1996 \& 1997; Ashford et al.,2000). Invertase responsible for this hydrolysis in the gut of Acyrthosiphon pisum has been characterized (Price et al.,2007). The products of the hydrolysis are polymerized into oligosaccharaides and excreted with honeydew, which is near-isoosmotic with body fluids of aphids (Downing, 1978; Wilkinson et al.,1997; Fisher 2000). Part of hexoses generated from sucrose is reabsorbed by the gut, providing aphids with energy for respiration and carbon intermediates for anabolic pathways (Ashford et al.,2000). Combined rates of polymerization and reabsorption must substantially exceed the rate of invertase reaction because hydrolysis products would increases the osmotic pressure exerted by WSC if not removed instantly.

Apart from the identificaton of invertase as an aphid enzyme (Price et al.,2007), it is not known whether bacterial endosymbionts participate on the conversion of WSC by aphids,

Wilkinson et al. (1997) showd that B. aphidicola was not involved in the ingestion of sugar. PK: "ingestion"? If possible specify what exactly they have shown. Bacterial endosymbionts are not responsible for sucrose hydrolysis in Acyrthosiphon pisum (Price et al., 2007) but it remains unclear whether they are involved in the polymerization of hydrolysis products 
In addition to obligatory primary endosymbionts, aphids harbour additional endosymbionts which are not essential for survival but contribute to the performance and possibly host plants specialization of aphids (Chen et al, 2000; Leonardo et al, 2003; Tsuchida et al.,2004). These so called secondary endosymbionts enhance the tolerance to suboptimal temperatures (Russell and Moran 2006) and improve resistance of aphids to natural enemies (Oliver et al., 2005; Scarborough et al., 2005). . Furthermore, mechanisms different from the conversion of WSC into products of low osmotic activity may also enhance the tolerance of aphids to WSC. Bacterial endosymbionts might be directly or indirectly involved. For example, reduction of the permeability of gut epithel for water or increase of the osmotic value of body fluids would supposedly enhance the tolerance of aphids to WSC.

Artificial diet has been a powerful tool in studies of the nutritional requirements of aphids. Knowledge gained in these studies might eventually lead to the development of new strategies for the control of these pests in plant production. So far artificial diet studies revealed that aphids do not survive dietary sucrose concentrations higher than $1 \mathrm{M}(34 \%$ $\mathrm{w} / \mathrm{v}$; Douglas et al., 2006b). Circumstantial evidence indicates that the presence of bacterial endosymbionts affects the performance of pea aphid Acyrthosiphon pisum on a diet with a high content of sucrose (Douglas et al.,1996b). As the concentration of sucrose in phloem sap of plants is species-specific, this finding indicates that bacterial endosymbionts may affect host specialization in aphids.

Plants breeders traditionally selected varieties with a high proportion of WSC, as soluble carbohydrate content is an indicator of drought and salt tolerance in wheat (Kerepesi \& Galiba, 2000) and resistance to brown strip disease (Sanada et al.,2004). In rye grass WSC concentration is known as an indicator of silage quality and factor contributing to milk production (Smith et al.,1997; Mayland et al.,2001; Miller et al.,2001). Remarkably, the role of WSC in the resistance of plants against aphids has so far not been experimentally addressed.

The English grain aphid Sitobion avenae (F.) is an important pest, especially in temperate climates on both Northern and Southern Hemisphere (Blackman \& Eastop 1984; Vickerman \& Wratten 1979; Wangai et al.,2000; Sunnucks et al.,1996). S. avenae is present throughout the year on grasses of family Gramineae, including cereals. It can be considered to be autoecious and restricted to Gramineae. Cocksfoot (Dactylis glomeratus L.), which is a common weed in cereal fields, is known as a host of S. avenae. Molecular marker analysis and the collecting site of aphid indicate the existence of specialized clones 
on Dactylis glomerata (De Barro et al, 1995; Sunnucks et al.,1997). Apart from beeing a weed in wheat fields, $D$. glomerata has been cultivated in Europe, Japan and elsewhere as a forage grass. Commercial cultivars of $D$. glomerata were selected for a high WSC content (Sanada et al.,2004).

We recently characterized secondary bacterial endosymbionts in Sitobion avenae clones and we found significant indicter that the bacterial endosymbionts mediate the interaction between S. avenae clones and it host plants, Dactylis glomerata "cv. Prairial" was on of these (Chapter 1).

The aim of this study was to examine how collection site and genotype of $S$. avenae influence specialization on host plants, whether selection for WSC can be used in breeding for resistance against $S$. avenae, and whether secondary endosymbionts differently affect the performance of $S$. avenae on plants with different content of WSC.

\section{2-2Material and methods:}

\section{2-2-1Host plants used in experiments:}

Cocksfoot (Dactylis glomerata L. .cv." Amba") was bought from C. Appel Company, Germany. All other cultivars were bought from National Agricultural Research Center for Hokkaido Region and all were analyzed for the continent of water soluble carbohydrate (Sanada et al.,2004) and listed in table (1).They were germinated in greenhouse in trays then transplanted to small pots with a diameter of $11 \mathrm{~cm}$, filled with a 2:1 mixture of soil (Fruhstorfer Typ P) and sand and used as seedlings one month old. Fertilizer was not applied for the plants in this study and all plants were watered in the greenhouse once a day in the morning. all pants used in this study were grown in the greenhouse at $25^{\circ} \mathrm{C}$, $50 \%$ humidity, 16:8 light/ dark hour and under $200 \mu \mathrm{E}$ photon flux density .

\section{2-2-2Aphid cultures and rearing procedures:}

Sitobion avenae clones were collected from different regions in central Germany (Goettingen, Kassel and Giessen, respectively) in 2004 by sweep-net sampling from wheat (Triticum aestivum), cocksfoot (Dactylis glomeratus) and graminoid grasses (Table 2). 65 clones were established from single aphids kept on wheat seedlings 7 day old (winter wheat cultivar "Bussard"; Lochow Petkus Company, Germany) grown in pots with a diameter of $11 \mathrm{~cm}$, filled with a 2:1 mixture of soil (Fruhstorfer Typ P) and sand, and covered with transparent ventilated cylindrical tubes of $10 \mathrm{~cm} \times 30 \mathrm{~cm}$ size. Aphids were transferred to new plants every second week and the cultures were kept at $20 C^{\circ}, 16: 8$ light/dark hour conditions, $60-80 \%$ humidity and under $200 \mu \mathrm{E}$ photon flux density in climate chamber "TE-17 Raum 289180" ( VIESSMANN ,2002 Germany) ; water was 
applied twice a week from below. Given these conditions all clones reproduced parthenogenetically. Also fertilizer was not applied for wheat plants.

The 10 clones used in this study were selected based on five microsatellite loci representing 6 common genotypes, 4 of them regularly occurring in central Germany, nine of them harbour secondary bacterial endosymbionts either Regiella insecticola or Hamiltonella defensa (table 2) (Chapter 1)

\section{2-2-3Experimental procedures}

All experiments were done in growth chamber in the same rearing conditions and system (The plants with aphid were covered with transparent cylinder) which was described in rearing of aphid at $20 \mathrm{C}^{\circ}, 70 \%$ humidity, 16:8 hours light: dark hour and under $200 \mu \mathrm{E}$ photon flux density in the climate chamber "TE-17 Raum 289180" ( VIESSMANN ,2002 Germany) .

\section{2-2-4Clonal performance on cocksfoot:}

\section{2-2-4-1Performance of selected clones 1-10 on ten cocksfoot cultivars}

The clonal performance of $S$. avenae selected clones (see table 2) was tested on ten Dactylis glomerata cultivars (see table 1) by recording the population of 10 synchronized first stage nymphs within one month of each clone on each cultivar with five replication using the same standard rearing conditions which mentioned above and they were observed weekly. The seedling of all cocksfoot cultivars were grown for one month in greenhouse (see host plants), when aphids were propagated on the plants and closed with cylinders in the growth chambers, they were watered from below twice a week and no fertilizers were applied in the greenhouse or in the growth chambers.

\section{2-2-4-2Performance of all collected clones on cultivar Amba}

Cultivar Amba is available commercially in Germany and used as forge. We reared all collected clones ( 65 clones) on cultivar Amba by propagating of 5 synchronized forth stage nymphs on Amba from each clones for one month using standard rearing conditions and they were observed weekly. The seedling of cultivar Amba were grown in the greenhouse then transferred to growth chambers. The same system and condition which mentioned above for all cocksfoot cultivars used for Amba (watered twice a week from below and no fertilizer application).

\section{2-2-4-3Performance of clone 5 on wheat with advanced feeding on cultivar Amba}

The affect of cocksfoot cultivar Amba on S. avenae clone 5 was tested by measuring the clonal performance on Wheat seedlings 7 days old grown in the condition described in rearing of aphid ( with the same wheat cultivar used for the rearing) for two weeks, before 
the nymphs of clones 5 propagated on wheat they were previously fed on cocksfoot (Amba) in different ways as followed : either by caging nymphs of clone 5 for 1,2 and 3 days, and thereafter by using 5 synchronized nymphs of the fourth stage caged on wheat for two weeks. Or, using nymphs, caged on cultivar Amba for 2 and 3 days, were the first and second generation of those caged on cultivar Amba for one day subsequently.

The plants with aphid were incubated in the growth chamber where all pervious described experiments done and dialled exactly as described in the previous experiments. This experiment was done with ten replications for each feeding treatments on Amba.

\section{2-4-4 Statistic analysis:}

Analysis of variance (ANOVA) was used to analyze the effect of WSC concentration, genotypes on clonal performance whereas the population was the dependent factor and WSC concentration, clones, and intersections between them were independents factors. ANOVA was used too to analyse the effect of WSC concentration, the bacterial endosymbionts on clonal performance whereas the population was the dependent factor and WSC concentration, the bacterial endosymbionts and intersections between them were independents factors. Also Fisher's LSD adjustment made to compare the clonal performance. For analysing the effect of feeding duration on cocksfoot Amba on clonal performance we used ANOVA in case of simple feeding the population was the dependent factor and feeding duration the independent factor; in case of performance of $S$. avenae clone on wheat in advanced to feeding on Amba the dependent factor was population and independent factor was feeding duration on Amba ; in both cases Fisher's LSD adjustment used to compare the effect of feeding duration. Systat for windows version 12.01.02 (Systat 2007) was used to perform analysis. And sigma plot for windows Release 10.0 (Sigma plot, 2006) used to draw all graphics.

\section{2-3Results}

\section{2-3-1Performance of selected clones 1-10 on ten cocksfoot cultivars}

Sitobion avenae clones was not able to colonize Dactylis glomerata cultivars which have WSC proportions higher than $1.7 \%$ (Fig.1 A) and all clones had not survived more than two weeks on them. On the other cultivars which have less than $1.7 \%$ WSC all clones of Sitobion avenae have survived over the experiment time (Fig.1 B). On cultivar Prairial which has $1.7 \%$ WSC only clones 5,7 and 8 have survived (Fig1 B); these three clones were collected from wheat and all other clones had been survived only in the first two weeks.

The clonal performance of clones which collected from different host plants and harboured different bacterial endosymbionts (table 2) varied significantly on cocksfoot tested 
cultivars; some clones have a good performance on all cultivars such as clones 7,8 and 5 while other clones such as 10 suffered mortality on all test cultivars (Fig.2).

Our statistics (table 3 and 4) showed that, the clonal preference of $S$. avenae was high significantly affected by WSC proportion of cocksfoot cultivars. On cultivar which have $1.7 \%$ or less WSC, we found high significant variation in the clonal performance which was affected by the genotype of the clone and it secondary endosymbionts.

Comparing the effect of bacterial endosymbionts on the clonal performance on all tested cultivar showed, that presence of Hamiltonella defensa did not effect the performance of clones $(4,9$, and 10) when compared to clone 6 which did not posses secondary endosymbionts, but in only clone 5 Hamiltonella defensa enhance the performance on tested cultivar especially on Prairial where this clone the only clone harbour Hamiltonella defensa and survived. Four clones (2,3,7,and 8$)$ which harboured Regiella insecticola have significantly better performance rather those harbour Hamiltonella defensa (except clone 5) on all cocksfoot tested cultivar but only clones 7 and 8 can survive on Prairial where was their performance twice better than clone 5 . The statistical analysis showed high correlation between clones and WSC $\left(R^{2}=0.993\right)$ rather than correlation between WSC and bacterial endosymbionts $\left(R^{2}=0.697\right)$.

\section{2-3-2Performance of all collected clones on cultivar Amba}

All tested clones on cultivar Amba survived about 5-10 days, few aphids still survived but they were died after 30 days. Thus, cultivar Amba is not a host plants for Sitobion avenae clones.

\section{2-3-3Performance of clone 5 on wheat with advanced feeding on cultivar Amba}

Feeding on cultivar Amba for 3 days caused a significant reduction in clonal performance of Sitobion avenae clone $5\left(\mathrm{~F}_{3,36}=9.914, \mathrm{P}<0.001\right)$, and even when the aphids which adapted over two generation to cocksfoot (Amba) $\left(F_{2,27}=27.810, P<0.001\right)$ (Fig. 2). When clone 5 adapted for three generation with total feeding on cocksfoot of 6 days as following 1,2 and 3 days respectively in first,second and third generations, its performance has enhanced, but those adapted aphid were died when they caged on cultivar Amba for one month.

Our results showed that increasing feeding on Amba in accumulation way over generation caused reduction in the performance on wheat $\left(R^{2}=0.673\right)$ rather than feeding only once on Amba $\left(R^{2}=0.452\right)$. 
To inspect what happen on Amba for clone 5 we incubate 5 nymphs of clone 5 from every stage separately on Amba seedling with ten replications in the same condition described in the methods; we found that most nymphs of stage 1 and 2 died after $3-5$ days and non of them reach the adults stage. Most nymphs of stage 3 and 4 also died in the first week only few (2-5) reached the adults stage; all of them were winged and they day after 2-3 days without laying any new offsprings.

We made one other supplementary experiment, we reared clone 5 (see clonlal performance on dactylis cultivar) mixture of D. glomerata "Amba" and one this host plants wheat (the same cultivar used in rearing) ,bluegrass ( Poa annua L., unknown cultivar) or of ryegrass (Lolium perenne L. cv. "Herault"). Both blue grass and ryegrass were obtained from Appels Wilde Samen Company, Germany.

After one month we did not collect any survived aphid from the culture.

\section{2-4Discussion}

\section{2-4-1Impact of host origin on performance and specialisation}

We found no relation between host plant-collecting site of clone and its performance or specialization, where the clones which collected from wheat related to different genotypes (clones 1, 5, 7 and 8) have better performance on cocksfoot; furthermore three of them (clones 7, 8 and 5) were specialized on cocksfoot. Also, the performance of clone (3) which collected from Bromus did not differ from clone 2 which collected from cocksfoot and even have better performance rather than other clones collected from cocksfoot (see Fig. 2). Thus, the collected host plants is not criteria or indicator to host specialization and the clones which collected from certain host plants have not to have better performance on it. Our results are conflicting with De Barro et al., (1995) who had stated existence of specialized clones of Sitobion avenae on cocksfoot in regards to collected host plant of clone and stated that the clone perform better on its collecting host plants rather than other host plants. Also our results conflicting with Sunnucks et al.,(1997); Lushai et al.,(2002) and Vialatte et al.,(2005) ; they had stated also existing of specialized genotypes of S. avenae on uncultivated host plants such cocksfoot and oat thus in regards to molecular markers and originating host plants; they had not induct the clonal performance.

\section{2-4-2Influence of WSC on S. avenae performance and specialization on cocksfoot}

The results of our study showed that WSC is responsible for resistance to all test clones of Sitobion avenae even we were able to determine the threshold of WSC proportion in 
cocksfoot cultivars which is responsible for absolute resistance to Sitobion avenae clones (more than $1.7 \%$ d.wt ${ }^{-1}$ ). Actually, it already known from nutritional studies of aphid on artificial diets that aphid is not able to survive or reproduce on artificial diets with high sucrose proportion (higher than $34 \% \mathrm{~W} / \mathrm{V}$ ) because of sugar barrier, when the sugar concentration increased in the diets, the osmotic pressures of aphid haemolymph increased too, which followed with poor performance and mortality of aphid because of osmotic stress (Douglas et al.,2006 b). The phloem of cocksfoot contain of WSC included mainly: sucrose, glucose, fructose and fructan (Chatterton et al.,1990), the cocksfoot cultivars used in this study have WSC proportion varied from 1 to $8 \% \mathrm{~d}^{-w t^{-1}}$, thus the mortality of all S. avenae clones on D. glomerata cultivars is explained by the sugar barrier as described by Douglas which faced all sucking insect. The correlation between WSC proportion of cocksfoot and the performance of Sitobion clones is very high decreasing the WSC results in increase the population of all tested clones on cultivars which have less than $1.7 \%$ WSC (see Fig. $1 \mathrm{~B}$ ). Thus the WSC trigger the specialization of Sitobion clones in cocksfoot. Furthermore our results proved that Sitobion avenae clones can not adapt to cocksfoot cultivars which have more than $1.7 \%$ of WSC like Amba. Thus, our results on cocksfoot are differing from De Barro et al.,(1995), they found that Sitobion avenae clones adapt to on the host plants and reduction in the clonal performance on cocksfoot of the clones collected from wheat disappeared after three generations, but our results assure those obtained from pervious studies (De Barro et al.,1995) where our results report specialization on dactylis cultivar Prairial (1.7\% WSC).

Before this study, there was no crucial evidence that WSC as food coefficient in the plants are responsible for resistance to Sitobion avenae, Ciepiela et al.,(1999) were not able to determine if the carbohydrates was the crucial food coefficient which has the role in resistant of wheat to Sitobion avenae or the other food coefficients like nitrogen or free amino acids.

Actually, there are no reports about accumulation of chemical compounds in dactylis cultivars during the selection for high WSC. But it known in some dactylis glomerata sub species there are an accumulation of phenols compound (Mika et al.,2003 and 2005) and silicate (Dietrich et al.,2003). Anyhow, Sitobion avenae does not affect by silicate (Massey

et al.,2006), furthermore it has in its salvia polyphenol oxidase and peroxidase enzymes ( Urbanska et al.,1998), thus it decrease the phenol level in their host plants (Eleftherianos et al.,2006). 
2-4-3Influence of secondary bacterial endosymbionts on tolerance of $S$.avenae clones to WSC and host specialisation of $S$. avenae

The results of this study showed no effect of bacterial endosymbionts on cocksfoot cultivars with WSC more than $1.7 \%$, because the later were absolutely resistance to all Sitobion avenae clones used in this study. But the affect of secondary bacterial endosymbionts appear on the cocksfoot cultivars which have less than $1.7 \%$ WSC, we found that Regiella insecticola enhanced the clonal performance significantly on cocksfoot rather than Buchnera aphidicola and Hamiltonella defensa which did not enhanced the clonal performance. Only one clone harbour Hamiltonella defensa show good performance and specialization on cocksfoot; this exception in addition to evidence that not all clones which harbour Regiella insecticola can survive on Prairial indicate that the secondary bacterial endosymbionts are not responsible for specialization but their presence enhance the clonal performance.

Our results conflict with those obtained by Douglas et al.,(2006a), they found presence of $R$. insecticola has a negative effect on the clonal performance of pea aphid on artificial diets with sucrose proportion from 0.25 to $1 \mathrm{M}$; but they found that presence of $H$. defensa has no impact on the clonal performance. Any way Douglas et al., did not found any positive or negative affect of presence of bacterial endosymbionts on diets with sucrose more than $1 \mathrm{M}$; further more they did not found constant pattern of clonal perfromnce regards to clones harboured the same secondary bacterial endosymbionts.

There are many examples inferred from the clonal performance of pea aphid assure that present of secondary bacterial endosymbionts affect only the performance of clones but not the specialization for example: clones of $A$. pisum which harbour $R$. insecticola have twice better performances on clover than those which have ,on the contrary, clones which harbour $H$. defensa do 50 \% better on alfalfa (Leonardo et al.,2003) but removing $H$. defensa from the clones did not allow them to survive on alfalfa (Leonardo et al.,2004). In Japan, pea aphid which has $R$. insecticola showed a higher performance on clover than vetch (Tsuchida et al.,2004).

However, no conclusive evidence for a contribution of secondary bacterial endosymbionts to host specialization of $A$. pisum on to its survival on artificial diet was found (Douglas et

al.,2006 a and b; Leonardo et al.,2004). The authors explained these results by supposedly large genetic variability in both aphids and endosymbionts.

Our results show on the contrary that the genetic variability in $R$. insecticola and $H$. defensa is limited, both in the same aphid species and among endosymbionts from 
different aphid species (Chapter 1), indication further evidence of the importance of the interaction between host plants quality and the clones in specialization of aphids.

Our study show for the first time an application of a food coefficients like WSC in natural resistance to Sitobion avenae clones, any way the selection for high WSC even have positive impact of plant production but it may have a negative effect on the environment and biodiversity over long times, such negative affects should be studies. 
Table (1) Cocksfoot cultivars used in the experiments

$\begin{array}{cccc}\text { Cultivar } & \text { Origin } & \text { WSC concentration } \% \text { S } & \text { Survival } \\ \text { Glorus } & \text { Sweden } & 8.3 & \text { No } \\ \text { Dedinovskaya } & \text { Russia } & 7.8 & \text { No } \\ \text { Hayking II } & \text { Japan } & 6.1 & \text { No } \\ \text { Grassland'skara } & \text { New Zealand } & 3.4 & \text { No } \\ \text { Amba } & \text { Denmark } & 3.2 & \text { No } \\ \text { Milona } & \text { Czech republic } & 2.2 & \text { No } \\ \text { Bartyle } & \text { Netherlands } & 2.1 & \text { No } \\ \text { Prairial } & \text { France } & 1.7 & \text { Yes } \\ \text { Barata } & \text { Netherlands } & 1.6 & \text { Yes } \\ \text { Dorise } & \text { Netherlands } & 1.1 & \text { Yes } \\ \text { Neva } & \text { Russia } & 1 & \text { Yes } \\ & & & \end{array}$


Table (2) The selected clones of Sitobion avenae which were tested on 10 cocksfoot cultivar

\begin{tabular}{|c|c|c|c|c|}
\hline Clone ID & $\begin{array}{l}\text { Number of clones in } \\
\text { a collection 2001- } \\
2003\end{array}$ & Collection site & Host plant & $\begin{array}{l}\text { Secondary } \\
\text { symbionts }\end{array}$ \\
\hline 1 & 194 & Goettingen 1 & Wheat & Regiella insecticola \\
\hline 2 & 194 & Kassel2 & Cocksfoot & Regiella insecticola \\
\hline 3 & 194 & Kassel & Bromus sp. & Regiella insecticola \\
\hline 4 & 115 & Goettingen & Cocksfoot & Hamiltonella defensa \\
\hline 5 & 115 & Giessen & Wheat & Hamiltonella defensa \\
\hline 6 & 115 & Kassel & Cocksfoot & $\begin{array}{c}\text { No secondary } \\
\text { symbiont }\end{array}$ \\
\hline 7 & 66 & Giessen 3 & Wheat & Regiella insecticola \\
\hline 8 & 66 & Giessen & Wheat & Regiella insecticola \\
\hline 9 & 0 & Kassel & Cocksfoot & Hamiltonella defensa \\
\hline 10 & 0 & Kassel & Cocksfoot & Hamiltonella defensa \\
\hline
\end{tabular}

Geographical position of Sites :Goettingen $151^{\circ} 31 \mathrm{~N} / 9^{\circ} 55 \mathrm{E}$; Kassel2 $51^{\circ} 19 \mathrm{~N} / 9^{\circ} 29 \mathrm{E}$ and Giessen3 $50^{\circ} 35 \mathrm{~N} / 9^{\circ} 29 \mathrm{E}$ 
Table (3) Analysis of Variance (AVOVA) effect of clones diversity and WSC on performance of S. avenae clones

\begin{tabular}{rrrrr}
\hline Source & df & Mean Squares & \multicolumn{1}{c}{ F-ratio } & \multicolumn{1}{c}{ p-value } \\
\hline WSC & 9 & $12.094,433$ & $3.916,591$ & 0,000 \\
CLONE & 9 & $3.053,611$ & 988,864 & 0,000 \\
WSC $^{*}$ CLONE & 81 & 565,957 & 183,276 & 0,000 \\
Error & 400 & 3,088 & & \\
\hline
\end{tabular}

Table (4) Analysis of Variance (ANOVA) effect of bacterial endosymbionts and WSC on the performance of $S$.avenae clones

\begin{tabular}{crrrr}
\hline Source & df & Mean Squares & \multicolumn{1}{c}{ F-ratio } & \multicolumn{1}{c}{-value } \\
\hline WSC & 9 & $6.153,697$ & 52,116 & 0,000 \\
BACTERIA & 2 & $3.539,901$ & 29,979 & 0,000 \\
WSC*BACTERIA & 18 & 665,775 & $5,638 \quad 0,000$ & \\
Error & 470 & 118,078 & & \\
\hline
\end{tabular}



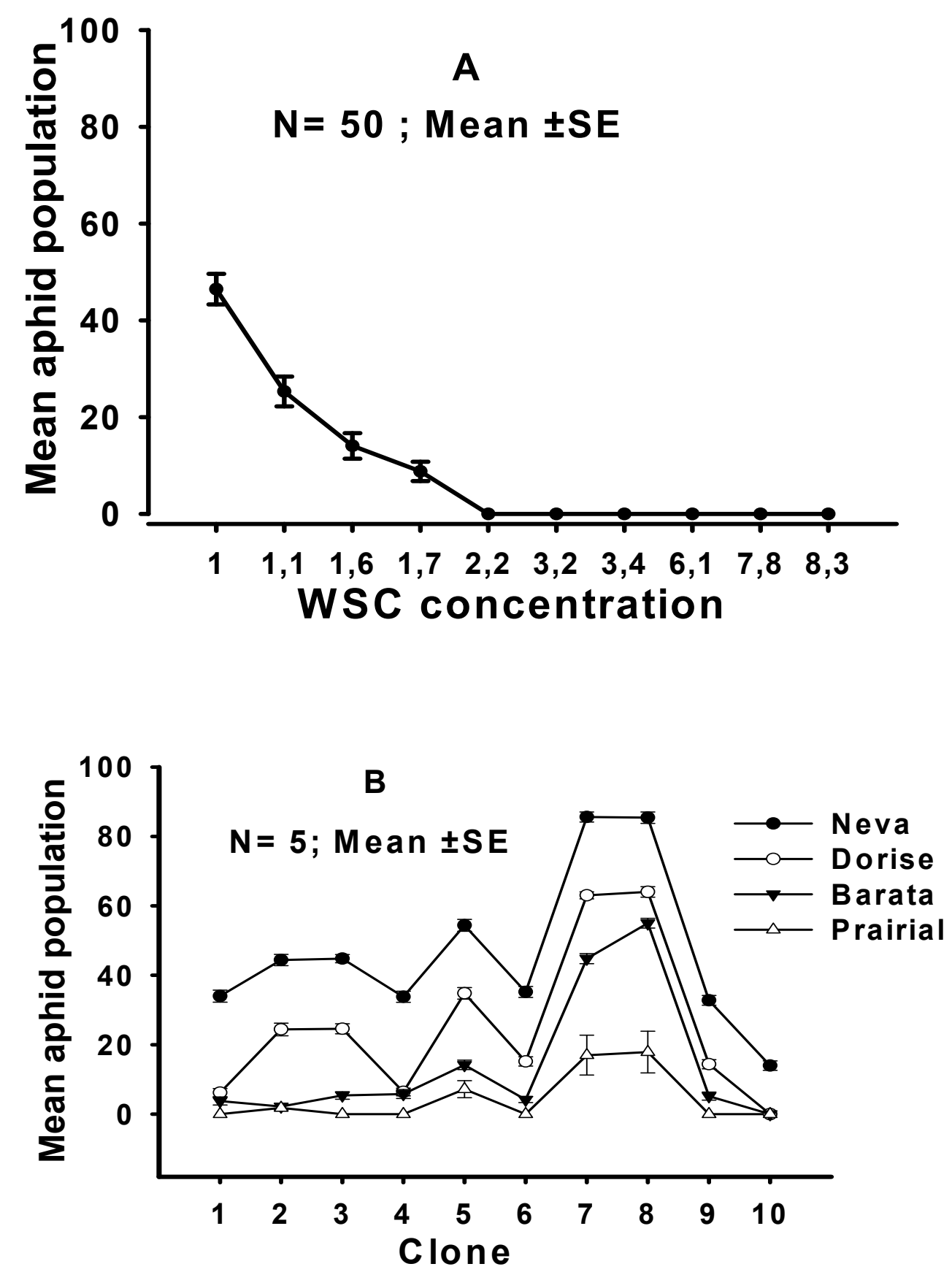

Fig. (1) (A) Relationship between population increase and concentration of WSC ( $F 9,400$ $\left.=3916.591, P<0.001 ; R^{2}=0.993\right)$. Each number on $X$ axis present a cocksfoot cultivar; on $\mathrm{Y}$ axis mean population of 10 clones.

(B) Mean aphid population on 4 cocksfoot cultivars. 


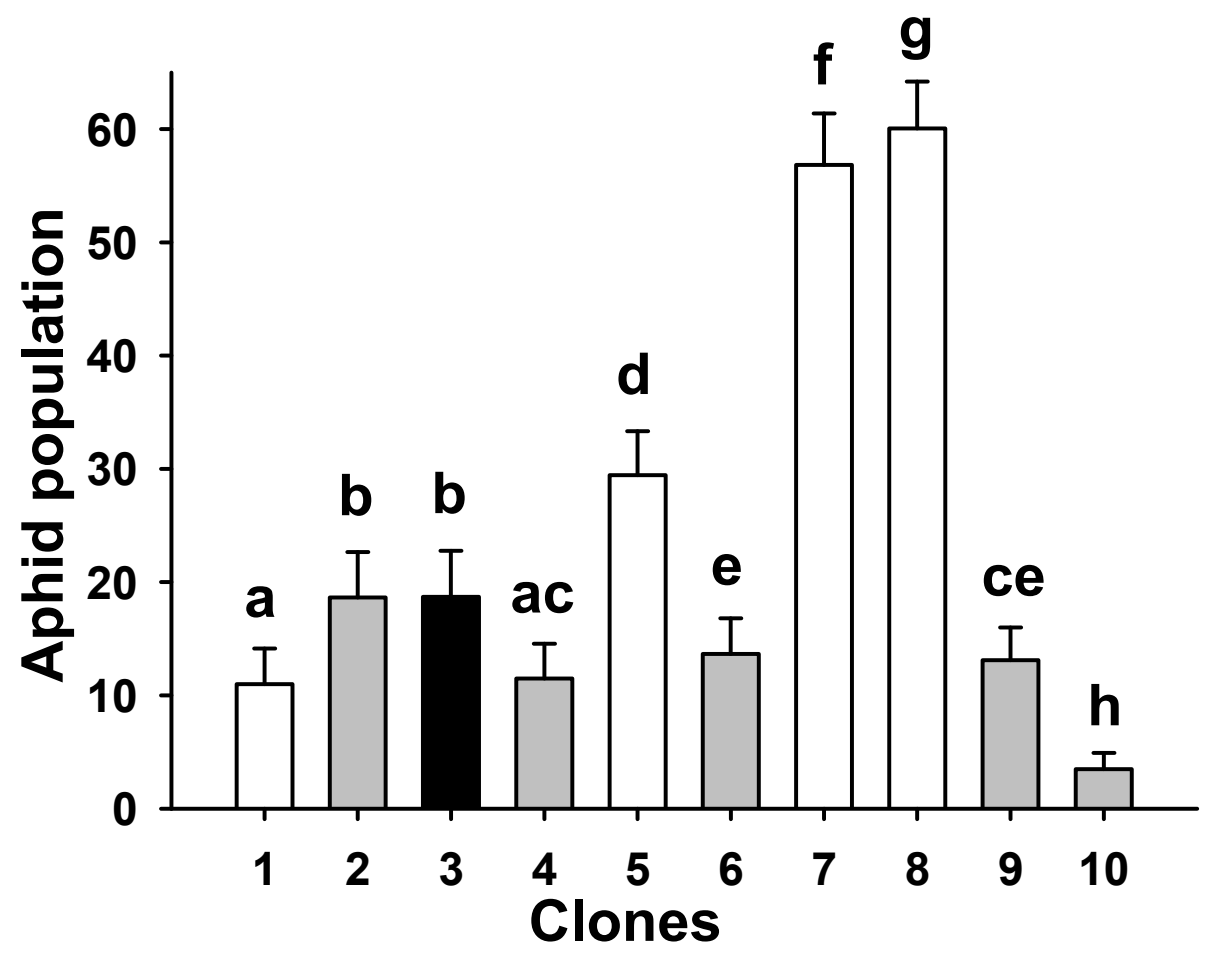

Fig. (2) Population (Mean $\pm S E, N=50$ ) of Sitobion avenae on 10 cocksfoot cultivars. White bars: clones collected from wheat; black bar: clones collected from Bromus; grey bars: collected from Dactylis (ANOVA F9,400 $=988,864, P<0.001 ; R^{2}=0.993$ ) 
A

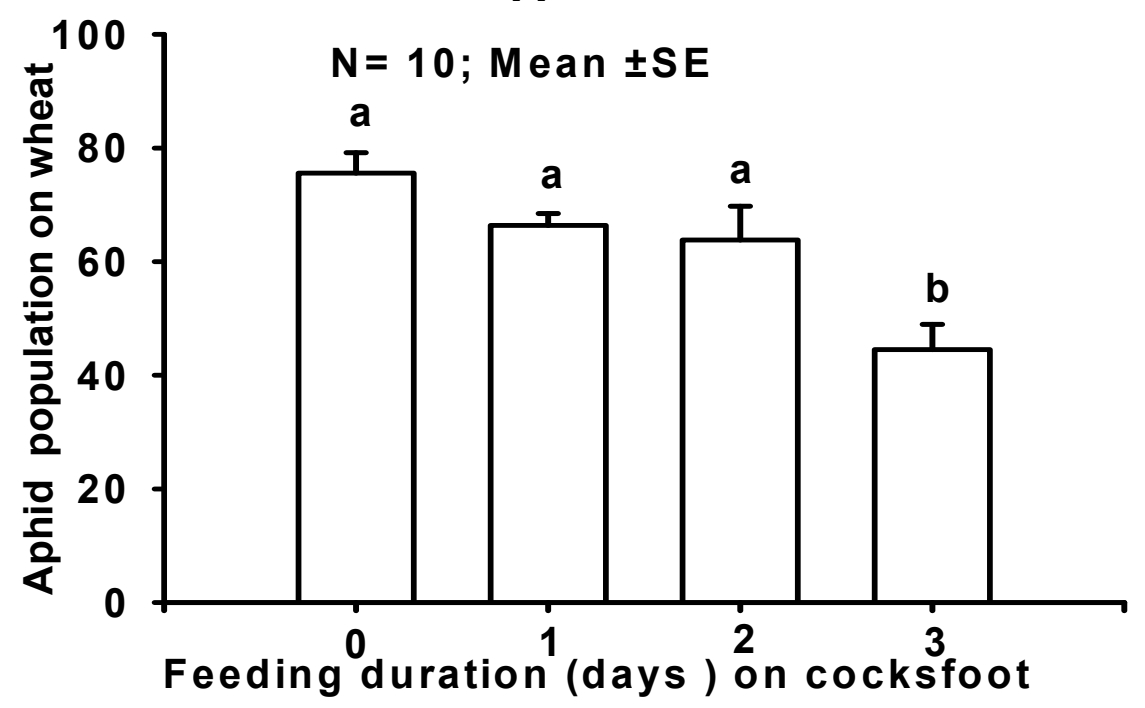

B

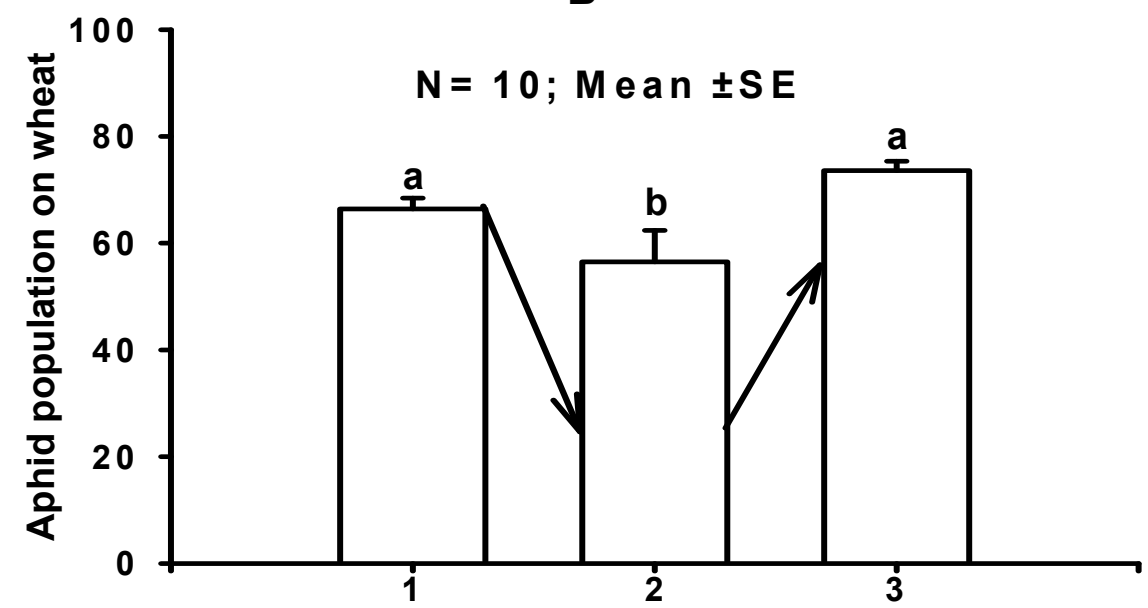

Feeding duration on cocksfoot/generation/day

Fig. (3) Effect of feeding duration on cocksfoot on performance of clone 5 on wheat (A) By feeding one times with different duration $\left(F_{3,36}=9,914, P<0.001 ; R^{2}=0.452\right),(B)$ by feeding many times with different duration in different generation $\left(\mathrm{F}_{2,27}=27.810, \mathrm{P}<\right.$ $\left.0.001 ; R^{2}=0.673\right)$. 


\title{
Chapter 3
}

Host plants use, performance and fitness of grain aphid Sitobion avenae F. clones in central Germany

\author{
Authors \\ Hussein Alkhedir ${ }^{1^{*}}$, Petr Karlovsky ${ }^{2} \&$ Stefan Vidal $^{1}$
}

\section{Addresses}

${ }^{1}$ Agricultural Entomology and ${ }^{2}$ Molecular Phytopathology and Mycotoxin Research,

Department of Crop Sciences, Georg-August University Goettingen, Grisebachstrasse 6 37077 Goettingen, Germany

Correspondence: Hussein Alkhedir

Tel +49 55139 3728, Fax +495513912105, e-mail halkhed@gwdg.de

Short Title: Sitobion avenae clones

Keywords: parthenogenetic, adaptability, bacterial endosymbionts 


\section{Abstract}

The genetic population structure of Sitobion avenae F. (Homoptera: Aphididae) indicate existing of common parthenogenetic and host adapted genotypes in Europe and differences in the genetic population structure of Sitobion avenae on different host plants. The information inferred from the molecular markers and host collecting site was not supported with studies of interaction between the Sitobion avenae genotypes and their potential host plants in the fields. In this study we investigate the performance of some common Sitobion avenae clones in central Germany to shed light on their abundance on some of their agricultural host plants in the field by offering the host plants in the same growth stage for aphids in during three successive generations. We found differences in the clonal performance over three consecutive generations of Sitobion clones on three host plants which reflect the impact of variation in life history traits and genetic diversity of clones on their abundance. Also our study showed that host-based genotypes can not be determined by collecting host plants neither by the genotype of Sitobion avenae clone but this term can be only determined by studying the interaction of both. Out of 8 general clones we found three host-adapted clones and the other clones showed adaptability on the tested host plants. The general clones harbour secondary bacterial endosymbionts which may contribute to different traits of the common clones. 


\section{3-1Introduction}

Aphids are a diverse family of herbivorous species with more than 4700 species described so far; about 100 of them being economically important (Eastop \& Blackmann, 2007). Aphids are known for their remarkable life cycle which might include a parthenogenetic and a sexual generation, an obligate shift between unrelated host plant taxa, a short generation time (about 10 days on average), and telescoping of generations, where granddaughters begin to develop directly within the daughters which are themselves not yet born (Dixon, 1985). Moreover, aphids are characterized by variation in life history traits, where one parthenogenetic female may give rise to up to eight discrete phenotypes differing in life history characteristics such as physiology, morphology, developmental time, longevity, number of progeny, timing of reproduction and fitness, host preferences and ability to use alternative host-plant taxa, respectively (reviewed by Moran, 1992).

Recent studies on the population dynamics and genetics of aphids, using molecular techniques, revealed that aphid species with cyclical parthenogenesis contain several common genotypes (Wilson et al., 2003). For example, the green bug (Schizaphis graminum Rondani) consists of multiple genotypes (Porter et al., 1997), the pea aphid (Acyrthosiphon pisum Harris) consists of two biotypes in north America (Via,1999), and the black bean aphid (Aphis fabae Scopoli) consists of a complex of closely related host plant-associated genotypes (Tosh et al.,2004). The build up and genetic stability of these common clones has been discussed in detail by Loxdale (2008).

The recent researches showed that, the secondary bacterial endosymbionts of aphid interact with different aphid traits, such as thermal tolerance (Montllor et al., 2002; Russell \& Moran 2006) or host-plant range and specialization (Chen et al., 2000; Tsuchida et al., 2004). The secondary endosymbionts are also involved in the improvement of fitness of aphid species on specific host plants (Leonardo et al., 2003; Tsuchida et al., 2004) and may confer resistance to parasitoids and fungal pathogens (Oliver et al., 2003 \& 2005; Ferrari et al., 2004; Scarborough et al., 2005). Thus, secondary bacterial endosymbionts may contribute to the overall abundance and distribution of aphid clones harbouring these bacteria.

The English grain aphid, Sitobion avenae (F.), is an important pest in agricultural systems, especially in temperate climates on the northern and southern hemisphere (Apablaza, 1974; Blackman \& Eastop, 1984; Vickerman \& Wratten, 1979; Wangai et al., 2000) and is regarded a major aphid pest on cereals in Germany (Weber, 1985). 
Studies on the genetic structure of Sitobion avenae found a high genetic variability these populations, with spatial and temporal variation, the existence of predominant cyclic parthenogenesis clones and host plant adapted clones (De Barro et al., 1995b; Sunnucks et al., 1997; Simon et al., 1999; Haack et al., 2000; Papura et al., 2003, Reimer, 2005). The indicator of existence of common genotypes of S. avenae was supported by Helden et al. (2002), they reported existence of S. avenae clones which are obligatory parthenogenetic.

Recently, we evaluated the diversity of secondary bacterial endosymbionts in German populations of $S$. avenae (Chapter 1 ) and reported on clones specialized on the host plant Dactylis glomerata (Chapter 2). The clonal performance was found to be enhanced when the individuals harboured the secondary endosymbiont Regiella insecticola; however, this endosymbiont mediated effect on the clonal performance of S. avenae on their host plants did not follow a predictable pattern because of the both the diversity of the clones and the bacterial endosymbionts (Chapter 1 and 2).

The evidence of existing common and host adapted clones were inferred only from genetic markers Furthermore, the effect of secondary bacterial endosymbionts which harboured by Sitobion avenae clones was not releaved on their agricultural host plants i.e. Wheat and forage grasses (ryegrass, cocksfoot and bluegrass).

Here we hypothesized that (i) the both genetic diversity and variation in life history traits affect the abundance of the common Sitobion avenae clones and (ii) that the secondary bacterial endosymbionts contribute to performance of the common clones on their agricultural host plants, thus contribute to their distribution. To test these hypotheses, we evaluated the clonal performance of common clones of Sitobion avenae sampled in Central Germany on four agricultural host plants during three concessive generations using a standard protocol; these clones relate to different genotypes and harbour different secondary endosymbionts.

\section{3-2Materials and methods}

\section{3-2-1Culturing of host plants}

We used 4 agricultural host plants in this study: wheat (winter wheat cultivar "Bussard"; Lochow Petkus Company, Germany), ryegrass (Lolium perenne L. cv. “Herault”), cocksfoot (Dactylis glomerata L. cv." Amba”) and bluegrass (Poa annua L., unknown cultivar; the latter three spcies obtained from Appels Wilde Samen 
Company, Germany). Seeds were germinated in trays filled with a 2:1 mixture of soil (Fruhstorfer Typ P) and sand.and transplanted into small pots ( 3 seedlings per pot; diameter $11 \mathrm{~cm}$ ). The host plants were germinated in a greenhouse at $20^{\circ} \mathrm{C}$ and $16: 8$ light/dark regime at $200 \mu \mathrm{E}$ photon flux density, and $60-80 \%$ r.h. These seedlings were used for the experiments when being one month old.

\section{3-2-2Aphid cultures}

Sitobion avenae clones were collected from different regions in central Germany (Goettingen, Kassel and Giessen, respectively) in 2004 by sweep-net sampling from wheat (Triticum aestivum), cocksfoot (Dactylis glomeratus) and graminoid grasses. 65 clones were established from single aphids kept on wheat seedlings (winter wheat cultivar "Bussard"; Lochow Petkus Company, Germany) grown as described above, and covered with transparent ventilated cylindrical tubes of $10 \mathrm{~cm} \times 30 \mathrm{~cm}$ size. Aphids were transferred to new plants every second week and the cultures were kept in a climate chamber at $20 \mathrm{C}^{\circ}$ and 16:8 light/dark regime at $200 \mu \mathrm{E}$ photon flux density and $60-80 \%$ r.h.; plants were watered twice a week. Given these conditions all clones reproduced parthenogenetically.

The 10 clones used in this study (Table 1) are belonging to different genotypes, eight of them being frequently found in central Germany (pers. observ.), and nine of them harbouring secondary bacterial endosymbionts (i.e clone 1, 2, 3, 7 and 8 harbour Regiella insecticola "PAUS", clones 4, 5, 9 and 10 harbour Hamiltonella defensa "PABS" and clone 6 harbours no secondary endosymbionts (Chapter 1).

\section{3-2-3Experimental set up}

The clonal performance of the 10 aphid clones used in this study was measured by monitoring the number and fresh weight of offspring, number of surviving aphids, and numbers of alatae aphid mothers by using ten synchronized $1^{\text {st }}$ instar nymphs reared on each of the host plants species for two weeks during three consecutive generations. The experiments were carried out using the same rearing systems and conditions as described above in ten replications for each clone. 10 aphids from each clone on each host plant and each generation were genotyped to check the genetic identity of the clones during the course of the experiments, tested beginning with the time of collection in July 2004 at six month intervals on all host plants during three successive generations.

\section{3-2-4Statistics}


Multivariate Analysis of Variance (MANOVA) was used to analyze the effect of host plants, clones, generations and bacterial endosymbionts in addition to the interaction between each of these parameters on the performance of Sitobion avenae clones, using clone, host plant, generation, bacterial endosymbiont and the interaction between them as independent variables. Number of offspring produced, fresh weight of offspring produced, number of aphid mothers surviving, and alatae were used as independent variables. Host plants, generation number and bacterial endosymbionts were used as categorical variables. The interaction between clones and symbionts was excluded because the test can not be done because of a singular matrix; in this case clones were treated as covariant factors. MANOVA was repeated twice with the factors described before the first once excepted bacterial endosymbionts to inspect the effect of clone as main factors and the second without clones to inspect the effect of symbionts as main factors. Analysis of Variance (ANOVA) was used to analyze the effect of bacterial endosymbionts on each of the dependent factors separately and to analyze the effect of offspring on alatae production, survival and fresh weight, respectively.

Fisher's LSD adjustment was used to compare each of the independent variables on each host plants in each generation for each clone and between clones. Systat for Windows, version 12.01.02 (Systat 2007) was used to perform these analyses.

\section{3-3Results}

3-3-1Genetic variability, variation in life history traits, bacterial endosymbionts and clonal performance

Nine of the S. avenae clones tested hosted secondary bacterial endosymbionts (Table 1). All clones exhibited considerable variation in life history traits with regard to host plant use. MANOVA showed that clonal performance was either significantly influenced by the tested variables (offspring production, fitness, alatae and survival) and by host plants clone, bacterial endosymbiont and generation, respectively, and by the interaction between each of them (Table 2). By excluding the parameter symbionts or clones from the MANOVA analysis, the interaction between clones or symbionts as main factors and between host plant, generation or both of them was not significant and the results did not change ( $P<0,001$; data not shown).

All Sitobion avenae clones exhibited significant variability at least in one generation in the performance on the host plants tested (Table 3 and 4). 
In general, the average number of offspring produced for all Sitobion avenae clones tested was significantly higher on wheat as compared to blue grass and ryegrass, respectively (Figure $1 \mathrm{~A}$ ). All S. avenae clones tested significantly varied in their offspring production during three successive generations, except clone 6 on ryegrass, clone 7 on bluegrass and clone 8 on wheat (Figure 2, Table 4), those clones were subject to be host adapted clones and all of them reached the mean number of produced offspring on each of their adapted host.

We found considerable variation in the ability of the Sitobion clones to adapt to the host plants tested. All clones exhibited a positive adaptability to wheat and achieved their highest production of offsprings in their second generation, except clones 2, 4, 5 and 6 , respectively, which reached the highest production of offsprings in their third generation only. Most of Sitobion clones reached their high offsprings production on bluegrass in the second generation presenting positive adaptation, but clones 4,5 and 6 on bluegrass showed negative adaptation and their offspring production decreased during the second and third generation. On ryegrass all clones exhibited a positive adaptability and achieved their highest fecundity in the third generation, except clones 8, 9 and 10, respectively, which reached this in the second generation.

Bacterial endosymbionts have significantly impact on offspring production $(P<0,001$; $R^{2}=0.026$ ). the clones harboured the secondary endosymbionts bacteria PAUS produced more offsprings on bluegrass rather than those harbour PABS or no secondary endosymbionts respectively. The secondary bacterial endosymbionts have no impact on offsprings production on both wheat and ryegrass.

\section{3-3-1-2Fresh weight (host plants utilization or fitness)}

Fresh weight significantly varied with host plant (Figure 2, Table 4) and all S. avenae clones had a higher fresh weight on wheat as compared to bluegrass and ryegrass, respectively (Figure $1 \mathrm{~B}$ ). Offspring number was highly correlated with fresh weight ( $P$ $<0,001 ; R^{2}=0.965$ ); the fresh weight of all clones increase and decrease according to the production of offsprings. Significantly, the fresh weight of all clones varied over generations, except clone 7 on bluegrass. We found significant effect for bacterial endosymbionts on the fresh weight $\left(P=0.005 ; R^{2}=0.012\right)$; the clones harboured PAUS have a higher fresh weight on bluegrass as compared to clones harboured PABS or no secondary endosymbionts. There was no significant effect of bacterial endosymbionts on clonal fitness on both wheat and ryegrass.

\section{3-3-1-3Alatae production}


Several S. avenae clones showed variation in alatae production during three generations on the 4 host plants tested. However, we did not find variation in alate production in case of clone 2 on wheat, clone 9 and 10 on ryegrass and bluegrass, respectively (Figure 2, Table 4). Sitobion clones produced significantly more alatae on bluegrass as compared to ryegrass and wheat, respectively (Figure $1 \mathrm{C}$ ). Alatae production of Sitobion avenae clones was only marginally correlated with production of progeny $\left(P<0,001 ; R^{2}=0.025\right)$.

Even significantly, there was no relation between the bacterial endosymbionts and alatae production $\left(P<0,648.005 ; R^{2}<0,001\right)$, the clones harboured either PAUS or no secondary endosymbionts produce more alate on bluegrass.

\section{3-3-1-4Survival}

Survival of aphid mothers was highly correlated with their number of offspring $(P<$ 0001; $R^{2}=0.80$ ). $S$. avenae clones have significantly more individuals survived on wheat as compared to bluegrass and ryegrass, respectively (Figure $1 \mathrm{D}$ ). many $S$.avenae clones showed significant variation in surviving over three generation each of host tested plants except clones 1,4,6, and 9 on wheat, clones 1 and 9 on bluegrass, clones $1,3,5,6$ and 8 on ryegrass.

Test of the clones 4,5and 6 on bluegrass over three consecutive generations show increasing of mortality thus decreasing in number of aphid.

We found that clones harboured the secondary bacterial endosymbionts PAUS and PABS had a higher surviving rate on wheat and bluegrass rather than the clone which has no secondary bacterial endosymbiont. we did not found effect for secondary endosymbionts on clonal surviving on ryegrass $\left(P=0 ; R^{2}=0,026\right)$.

\section{3-3-2Genetic Stability of S. avenae clones}

The genotypic profile of all Sitobion avenae clones which generated with five microsatellite primers pair " those collected from three successive generations from three host plants and those collected every six month since collection in 2004 until December 2007" was stable.

\section{3-4Discussion}

3-4-1Genetic stability, variation in life history traits and host adaptability of S. avenae clones The genotyping with five microsatellite loci of test clones since collection in 2004 until December 2007 in addition to genotyping of the aphids collected from tested host plants over three successive generations in this study showed that clones are stable genetically. Rearing Sitobion avenae clones in constant conditions vs. temperature, 
humidity, light and maintaining the culture every two weeks let all clones reproduced parthenogenetically these conditions probably contribute for the genetic stability of our clones. There are evidence that five and seven microsatellites primers pairs were sufficient to genotypic sexual and asexual population of Rhopalosiphum padi L. respectively, so far three microsatellites primers pairs did not showed any defence in genotypic profile of 256 offsprings of parthenogenetic female Sitobion avenae representing five asexual generations (Loxdale \& Lushai, 2007).

The results of this study showed that Sitobion avenae clones showed variation in use of the test host plants whereas the clones differ in their fecundity and fitness in addition to alatae production on the tested host plants over three successive generations which maybe explain the temporal variation of these clones.

The effect of reduction of host quality and short photoperiods (Dixon,1998) on the fecundity, fitness and alatae production was excluded in our study by offering host plants of same age and maintaining the aphids culture every two weeks, also the crowing of both adults and offsprings (Watt \& Dixon, 1981) results in more alatae in rearing culture but it did not effect the nymphs on the following generation, probably crowding of the first nymph stage (Ankersmit \& Dijkman ,1983) responsible for production of alatae; this effect was excluded in our experiments.

Our results explain the temporal and spatial variation of Sitobion avenae clones in regards to their variation in life history traits and genetic variability. So far the results of this study also give further evidence for the results obtained from studying of genetic population structure of Sitobion avenae clones in Germany (Reimer, 2005).

Rearing Sitobion clones on wheat for six month before starting our experiments did not change the evolutionary and environmental trend of Sitobion avenae clones while only clone 8 did not show variation in their fecundity on wheat thus we supposed this clone as host adapted clone on wheat and the same for clones 6 and 7 on ryegrass and bluegrass, thus the environmental effect last for long time in aphid not only for two generation (De Barro et al.,1995b) where as the adapted clones on ryegrass and bluegrass were collected from other host plants and reared on wheat for many generation but that had not effect their performance on wheat in the same time on their host plants.

Our study indicates that the variation in life history traits of Sitobion clones contributes to their adaptability and colonization on host plants, while the host adapted clones did not show variation on their host plants and the other clone used the variation in life history traits to reach their optimum fecundity on the new host plants, the same 
results obtained by De Barro et al. (1995b) ; they found no changes in fecundity over four successive generations on Dactylis glomerata and wheat within Sitobion avenae clones which were suggested to be host adapted clones on wheat and Dactylis glomerata.

Host adapted and general clones of Sitobion avenae were determined by molecular markers or host- clone collecting site on maize, wheat, barely, cocksfoot and other graminoides (Weber , 1985; De Barro et al., 1995 a \& b; Sunnucks et al., 1997; Haack et al., 2000, Figueroa et al., 2005; Vialatte et al., 2005), but any way neither the molecular markers nor host-clone collecting site alone is not enough to determines the common or host adapted clones especially the if the interaction between the clones (biotype) and its host plant determined by genes responsible for host plant resistance as it in Schizaphis graminum (Ono et al.,1999) in such cases in addition to molecular markers the clonal performance should be studied.

\section{3-4-2Secondary bacterial endosymbionts of Sitobion avenae clones}

From eight common clones seven of them have secondary bacterial endosymbionts, three of them have PAUS, two have PABS and the other two rare clones have PABS. We found an effect of secondary bacterial endosymbionts on clonal performance of Sitobion avenae on bluegrass where as PAUS effect positively the fecundity and fitness of Sitobion avenae clones rather than PABS or Buchnera in addition PAUS and PABS enhanced the surviving of Sitobion clones on wheat and PAUS enhanced surviving on bluegrass more than PABS and Buchnera respectively.

In contrary, on the wild host plants, the secondary endosymbionts had non constant pattern of effect on the clonal performance for the same tested clones in this study, and the clone with has no secondary endosymbionts has the best performance on Elymus repens, so far the clone produce 6 times offspring on Holcus lanatus rather of other clones (Chapter 1).

in other aphid species such as Acyrthosiphon pisum is known that the secondary endosymbionts effect the clonal performance and fitness of Acyrthosiphon pisum ; genotypes of $A$. pisum which harbour PAUS have twice better performances on clover than those which have PABS but they can not survive on alfalfa, in the opposite the genotypes which harbour PABS do 50 \% better on alfalfa (Leonardo et al., 2003).also in Japan pea aphid which have PAUS have good performance on clover than vetch (Tsuchida et al., 2004). Also A. pisum in Japan exhibit characteristic geographical distribution of PAUS (Tsuchida et al., 2002). 
The mean freezing temperatures (supercooling points) of overwintering nymphs and adults of S. avenae are consistently below $-20{ }^{\circ} \mathrm{C}$ (Knight et al.,1986), any how S. avenae was proved to survive at low temperatures up to $-8 \mathrm{C}^{\circ}$ (Powell \& Bale ,2004) and by acclamation the aphids at $10^{\circ} \mathrm{C}$ for three generation they can survive at $-12^{\circ} \mathrm{C}$ (Powell \& Bale, 2005).

Montllor et al. (2002), and Russell and Moran (2006) proved that bacterial endosymbionts may contribute to cold hardening and thermal tolerance of $S$. avenae. This has been attributed to the possession of a gene in the primary bacterial endosymbionts Buchnera aphidicola responsible for adapting to low temperatures (Shigenobu et al., 2000; Tamas et al., 2002; Perez-Brocal et al., 2006). This gene is a member of the cspA-family, also known from Escherichia coli and responsible for producing the cold shock protein CS7.4 (Goldstein et al., 1990; Nakashima et al., 1996). Thus, the bacterial endosymbionts of $S$. avenae may contribute to cold hardening of Sitobion avenae and survival of parthenogenetic clones during winter.

From the pervious (Chapter 1and 2) and this study, we can indicate that secondary bacterial endosymbionts may contribute to distribution and abundance of the common clone by enhancing fecundity and fitness of these common clones on their agricultural and some other wild host plants.

However, the effect of secondary bacterial endosymbionts in Sitobion avenae clones on other traits need to be studied in more details using more clones with or without secondary bacterial endosymbionts, more rare clones on many other host plants and genetic variability of both clones and symbionts should be considered in such studies.

\section{3-4-3 Common and clones of Sitobion avenae}

The common clones of Sitobion avenae were supposed to be obligatory parthenogenetic host- adapted or general clones (Weber, 1985; De Barro et al., 1995a\&b ; Sunnucks et al.,1997; Haack et al., 2000, Figueroa et al., 2005;Vialatte et al., 2005,Loxdale and Lushai 2007; Loxdale, 2008) , our study give further evidence for the pervious studies which based on the molecular marker and shed light over the factors mediate the interaction between the clones and the host plants which can contribute to the adaptability of Sitobion avenae clones such variation in life history traits and secondary bacterial endosymbionts.

Further studies are required to inspect the influence of secondary bacterial endosymbionts on different traits of Sitobion avenae clones such as tolerance to heat and cold, resistant to natural enemies, or pathogens. 


\section{Figure legends}

Figure (1) Performance of Sitobion avenae clones (a: offspring, b: fresh weight, c: alatae, d: survival; mean \pm SE) on the three host plants tested ( 1: wheat, 2: bluegrass and 3: ryegrass respectively).

Figure (2) Performance (number of aphids produced, fresh weight [mg], number of alatae, survival of aphids) of Sitobion avenae clones 1 - 10 on three host plants species (wheat: white bars), bluegrass: black bars, ryegrass: grey bars) during three successive generations. 
Figures

Figure (1)
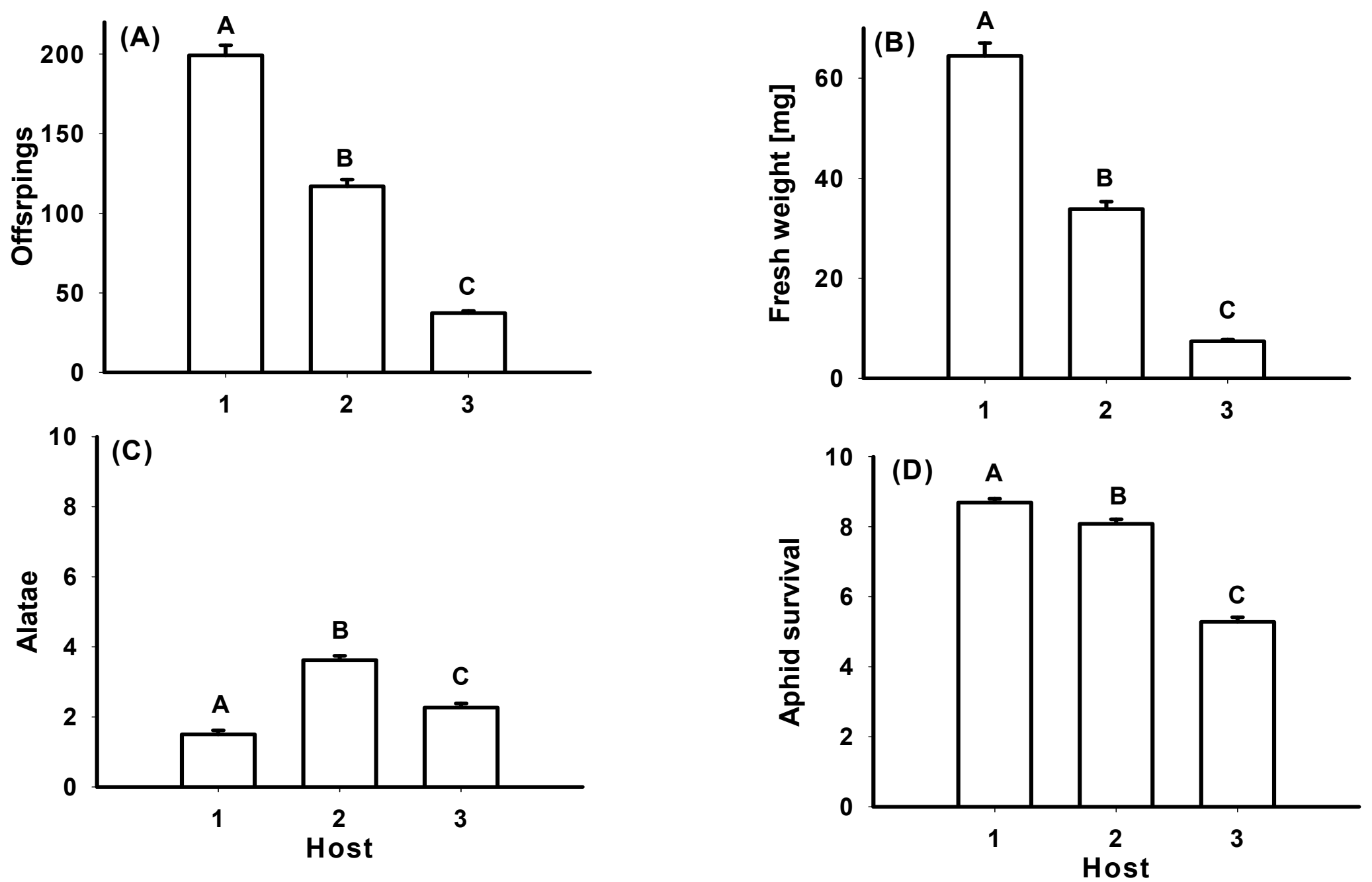
Figure (2)
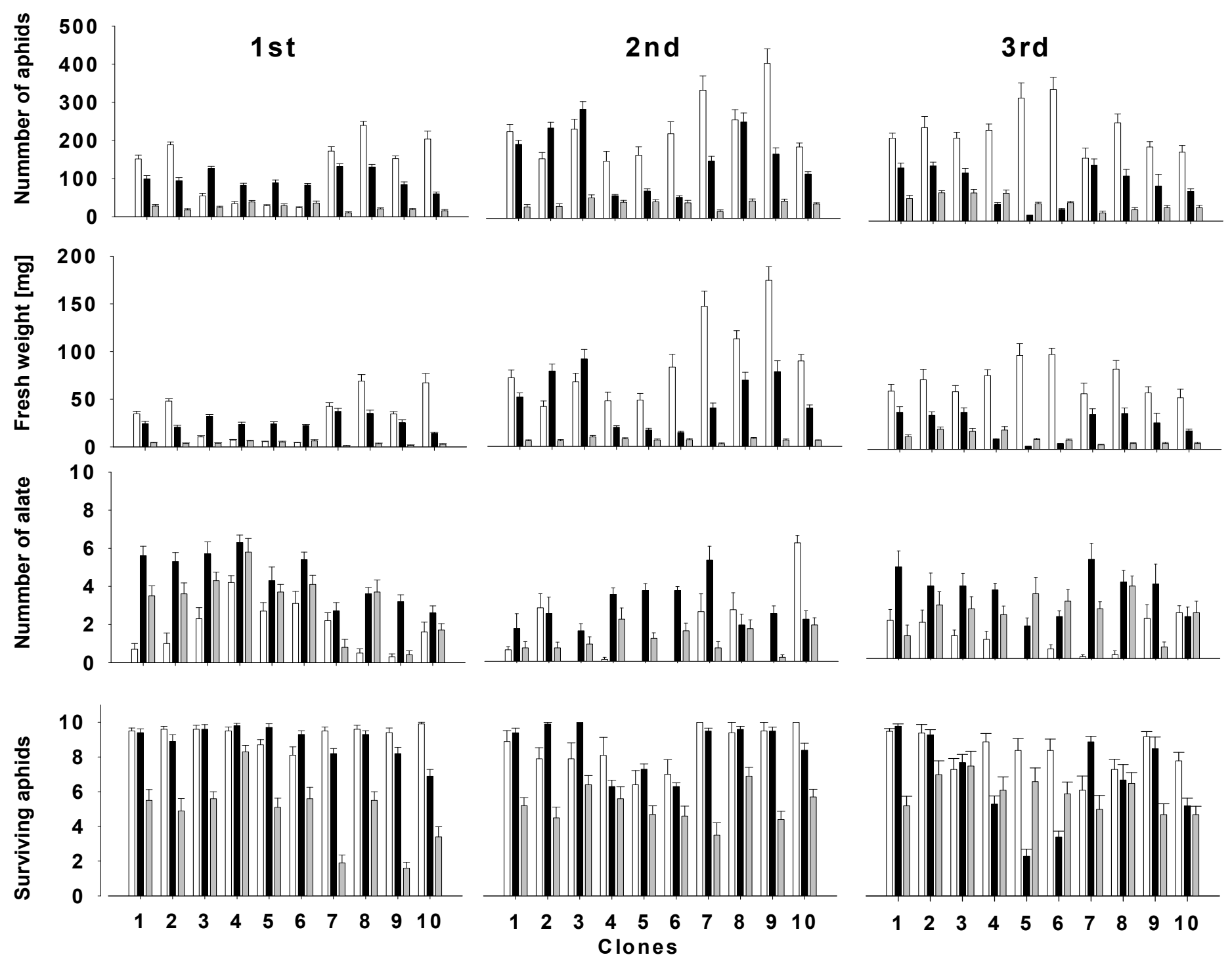


\section{TABLES}

Table (1) Geographic origin, and host plants of Sitobion avenae clones used in the experiments and primary and secondary endosymbiont profiles

\begin{tabular}{cccc}
\hline Clone ID & Collection site & Host plant & Endosymbionts \\
\hline 1 & Goettingen & Wheat & Regiella insecticola \\
2 & Kassel & Cocksfoot & Regiella insecticola \\
3 & Kassel & Bromus sp. & Regiella insecticola \\
4 & Goettingen & Cocksfoot & Hamiltonella defensa \\
5 & Giessen & Wheat & Hamiltonella defensa \\
6 & Kassel & Cocksfoot & Regiella insecticola \\
7 & Giessen & Wheat & Regiella insecticola \\
8 & Giessen & Wheat & Hamiltonella defensa \\
9 & Kassel & Cocksfoot & Hamiltonella defensa \\
10 & & Cocksfoot & \\
\hline
\end{tabular}


Table (2) Multivariate repeated measures analysis on the effects of several factors and the interaction between these factors on the fecundity, fitness, alate production and surviving of the test clones of $S$. avenae

\begin{tabular}{|c|c|c|c|c|c|}
\hline Factor & SS & df & Mean Squares & F-ratio & p-value \\
\hline $\mathrm{CLONE}^{1}$ & $38.340,178$ & 1 & $38.340,178$ & 26,194 & 0,000 \\
\hline HOST & $65.567,023$ & 2 & $32.783,511$ & 22,398 & 0,000 \\
\hline GENERATION & $116.223,648$ & 2 & $58.111,824$ & 39,703 & 0,000 \\
\hline SYMBIONTS & $135.755,364$ & 2 & $67.877,682$ & 46,375 & 0,000 \\
\hline $\mathrm{HOST}^{*} \mathrm{CLONE}$ & $92.447,019$ & 2 & $46.223,510$ & 31,580 & 0,000 \\
\hline GENERATION*CLONE & $71.656,979$ & 2 & $35.828,490$ & 24,478 & 0,000 \\
\hline GENERATION*HOST & $228.846,457$ & 4 & $57.211,614$ & 39,087 & 0,000 \\
\hline SYMBIONTS*HOST & $138.328,635$ & 4 & $34.582,159$ & 23,627 & 0,000 \\
\hline SYMBIONTS*GENERATION & $57.237,194$ & 4 & $14.309,298$ & 9,776 & 0,000 \\
\hline SYMBIONTS*GENERATION*HOST & $178.625,964$ & 8 & $22.328,246$ & 15,255 & 0,000 \\
\hline GENERATION*HOST*CLONE & $86.145,769$ & 4 & $21.536,442$ & 14,714 & 0,000 \\
\hline Error & $1.264 .620,403$ & 864 & $1.463,681$ & & \\
\hline
\end{tabular}

${ }^{1}$ Clone treated as covariant 
Table (3) Pairwise comparisons of the performance of $S$. avenae clones on three host plants during three successive generations (G1, G2 and G3) for each of the following variables: $O$ (offspring), $\mathrm{F}$ (fresh weight), $\mathrm{A}$ (number of alatae) $)^{1}, \mathrm{~S}$ (survival) ${ }^{2}$. Only the results significantly differing are shown.

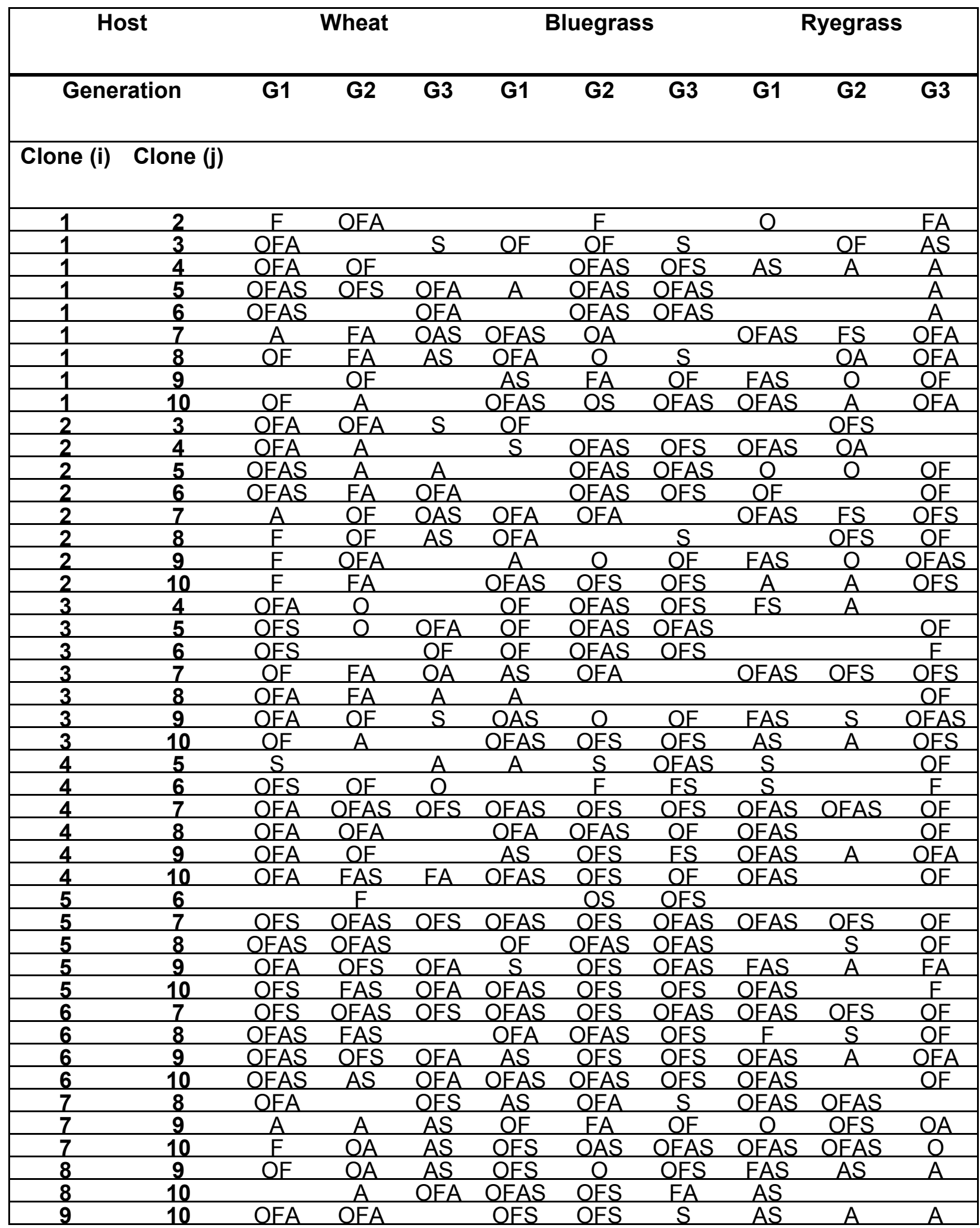

1,2 alate und surviving of aphid mothers 
Table (4) Pairwise comparisons for all parameters tested: O (offspring), F (fresh weight), A (alatae)1, S (survival)2 during three generations (G1, G2 and G3) on three host plants for each of the clones. Only significant results are given.

\begin{tabular}{|c|c|c|c|c|c|c|c|c|c|c|c|}
\hline CLONE & & 1 & 2 & 3 & 4 & 5 & 6 & 7 & 8 & 9 & 10 \\
\hline HOST PLANT & G & & & & & & & & & & \\
\hline \multirow{3}{*}{ Wheat } & G1/G2 & OF & $\mathbf{S}$ & OFAS & OFA & OFAS & OFA & OF & FA & OF & A \\
\hline & G2/G3 & A & OF & A & OFA & OFS & 0 & OFAS & FAS & OFA & FAS \\
\hline & G1/G3 & OFA & & OFS & OFA & OFA & OFA & AS & $\mathbf{S}$ & OFA & $\mathbf{S}$ \\
\hline \multirow{3}{*}{ Bluegrass } & G1/G2 & OFA & OFAS & OFA & OAS & FS & OFAS & AS & OFA & OF & OFS \\
\hline & G2/G3 & OFA & OF & OFAS & OFS & OFAS & OFAS & & OFAS & OF & OFS \\
\hline & G1/G3 & OF & OF & $\mathbf{S}$ & OFAS & OFAS & OFAS & $\mathbf{A}$ & $\mathbf{S}$ & & OFS \\
\hline \multirow{3}{*}{ Ryegrass } & G1/G2 & A & A & OFA & AS & OA & A & $\mathbf{F}$ & OFA & OFS & OFS \\
\hline & G2/G3 & OF & OFAS & FA & OF & FA & & $\mathbf{A}$ & OA & & \\
\hline & G1/G3 & OFA & OF & OFA & OFAS & OF & $F$ & OFAS & $\mathbf{F}$ & OFS & OFS \\
\hline \multirow[t]{3}{*}{ Wheat/Bluegrass } & G1 & OFA & OFA & OFA & OFA & OFA & OFA & & OFA & OFA & OFAS \\
\hline & G2 & & $\mathbf{F}$ & AS & OFA & OFA & OFA & OFA & $\mathbf{F}$ & OFA & OFAS \\
\hline & G3 & OFA & OF & OFA & OFAS & OFAS & OFAS & AS & OFA & OF & OFS \\
\hline \multirow[t]{3}{*}{ Wheat/Ryegrass } & G1 & OFAS & OFAS & OFAS & AS & $\mathbf{S}$ & OS & OFAS & OFAS & OFS & OFS \\
\hline & G2 & OFS & OFAS & OFA & OFA & OFA & OFAS & OFS & OFS & OFS & OFAS \\
\hline & G3 & OFS & OFS & OF & OFAS & OFA & OFAS & OFA & OFA & OFS & OFS \\
\hline \multirow[t]{3}{*}{ Bluegrass/Ryegrass } & G1 & OFAS & OFS & OFS & OFS & OFS & OFS & OFAS & OFS & OFAS & OFS \\
\hline & G2 & OFS & OFAS & OFS & FA & OFAS & FA & OFAS & OFS & OFAS & OFS \\
\hline & G3 & OFAS & OFS & OF & OF & OFAS & OFS & OFAS & OF & OFAS & OF \\
\hline
\end{tabular}

1,2 alatae und survival of aphid mothers 


\section{Chapter 4}

The effect of light intensity on the colour morph formation and performance in grain aphid clones (Sitobion avenae F.) (Homoptera: Aphididae)

Hussein Alkhedir ${ }^{\mathrm{a}}$, Petr Karlovsky ${ }^{\mathrm{b}}$, Stefan Vidal ${ }^{\mathrm{a}}$

${ }^{a}$ Agricultural Entomology and ${ }^{\mathrm{b}}$ Molecular Phytopathology and Mycotoxin Research, Department of Crop Sciences, Georg-August University Goettingen, Grisebach Strasse 6 - 37077 Goettingen Germany

Corresponding author: Hussein Alkhedir

Department of Crop Sciences, Agricultural Entomology, Georg-August University Goettingen, Germany.

Grisebach Strasse 6 - 37077 Goettingen - Germany

Tel +4955139 3728, Fax +495513912105, e-mail halkhed@gwdg.de 


\begin{abstract}
The grain aphid Sitobion avenae F. present colour polymorphisms even within the same clone. The mechanisms determining the induction of colour morphs in the $S$. avenae are still not adequately unravelled. The common understanding is that colour morphs are genetically determined and influenced by environmental factors and the host plants. In the last decade, it was proved that green and brown colour morphs of Sitobion avenae have different carotenoides. So far there is no clear evidence whether light intensity, time period the morphs are exposed, or a mixture of several parameters is involved in the induction of Sitobion colouration therefore in the carotenoides synthesis processes. This study determines the effect of light intensity on the performance and colour in the grain aphid Sitobion avenae $\mathrm{F}$. and inspect the role of host plants and genetic factor on the colour formation of Sitobion avenae clones. Results showed that colour of Sitobion avenae is determined first genetically and regulated by light intensities which affect the clonal performance and synthesis of carotenoides of Sitobion avenae. Host plants do not effect the colour formation of Sitobion avenae and the colour of clone dose not influenced its performance. High light intensity enhanced the fecundity and fresh weight of Sitobion avenae clones, further more Sitobion avenae clones produced more alate under low light intensity.
\end{abstract}

Keywords: Sitobion avenae; Carotenoides; Light intensity; Colour polymorphisms 


\section{4-1Introduction}

Aphid present polymorphisms in life cycles and in colour (Blackman and Estop, 1984; Dixon, 1998). The colour of aphid results from colour of cuticle and from pigmentation of haemolymph (Müller, 1961). The colour of cuticle affect by temperature (Dixon, 1973) and the pigmentation of haemolymph affect by temperature, photoperiod and light intensities (Markkulaand Rautapää, 1965, Jenkins et al., 1999).Haemolymph pigments consist of aphins or protoaphins which is restricted to Aphididae (Bowie et al., 1966) or carotenoides which are associated with higher plants or micro organisms (Goodwin, 1986). Aphins give different colour to aphids red ,yellow or orange; the main colour of Aphis fabae resulted from aphins and carotenoides are responsible about the colour of many other aphids such Macrosiphum liriodendri, Amblycorypha sp., Metapolophium dirhodum and Sitobion avenae; different colour morphs have different carotenoides (Andrewes et al., 1971; Weisgraber et el., 1971, Jenkins et al.,1999). Aphids like other animals can not produce precursors needed for synthesis of terpenoids, sterols and carotenoides, thus Buchnera aphidicola the primary bacterial endosymbionts of aphid were supposed to synthesize them for aphid (Moran et al., 1994; Douglas et al.,1998). Colour polymorphisms of aphid may have selective advantages under certain conditions. For instance colour polymorphisms may change the escape behaviour of aphids from their predators (Braendle and Weisser , 2001) , foraging behaviour of coccinellid species (Harmon et al., 1998), effect the performance of aphid (Weber,1985) and involved into resistant to aphid parasitioides (Ankersmit , 1981,1986$)$. The abiotic factors causing colour polymorphisms such light intensity, photoperiods and temperature affect not only the colour formation of aphid but they fecundity of aphid( (Markkula et al., 1965,1967) and in the same time the quality of its host plants. The grain aphid Sitobion avenae F. has different colour morphs differ from green - red -brown to pink (Phillips, 1916; Müller, 1961; Markkula et al., 1963, 1965, 1967; Jenkins et al., 1991, 1999). Colour polymorphism of Sitobion avenae results mainly from differences of carotenoides proportion (Jenkins et al., 1991, 1999). The brown colour morphs of Sitobion avenae supposed to have selective advantages such abetter performance or resistance to parasitoides (Ankersmit; 1981, 1986; Weber, 1985). The mechanisms determining the induction of colour morphs in Sitobion avenae and the impact of light intensities on the colour formation and performance of Sitobion clones still not exactly revealed. In this study we tested if the colour morphs of Sitobion clones is genetically determined and we determined the influence of light intensities and host plants on colour formation and performance of Sitobion avenae clones. The purpose of the study was achieved by using genetically identified clones of Sitobion avenae which have 
different colour morphs when had been collected. The carotenoides of tested aphid were separated on thin layer chromatography ( TLC) and the clonal performance was tested under different light intensities in addition to observation of aphid colouration on many host plants under different light intensities.

\section{4-2Material and methods}

\section{4-2-1Aphid cultures and determination of light intensity}

The ten clones used in this study were established from single aphid by propagating them on wheat seedlings (winter wheat cultivar "Bussard" bought from LOCHOW PETKUS company, Germany) grown in pots with a diameter of $11 \mathrm{~cm}$, filled with a 2:1 mixture of soil (Fruhstorfer Typ P) and sand, covered with transparent ventilated cylindrical tubes of 10 $\mathrm{cm} \times 30 \mathrm{~cm}$ size. Aphids were transferred to new cultures every second week and the cultures were kept at $20 \mathrm{C}^{\circ}$ and 16:8 light/dark hour conditions, $15 \mu$ Einstein flux intensity, 60-80\% humidity in the climate chamber WB 750 KFL (Mytron Bio- Und Solartechnik $\mathrm{GmbH}$, Germany)and were watered from below twice a week. Under these conditions all clones reproduced parthenogenetically and were light green in colour. All clones used in this study already used by Alkhedir et al. (Chapter 1and 2), they were collected from different regions and different host plants. The clones related to different genotypes and harbour different bacterial endosymbionts (Chapter 1); also they had different colour morphs by collection time (Tab.1). Light intensity was measured by LI - COR Quantum Radiometer / Photometer (Inc Bioscience). All experiments under high light intensity were don in the climate chamber "TE-17 Raum 289180" ( VIESSMANN ,2002 Germany). The experiments under low light intensity or in darkness were done the climate chamber WB 750 KFL (Mytron Bio- Und Solartechnik GmbH, Germany).

\section{4-2-2Determination colour of Sitobion avenae on host plants}

Many host plants were used in the experiments; Triticum aestivum, cultivar "Bussard" bought from LOCHOWPETKUS, Poa annua, Lolium perenne cv. "Herault", Avena sp., Phalaris arundinacea (culture form), and Agropyron repens were bout from Appels Wilde Sammen Company, Germany .Dactylis glomerata cv. "Neva", was brought from bought from National Agricultural Research Center for Hokkaido Region. wheat was grown as described in aphid culture and used as seedlings seven days old, all other host plants were germinated in greenhouse in trays then transplanted to small pots with a diameter of $11 \mathrm{~cm}$ filled as the trays with a mixture 2:1 of soil (Fruhstorfer Typ P) and sand ; all of them used as seedlings one month old (from planting to time of use). Sitobion avenae clones 1- 10 were reared on host plants with 12 replications each clone on each host plants (every pots contained 3 seedlings of about $10-13 \mathrm{~cm}$ long except wheat ;the pots 
contain 10 seedlings); they were divided equally into two groups. The first group of Sitobion cultures were distributed randomly in growth chambers at $20 \mathrm{C}^{\circ}$ and $60-80 \%$ humidity under $15 \mu \mathrm{E}$ with 18:6 light - dark illumination periodsand the second group under $200 \mu \mathrm{E}$ with 18:6 light - dark illumination periods. The colours of aphids in culture were observer over one month, then after the aphid were transferred to fresh host plants.

The first group which reared under $15 \mu \mathrm{E}$ divided into two groups, one reared under $200 \mu \mathrm{E}$ with 18:6 light - dark illumination periods and the second in darkness. Also clones which reared under $200 \mu \mathrm{E}$ divided into two groups one reared under $15 \mu \mathrm{E}$ with 18:6 light - dark illumination periods and the second in darkness.

The experiments were done on each host pants separately

\section{4-2-3Determination colour of Sitobion avenae Clone 9 reared in petri dishes}

Ten green adult of clone 9 were chosen randomly from the aphid culture on wheat. Every adult of them was propagated in Petri dishes included wet filter paper and small cut of wheat seedling leafs under $200 \mu \mathrm{E}$ in the same conditions of last experiment. After 5 days, half of Petri dishes were covered to obtain dark conditions. The new offsprings of all aphids in petri dishes (in light, darkness) were left to become adults and have new offsprings. The colour of aphids and their offsprings was observed, as well as the colour of progeny in adults was registered.

\section{4-2-4Determination colour of clone 6 reared on one seedling in transparent culture}

Five synchronized nymphs of the first stage of clone 6 green in colour were propagated on one wheat seedling (seven $\mathrm{cm}$ long) and its root and apart of stem immersed in transparent flask filled with $200 \mathrm{ml}$ water. The whole set (aphid and seedling) covered with transparent ventilated cylinder. The aphid were reared under light intensity of $200 \mu \mathrm{E}$ (in the same rearing condition) and there colour were observed daily over one time. In this system the aphids were good exposed to light. The experiment made with five replications.

\section{4-2-5Performance of all tested S. avenae clones under different light intensities}

Clonal performance was estimated by recording the number of aphids, fresh weight, and alate production of 10 synchronized nymphs of the first stage when they were propagated on 7 days old wheat" Triticum aestivum", seedlings, kept in transparent ventilated cylinders for two weeks in growth chambers at $20 \mathrm{C}^{\circ}$ and $60-80 \%$ humidity under two different light intensities (i.e. 15 and $200 \mu \mathrm{E}$, respectively with 18:6 light - dark illumination period). The experiments made with seven replications for each clones under each of light intensities.

\section{4-2-6 Carotenoides analysis of Sitobion clones}


Aphids were harvested after each experiment under different light intensities and they separated into four groups. The first and second contain clones 7 and 8 collected from $15 \mu \mathrm{E}$ and $200 \mu \mathrm{E}$ respectively (all of them were green in colour). The third and four groups include all clones except 7 and 8 collected from 15 and $200 \mu \mathrm{E}$ respectively; the third group was green in colour and the fourth was coloured (red -brown). Carotenoides were extracted and separated in TLC from each group as described briefly in (Jenkins et al., 1999). Samples, using pre-chilled acetone three times $(2 \mathrm{ml})$, methanol/acetone $(1: 1, \mathrm{v}: \mathrm{v})$ one time $(2 \mathrm{ml})$ and finally petroleum ether two times $(2 \mathrm{ml})$. All extracts were pooled in a plastic vial , centrifuged at $2000 \mathrm{rpm}$ for $20 \mathrm{~min}$, then after placed in separating funnel include $5 \mathrm{ml}$ petroleum ether. A sufficient quantity of distilled water was added at the end to aid in the separation of the phases. The bulked extracts partitioned in two phases: The extract of the brown clone separated into a blue-green aqueous phase and an orange epiphase; the extract of the green clone separated into the same blue-green hypophase but the epiphase was yellow.

The epiphase was collected in new plastic vial, the petroleum ether was added again to the bulk extracts to retained the any pigments. The collected epiphase $(10 \mathrm{ml})$ washed three time with distilled water, finally we left the extract to dryness under vacuum. The extract which contained pigments in various stages of

esterification with fatty acids was saponified under nitrogen gas for $16 \mathrm{~h}$ at $5^{\circ} \mathrm{C}$ in $5 \mathrm{ml}$ petroleum ether with $6 \% \mathrm{KOH}$. The saponified extraction placed in separating funnel with $5 \mathrm{ml}$ distilled water, the organic phase collected in new vial and the petroleum ether was added again to the bulk extracts to retained the any pigments.

We deride the extraction in rotary vacuum, then we solved in $200 \mu \mathrm{l}$ petroleum ether. The pigments were separated in TLC using either Silica gel or Aluminum oxide foils (20X20 $\mathrm{cm}$ ) (Fluka, Germany) pre 7 washed with $3 \% \mathrm{KOH}$ in methanol, placed in tanker include Diethyl ether in petroleum ether $(5 \% \mathrm{v} / \mathrm{v})$ or Diethyl ether in hexane $(5 \% \mathrm{v} / \mathrm{v})$. TLC was done in darkness at $5^{\circ} \mathrm{C}$. The extracts were co-chromatographed with b-carotene (Sigma) and the $\mathrm{Rf}$ values for each band recorded.

\section{4-2-7Statistic analysis}

MANOVA was used to analyze the light effect on the clonal performance of Sitobion clones; whereas number of aphid, fresh weight, alate number and survived aphid were the dependent factors and clones, light intensities and interaction of them were the independent factors; clones and light intensities were considered as categorical variables. MANOVA used also to analyze the effect of colour morph on clonal performance of 
Sitobion clones; whereas number of aphid, fresh weight, alate number and survived aphid were the dependent factors and clones, colour morphs was the independent factor and was considered as categorical variable.

Kruskal-Wallis One-way Analysis of Variance test was made to compare the performance for each clones under different light intensities. Bonferroni adjustment was made to compare the clonal performance for each variable under each of light intensities. Systat for windows version 11.00.01 (Systat, 2004) was used to perfume analysis and Sigma Plot for windows version 10.0 (Sigma plot, 2006) was used to produce graphics.

\section{4-3Results}

\section{4-3-1Colour morphs under different light intensities on different host plants}

Host plants did not affect the colour formation of Sitobion clones; whereas the colour of each Sitobion clone is the same under each of light intensities on all host plants.

The colour of Sitobion avenae clones was influenced by light intensities. The initial colour of Sitobion clones when collected was changed under the rearing conditions and all become light -pale green. Under light intensity of $200 \mu \mathrm{E}$, we observed in the first ten days different colour varied within time from red - to brown in all clones except clones 7 and 8 which become dark green, then after ten days all clones kept their final colour. In case of aphid under $15 \mu \mathrm{E}$ light intensity all clones still green in colour. The aphids reared under $15 \mu \mathrm{E}$ become coloured except clone 7 and 8 (become dark green) when they were transferred to $200 \mu \mathrm{E}$ within ten days and the aphids reared under $200 \mu \mathrm{E}$ become light to pale green when transferred to $15 \mu \mathrm{E}$ within ten days.

The aphid which transferred to darkness either from $15 \mu \mathrm{E}$ or from $200 \mu \mathrm{E}$ become light to pale green in colour within ten days; but after two weeks in darkness the plants become yellow and collapsed and the mortality of aphids was very high and the colour of aphid was pale green to yellow (the intensity of the colour was very low comparing to those aphid in normal situation). The process of changing the colour from green to coloured or from coloured to green took place within ten days. There were differences within clones, some clones coloured before the other such clone 9 which start to be coloured after three days under $200 \mu \mathrm{E}$. The colour of clones which respond to high light intensities graduated under high light intensities between green- red -pink- brown (the aphid cloud has different colour) then after 10 days the coloured clones become brown (light to dark).

We noticed when the host plants is small (in first two weeks) aphid become coloured (the green colour disappeared from aphid) then after when the leaf become larger and cover 
the top of cylinder we find within every cylinder different colour; aphid which not directly expose to light become green or has mixture of colour and aphid which expose to light still coloured. We noticed that the intensity of green colour of aphid under low light intensity was less than it under high light intensities.

\section{4-3-2Colour morphs of clone 9}

All adults laid new nymphs in the first day they were green in colour after birth. The adults under light $(200 \mu \mathrm{E})$ start to be coloured after two days but not exactly coloured they have green and other colours on the body, but their offspring start to get coloured in 24 hours after birth. After 5 days ,the aphids which still in high light condition under $200 \mu \mathrm{E}$ become coloured (pink to deep brown) and after they become adults their offsprings were coloured after birth even the progenies inside them were coloured. But those aphids which were covered (in dark condition) become after 3-5 days green in colour, and when they become adults their offsprings were green even their progenies inside them were green.

We noticed that aphids supposed directly to light on upper leave surfaces become coloured before those fed on lower surface of leaves

\section{4-3-3Colour change of clone 6}

The colours of nymphs were changed from green to red and final colour was (dark brown to pink), this process took place over four days and the nymphs become in stage four. The adults (aptera or alate) and their offsprings were brown in colour. The seedlings become totally yellow in three weeks but they still soft and the tips of leaves were brown, under the conditions we got the second generation of initial nymphs, whereas the same culture include aphids and their granddaughters. In general the colour of aphid and their offsprings in this transparent system was very dark and more intensive than colour of aphid in normal culture. Thus, this experiment proved that more expose to light results in more intensive colour and the colour change of aphid in the transparent system took place shortly comparing to it in the normal rearing culture where it took place after five to six days.

\subsection{Effect of light intensities on clonal Performance of Sitobion avenae clones}

The clonal performance of Sitobion avenae is influenced by clones $\left(F_{9,120}=58.443, P<\right.$ $0.001)$ and light intensities $\left(F_{1,120}=115.839, P<0.001\right)$ and interaction of both $\left(F_{9,120}=\right.$ 37.570, $P<0.001)$.

\section{4-3-4-1Population size of aphid}

Size of clonal population differing significantly under different light intensities (Fig.1A);only clone 9 was not significantly affected by intensities. Clones 1,2,3,,7,8,9 and 10 have large 
population size under high light intensities, vice versa clones 4,5 and 6 which have the larger population size under low light intensities. There is significantly difference between the $S$.avenae clones; clone 9 has the best performance under low light intensity while clone 8 has the best performance under high light intensity.

\section{4-3-4-2Fresh weight}

Fresh weight also was differing significantly under different light intensities (Fig.1B); only clone 9 was not significantly affected by light intensities. Increasing or decreasing of fresh weight each of tested clones was high positively correlated with population size of each tested clones $\left(P<0.001 ; R^{2}=0.920\right)$.

\section{4-3-4-3Alate production}

Alate production was differing significantly under different light intensities (Fig.1C). The alate production of all clones has increased under low light intensity only the increase of alate productions of clones 4 and 9 were not significant. Differences between clones were not significant under both light intensities; only clone 9 differs significantly from all clones and produce less alate than the other clones under low light intensity and clone 4 differ significantly from other clones and produce more alate under high light intensity.

\section{4-3-5Performance of different colour morphs of Sitobion avenae}

There were no differences in clonal performance between green and coloured morphs, whereas clones 7and 8 are green in colour but their performances under both light intensities were not distinct from the other clones which have coloured morphs (see Fig.1 $A, B$ and $C)$.

\section{4-3-6Carotenoides of Sitobion avenae clones}

The resolution of band was better on Silica gel plates rather than Aluminum plates. We found differences in $\mathrm{Rf}$ values and number of bands appeared on TLC plates, varied in regards to the solvent and plates type. On silica plates the bands were better separated by using Diethyl ether in hexane (5\% v/v) (Table 2). By using the solvent Diethyl ether in petroleum ether $(5 \% \mathrm{v} / \mathrm{v})$, we found the pigments of green morphs consist of 1 yellow bands and the pigments of coloured morph consist of 5 bands. But using the solvent Diethyl ether in hexane $(5 \% \mathrm{v} / \mathrm{v})$ showed that the pigments of green morphs consist of four yellow band and the pigments of brown colour morphs consist of seven different bands. In case of aphids obtained from $15 \mu \mathrm{E}$ of all clones, we obtain on TLC plates one yellow band by using Diethyl ether in petroleum ether ( $5 \% \mathrm{v} / \mathrm{v})$ and two yellow bands upon using Diethyl ether in hexane $(5 \% \mathrm{v} / \mathrm{v})$. 
In this study additionally, we analyzed the carotenoides of the clones which were dark brown in colour under $200 \mu \mathrm{E}$ then were transferred to $15 \mu \mathrm{E}$ when most of the aphid become light brown to red in colour after 5 days. The analyses showed disappearing of the carotenoide lycopen according to results obtained according to Jenkins et al. (1999).

\section{4-4Discussion}

\section{4-4-1Impact of light intensity on colour formation S. avenae clones}

Our results showed that Sitobion avenae clones separated into two groups, green morphs and coloured morphs. The green morphs differ genetically from coloured morphs.

Also our results showed that, the green colour morphs have the green colour under all light intensities but the coloured morphs can be varied from green -red - brown in regards to light intensities. In high light intensities $(200 \mu \mathrm{E})$ the coloured morphs become brown and under low light intensities $(15 \mu \mathrm{E})$ become green. When the aphid exposed more to the light they become coloured in short time and their colour become more intensive. Our results explain the abundance of green colour morphs in springs, and red-brown morphs in summer and autumn; the light intensities in natural conditions is higher than the laboratory, thus the coloured morphs which determined genetically appear as brown in summer. In winter the light intensity is very low thus collecting aphid of all colour morphs we be green either the parthenogenetic or genoparae females. In early year after winter and in the beginning of spring the aphid of early generations are green and more abundant then after by increasing the light intensities the genetically coloured aphid become red brown. In autumn the light intensities decrease but it still enough to change the colour of aphid. The differences in light intensities between seasons let the aphid present different colour and even different colour intensities. In our experiment we observed the colour of aphid which exposed to more light we found their colour intensities is more than those exposed to less light, even the aphid which had green colour under low light intensities(light to pale green) their colour is less intensive than those reared under high light intensities (dark green). The position of aphid on host plants effect their colour; the aphid which are exposed to less light need more time to become coloured and their colour intensity differ from those aphid which are exposed to more light thus the colour intensity of aphid on upper surface of leaves or on the panicles is more intensive than those fed on lower leaves. Our explanation is not conflicted with pervious observations which stated that, the green morphs occurred all times but the coloured morphs occurred in twice by 
heading of cereals in summer and in autumn when sexual reproduction begins (Phillips, 1916). We found that one clone can present two colour morphs and contain different carotenoides, the carotenoides synthesis took place in aphid by supposing that process are regulated by light, thus the photoperiods can affect the colour formation (long photoperiods may regulate the reaction and let aphid produce the red - brown colour in same times the short photoperiods so far darkness will let aphid produce only green colour) this explanation can be supported by our experiments when aphid translated to darkness. Markkula and Rautapää (1967) achieved the same results; they produced green colour morphs from brown morphs under photoperiods of half Hours, thus they have not excluded the effects of host plants which suffer in these extremely conditions. The previous studies (Markkula and Pullianien,1965 ; described the impact of temperature, photoperiods and light intensities on colour formation of Sitobion clones that studies were not convenience or sustainable, also they did not determined the colour morphs of Sitobion avenae and did not specified the role of each factor which effect the colour formation of Sitobion clones but any way that studies had somehow over light on the effect of light on Sitobion avenae clones. The effect of light described by Markkula was not obtained by repeating the same procedure (Ankersmit, 1986) and the effect of photoperiods on Sitobion were not obtained by Jenkins (1991). We proved by observation the colour of Sitobion clones on many host plants that host plants did not affect the colour of Sitobion clones, even when clone 6 reared for one week on yellow wheat leaves its colour was dark brown; the same results obtained experiments on artificial diets which were free from carotenoides (Jenkins, 1991). Analysing the carotenoides of Sitobion colour morphs is not conflicted with previous studies (Jenkins et al., 1999), but we got the same results only after analysing the aphids which were dark green and dark brown which obtained only from high light intensity $(200 \mu \mathrm{E})$. Our results proved that light intensities change the carotenoides of Sitobion clones; changing the colour of Sitobion clones from brown to green results in absence of coloured carotenoides in green morph even of the same clones.

Many organisms synthesize carotenoides and the carotenoides synthesis regulated by light and gene regulating this process can be expressed in E .coli (Huasmann and sandman, 2000). It was supposed that carotenoides of Sitobion avenae synthesized by Buchnera aphidiocola (Moran et al., 1994; Douglas et al.,1998). . The role of endosymbionts still need to be explained because the results of Jenkins (1991) show that colour formation of Sitobion did not influenced by endosymbionts whereas both coloured and green clones did not change their colours by treatment with antibiotic; his suggestion 
that progenies get the colour in ovarioles before treatment with antibiotic; thus Sitobion coloured clones should be reared on artificial medium with antibiotic for many generation.

\section{4-4-2Impact of light intensity on clonal performance of $S$. avenae clones}

We found that the clonal performance of Sitobion avenae clones differ under different light intensities. Under high light intensity all clones produced more offsprings and have a higher fresh weight except three clones (4,5 and 6) were vice versa. From pervious study on these clones (Chapter 3), these clone have positive adaptation on wheat under $200 \mu \mathrm{E}$, they have very small population in their first generation on wheat comparing to the second and third generation respectively. And the have the same positive adaptation on wheat under $15 \mu \mathrm{E}$ but their population over three following generations is higher under $200 \mu \mathrm{E}$ as compared to their population under $15 \mu \mathrm{E}$ ( unpublished data). The aphid of clones 4 , 5and 6 which used in this study were token from stock cultures reared under $15 \mu \mathrm{E}$, thus the differences between their population under different light intensity which was vice versa from all clones can be considered as artifact.

We found under low light intensities all Sitobion clones produce more alate Sitobion clones produced more alate under crowding or nutritional effect, and green morphs produce more alate than brown morphs (Ankersmit and Dijkman, 1983). Acyrthosiphon pisum produced more alate by crowding but the red morphs produced more alate than green morphs (Weisser and Braendle, 2001). Also ,aphid respond to photoperiods and produce alate morphs in short photoperiod (Dixon ,1998) In our experiments we had excluded the effect of crowding and nutritional effect described by Ankersmit and Dijkman (1983), thus we found under low light intensities Sitobion clones (all colour morphs) produce more alate, these results is further evidence that aphids respond not only to photoperiod but also to light intensity.

Our results showed that the colour of clone do effect its performance while the performance of brown clones are not better it of green clones, this results conflicting with results of Weber (1985) he found that brown clones had significantly increase than green clones on barley and oat. The colour of clone is not criteria for clonal performance for example clone 7and 8 are green morphs under all light intensities but their clonal performance is not differ from coloured clones like clone 1 . The differences in the performance between the colour morphs (green and brown) of the same clone is mainly because of impact of light intensities which influence the clonal performance and the colour of clone in the same time. 
To answer the question "How light intensity affect the clonal performance of Sitobion clones" we should test two effect, the first one is the direct effect of light intensity on physiological and chemical changes of the host plants and the second effect is the chemical changes in the host plants which caused by feeding of aphid.

Photosynthesis is light dependent thus, at low light intensities; this may become the limiting factor. The phloem sugar level varied between day and night by $10-20 \%$ to 2 fold and the sugar level in phloem varied with temperature, irradiance and other factors (Geiger and Servaites, 1994). From these two facts we can explain the high clonal performance under high light intensity.

It was observed proteinase inhibitors accumulation in barley leaves by aphid infestation, and this response depend on aphid species (Casaretto et al., 1998), the induction of proteinase inhibitors is known to be regulated by endogenous chemical factors including phytohormones such as abscisic acid and jasmonic acid which increased the induction of proteinase inhibitors in barley leaves when being applied as exogenous (Casaretto et al., 2004). Putative jasmonic acid and salicylic acid accumulate in plants Medicago truncatula by feeding of piercing-sucking herbivores "Tetranychus urticae" ( Leitner et al., 2005), also such effect can be expected in our experiments resulting variability in the clonal performance.

\section{4-4-3Selective advantages of colour in Sitobion avenae clones}

Colour polymorphisms of aphid have selective advantages, red colour morphs of Acyrthosiphon pisum produced more alate (Weisser and Braendle, 2001) and escape quickly from predators comparing to green morphs (Braendle and Weisser , 2001). The colour polymorphisms of Sitobion clones which results from the accumulation or presence of certain carotenoides my have a selective advantages for Sitobion avenae in resistant to parasitoides, Ankersmit (1981) found out that colour morphs of Sitobion avenae differ in their susceptibility to Aphidius rhopalosiphi ; where as the brown clones of S. avenae were more resistant to the parasitism and again Ankersmit (1986) had assured his results and found that resistance of brown clones related to increasing handling time of brown colour forms and increase the developing time and mortality of parasitoides in brown morphs even when the tow colour forms aphid related to same clone.

Finally, our study shed light on the impact of light intensity on both the colour formation and clonal perfroamnce of Sitobion avenae clones. Further studies still needed such as characterisation of Sitobion pigments in HPLC and rearing aposymbiont clone on artificial 
diets for at least 3 generation in order to determined the origin of pigments and its pathway synthesis. Investigate of putative phytohormens level changes by feeding of aphid under different light intensity still needed to explain the variation between Sitobion avenae clones which results from the interaction between them and wheat. 
Fig.1. Effect of light intensities on clonal performance of Sitobion avenae; offsprings production, fresh weight and alate production. Black bar under light intensity of $200 \mu \mathrm{E}$, white bar under $15 \mu \mathrm{E}$. large letter compare the black bars, small letter compare the white bars. NS, and ${ }^{* *}$ compare black bar with white bar for each clone: NS not significant, ** significant. $\mathrm{Y}$ bar: Mean with error bar, $\mathrm{X}$ : clones.

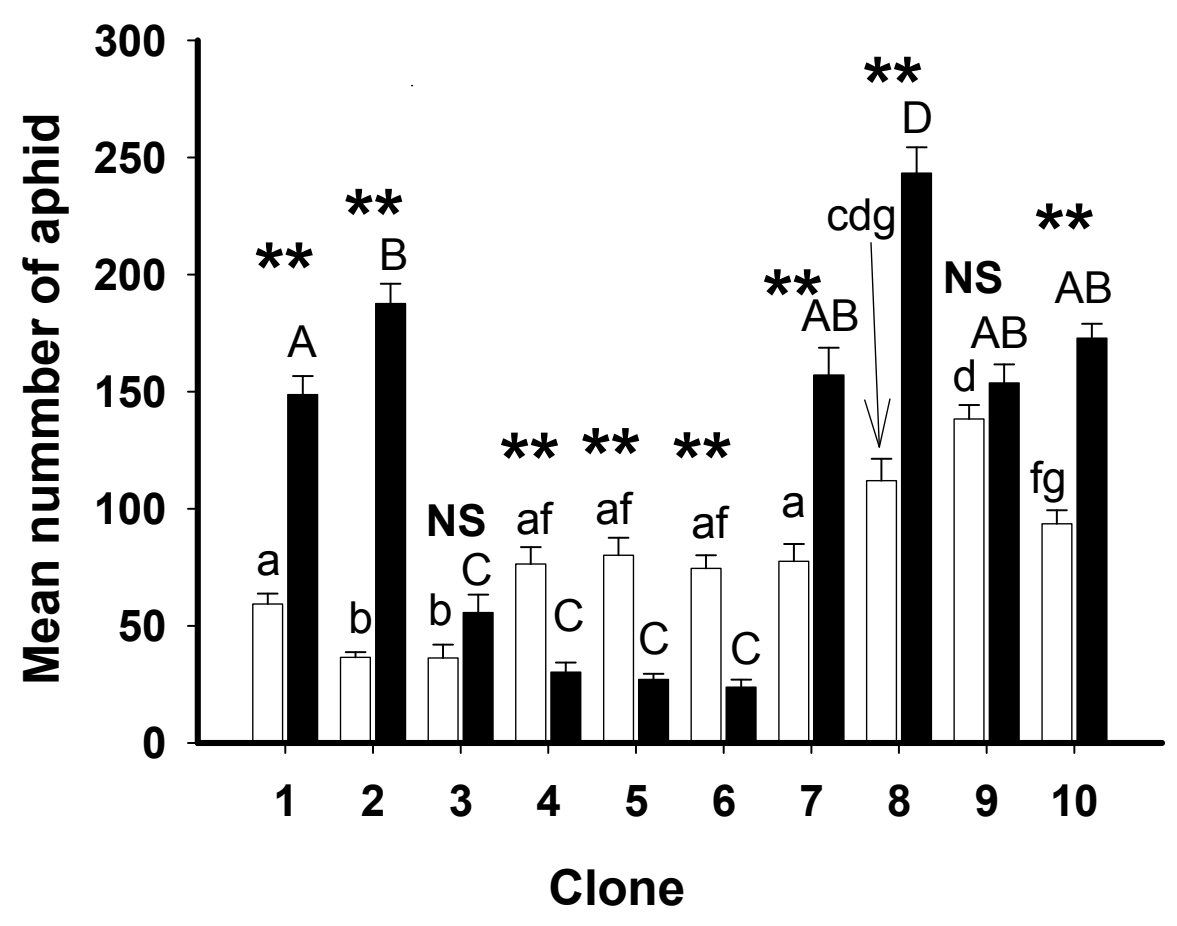



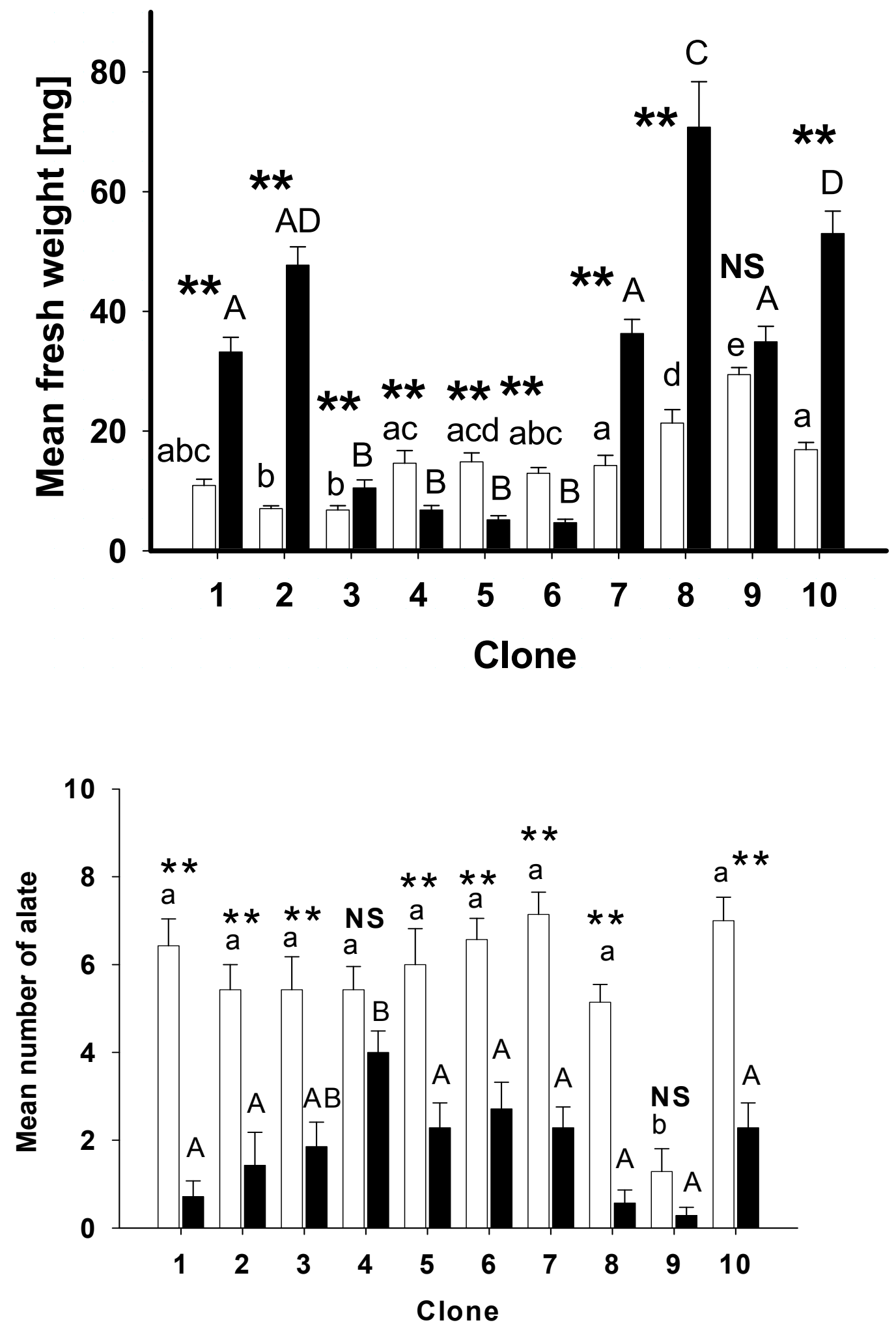
Table (1) the clones used in this study

\begin{tabular}{lllll}
\hline Clone ID & Place & Host plant & collecting stage & collecting colour \\
\hline 1 & Göttingen & Wheat & Virginoparae & Green \\
2 & Kassel & Cocksfoot & Virginoparae & Green -Brown \\
3 & Kassel & Bromus sp. & $2^{\text {nd }}$ nymph & Green -Brown \\
4 & Goettingen & Cocksfoot & Virginoparae & Green -Brown \\
5 & Giessen & Wheat & Virginoparae & Green -Brown \\
6 & Kassel & Cocksfoot & Virginoparae & Green -Brown \\
7 & Giessen & Wheat & Virginoparae & Light green \\
8 & Giessen & Wheat & Virginoparae & Light green \\
9 & Kassel & Cocksfoot & 4 th, wing & Brown \\
10 & Kassel & Cocksfoot & $4^{\text {th }}$ nymph & Brown \\
\hline
\end{tabular}


Table (2) thin layer chromatography of the carotenoides of different morph of Sitobion avenae

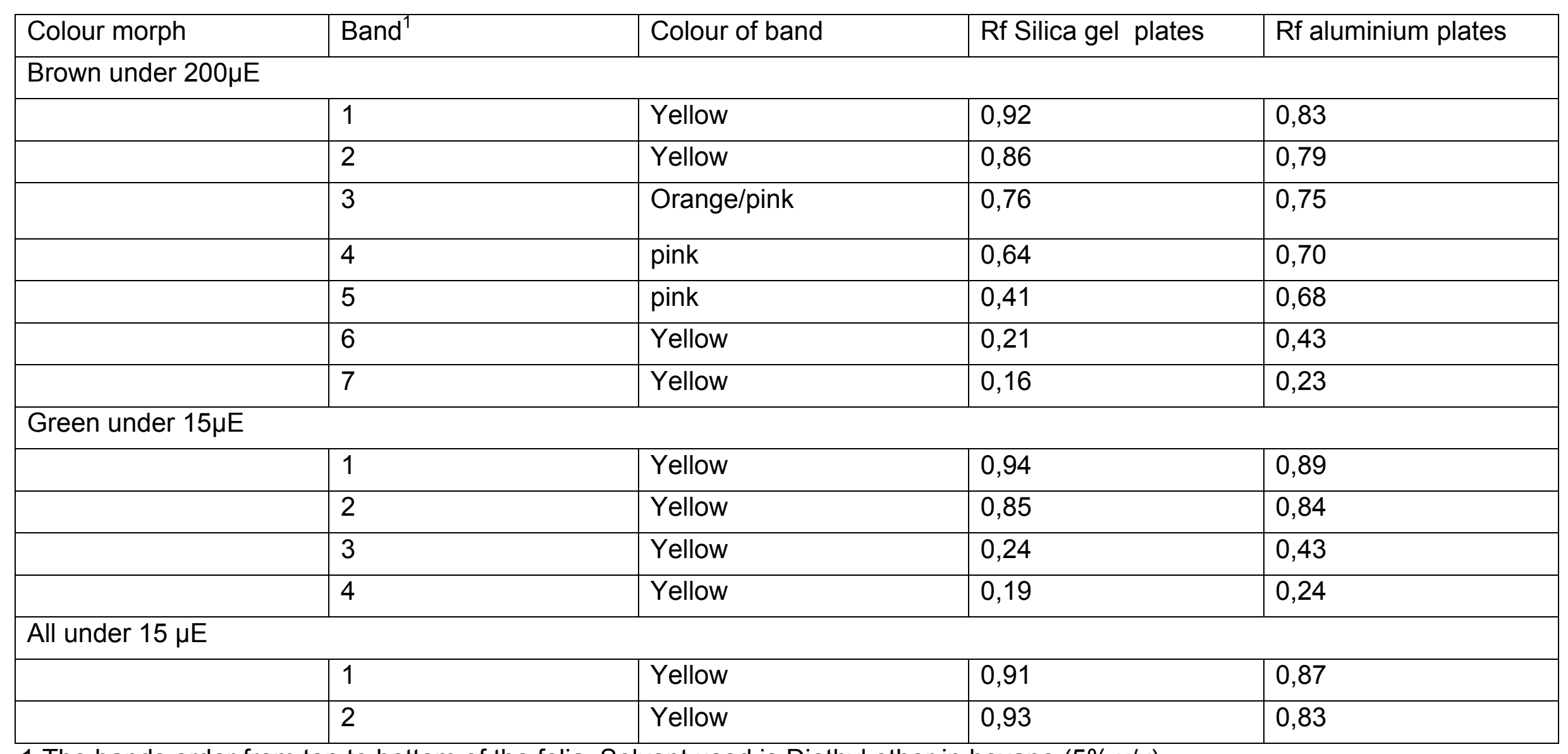

1 The bands order from top to bottom of the folia. Solvent used is Diethyl ether in hexane (5\% v/v) 


\section{Discussion}

The results of this study demonstrate that Sitobion avenae clones exhibit variation in the use of the host plants tested. Clones also differed in their fecundity and fitness in addition to alate production on these host plants during three successive generations, pointing to a temporal variation in these clones. Spatial and temporal variation in $S$. avenae was previously published using molecular techniques by Sunnucks et al. (1997), Simon et al., (1999), Haack et al. (2000), Papura et al. (2003), and Reimer (2005).

We found that variation in life history traits of $S$. avenae clones contributes to their adaptability and colonization of host plants, while the host adapted clones did not show variation in life history traits on their host plants; some clones exhibited variation to obtain their optimum fecundity on the new host plants. These results are in accordance with data published by De Barro et al. (1995b).

Clones of $S$. avenae adapted or not adapted to their host plants were also determined by molecular markers or host- clone collecting sites on maize, wheat, barely, cocksfoot and other graminoid grasses (Weber , 1985; De Barro et al., 1995 a \& b; Sunnucks et al., 1997; Haack et al., 2000, Figueroa et al., 2005; Vialatte et al., 2005). However, neither the molecular markers nor host-clone collecting sites alone are sufficient to characterize common or host plant adapted clones, especially if the interaction between the clones (biotype) and their host plant is determined by genes responsible for host plant resistance, as it has been shown in Schizaphis graminum (Ono et al., 1999). In these cases, in addition to molecular markers, the clonal performance on different host plants need to be studied.

We found that the WSC content of Dactylis glomerata cultivar triggers the resistance to S. avenae; a proportion of WSC above $1.7 \%$ in cocksfoot cultivars will result in no survival of the aphids. However, S. avenae clones are specialized on the cultivar Prairial, containing 1.7\% WSC. This has also been published by De Barro et al. (1995b) reporting specialized clones of $S$. avenae on Prairial.

We characterized for the first time the secondary bacterial endosymbionts (PAUS and $\mathrm{PABS}$ ) in common clones of $S$. avenae. Within eight common clones seven of them harbour secondary bacterial endosymbionts, three of them harbour PAUS, two PABS and two rare clones have also PABS.

We found that clones tolerant to WSC and having a high clonal performance on cocksfoot, especially on the cultivar Prairial, hosted the secondary bacterial endosymbionts PAUS. 
We found an effect of secondary bacterial endosymbionts on clonal performance of $S$. avenae on bluegrass, whereas PAUS positively influenced the fecundity and fitness of clones as compared to PABS or Buchnera. In addition PAUS and PABS significantly increased the survival of Sitobion clones on wheat and PAUS increased the survival on bluegrass as compared to PABS and Buchnera, respectively. On the remaining graminoid grasses tested we found secondary bacterial endosymbionts affecting the clonal performance and adaptability of the aphid.

From other aphid species, such as Acyrthosiphon pisum, it is known that the secondary endosymbionts affect the clonal performance and fitness of the aphids; genotypes of $A$. pisum which harbour PAUS have a twice as good performance on clover than those which have PABS, however these clones cannot survive on alfalfa. On the opposite the genotypes which harbour PABS do 50 \% better on alfalfa (Leonardo et al., 2003). In Japan, pea aphid hosting PAUS have a better performance on clover than on vetch (Tsuchida et al., 2004). Moreover, A. pisum exhibits a characteristic geographical distribution of PAUS in Japan (Tsuchida et al., 2002).

We demonstrate that the colour of $S$. avenae clones is genetically determined, thus S. avenae clones separate into two groups, the green and the coloured morphs.

The green morphs do not change their colour under the different light regimes tested while the coloured morphs are able to change their colour from green -red - brown with regards to the light intensities.

The results of the carotenoide analyses of Sitobion colour morphs found contrasting results to those published previously (Jenkins et al., 1999). We proved that light intensities change the carotenoide composition of Sitobion clones; a change of the colour of Sitobion clones from brown to green results in the absence of coloured carotenoides in the green morph (Andrews et al., 1971; Jenkins et al., 1999) even within the same clones.

We found that all colour morphs of Sitobion avenae clones respond to light intensities, the intensive light regimes enhance the fecundity and fitness of most $S$. avenae clones as compared to low light intensity regimes which resulted in a higher production of alate in all clones. We also found that the colour of the clones did influence its performance. The performance of brown clones was not enhanced as compared to green clones, a result opposite to the findings of Weber (1985). 
Colour polymorphisms of aphid may have selective advantages. For example, red colour morphs of Acyrthosiphon pisum produce more alate (Weisser and Braendle, 2001) and are able to escape predators more rapidly as compared to green morphs (Braendle and Weisser, 2001). The colour polymorphisms of Sitobion clones, resulting from the accumulation or presence of certain carotenoides my have a selective advantages for $S$. avenae with regard to parasitoids. Ankersmit (1981) reported that colour morphs of $S$. avenae differed in their susceptibility to Aphidius rhopalosiphi. Brown clones of $S$. avenae were more resistant to parasitism. Resistance of brown clones to parasitoids was related to an increase in handling time of brown colour forms and an increase in the developing time and mortality of parasitoids, even when both colour forms were belonging to the same clone (Ankersmit, 1986).

Further studies should aim at evaluating the interactions between Sitobion avenae host plants genotypes by studying the impact of secondary bacterial endosymbionts on Sitobion avenae traits. 


\section{References}

Abbot, P., Moran, N.A., 2002. Extremely low levels of genetic polymorphism in endosymbionts (Buchnera) of aphids (Pemphigus). Molecular Ecology 11, 2649-2660.

Agnelli, A., Ascher, J., Corti, G., Ceccherini, M.T., Nannipieri, P., Pietramellara, G., 2004. Distribution of microbial communities in a forest soil profile investigated by microbial biomass, soil respiration and DGGE of total and extracellular DNA. Soil Biology \& Biochemistry 36 859-868.

Andrewes, A.G., Kjosen, H., S., L.-J., Weisgraber, K.H., Lousberg, R.J., Weiss, U., 1971. Animal carotenoids. 7. Carotenes of two colour variants of the aphid Macrosiphum liriodendri-identification of natural gamma, gamma-carotene. Acta chemica Scandinavica $25,3878-3880$.

Ankersmit, G.W., Acreman, T.M., Dijkman, H., 1981. Parasitism of colour forms in Sitobion avenae. Entomologia Experimentalis et Applicata 29, 362-363.

Ankersmit, G.W., Bell, C., Dijkman, H., Mace, N., Rietstra, S., Schro?Der, J., De Visser, C., 1986. Incidence of parasitism by Aphidius rhopalosiphi in colour forms of the aphid Sitobion avenae. Entomologia Experimentalis et Applicata 40, 223-229.

Ankersmit, G.W., Dijkman, H., 1983. Alatae production in the cereal aphid Sitobion avenae. Netherlands Journal of Plant Pathology 89, 105-112.

Apablaza, J., 1974. Presencia de Macrosiphum(Sitobion ) avenae (F.)(Homoptera, Aphididae) en sementeras de trigo en Chile. Ciencia e Investigacion Agraria 1, 69-70.

Ashford, D.A., Smith, W.A., Douglas, A.E., 2000. Living on a high sugar diet: the fate of sucrose ingested by a phloem-feeding insect, the pea aphid Acyrthosiphon pisum. Journal of Insect Physiology 46, 335-341.

Baumann, P., Baumann, L., Clark, M.A., 1996. Levels of Buchnera aphidicola chaperonin GroEL during growth of the aphid Schizaphis graminum. Current Microbiology 32, 279-285.

Baumann, P., Baumann, L., Lai, C.Y., Rouhbakhsh, D., Moran, N.A., Clark, M.A., 1995. Genetics, physiology and evolutionary relationships of the genus Buchnera: Intracellular symbionts of aphids. Annual Review of Microbiology 49, 55-94.

Baumann, P., Moran, N.A., Baumann, L., 1997. The evolution and genetics of aphid endosymbionts. BioScience 47, 12-20. 
Blackman, R.T., Eastop, V.F., 1984. Aphids on the World's Crops: an Identification Guide. Wiley, New York.

Bowie, J.H., Cameron, D.W., Findlay, J.A., Quartey, J.A.K., 1966. Haemolymph pigments of aphids. Nature 210, 395-397.

Braendle, C., Weisser, W.W., 2001. Variation in escape behavior of red and green clones of the pea aphid. Journal of Insect Behavior 14, 497-509.

Buchner, P., 1965. Endosymbiosis of Animals with Plant Microorganisms. Interscience, New York.

Caillaud, C.M., Rahbe, Y., 1999. Aposymbiosis in a cereal aphid: Reproductive failure and influence on plant utilization. Ecological Entomology 24, 111-114.

Casaretto, J.A., Corcuera, L.J., 1998. Proteinase inhibitor accumulation in aphidinfested barley leaves. Phytochemistry 49, 2279-2286.

Casaretto, J.A., Zuniga, G.E., Corcuera, L.J., 2004. Abscisic acid and jasmonic acid affect proteinase inhibitor activities in barley leaves. Journal of Plant Physiology 161, 389396.

Chatterton, N.J., P. A. Harrison, Thornley, W.R., Draper, E.A., 1990. Oligosaccharides in foliage of Agropyron, Bromus, Dactylis, Festuca, Lolium and Phleum. New Phytologist 114, 167-171.

Chen, D.Q., Campbell, B.C., Purcell, A.H., 1996. A new Rickettsia from a herbivorous insect, the pea aphid Acyrthosiphon pisum (Harris). Current Microbiology 33, 123-128.

Chen, D.Q., Montllor, C.B., Purcell, A.H., 2000. Fitness effects of two facultative endosymbiotic bacteria on the pea aphid, Acyrthosiphon pisum, and the blue alfalfa aphid, A. kondoi. Entomologia Experimentalis et Applicata 95, 315-323.

Chen, D.Q., Montllor, C.B., Purcell, A.H., 2000. Fitness effects of two facultative endosymbiotic bacteria on the pea aphid, Acyrthosiphon pisum, and the blue alfalfa aphid, A. kondoi. Entomologia Experimentalis et Applicata 95, 315-323.

Ciepiela, A.P., Sempruch, C., Chrzanowski, G., 1999. Evaluation natural resistance of winter triticale cultivars to grain aphid using food coefficients. Journal of applied entomology 123, 491-494. 
Clark, M.A., Moran, N.A., Baumann, P., Wernegreen, J.J., 2000. Cospeciation between bacterial endosymbionts (Buchnera) and a recent radiation of aphids (Uroleucon) and pitfalls of testing for phylogenetic congruence. Evolution 54, 517-525.

De Barro, P.J., Sherratt, T.N., Carvalho, G.R., Nicol, D., lyengar, A., MacLean, N., 1995. Geographic and microgeographic genetic differentiation in two aphid species over southern England using the multilocus (GATA)4 probe. Molecular Ecology 4, 375-382.

De Barro, P.J., Sherratt, T.N., David, O., Maclean, N., 1995. An investigation of the differential performance of clones of the aphid Sitobion avenae on two host species. Oecologia 104, 379-385.

Dietrich, D., Hinke, S., Baumann, W., Fehlhaber, R., Bäucker, E., Rühle, G., Wienhaus, O., Marx, G., 2003. Silica accumulation in Triticum aestivum L. and Dactylis glomerata L. Analytical and Bioanalytical Chemistry 376, 399-404.

Dixon, A.F.G., 1973. Metabolic acclimatization to seasonal changes in temperature in the sycamore aphid, Drepanosiphum platanoides (Schr.), and lime aphid, Eucallipterus tiliae L. Oecologia 13, 205-210.

Dixon, A.F.G., 1985. Structure of aphid populations. Annual review of entomology. Vol. 30, 155-174.

Dixon, A.F.G., 1998. Aphid ecology. Chapman \& Hall, London,United Kingdom.

Dixon, A.F.G., 1998. Aphid ecology. Chapman and Hall, London,United Kingdom.

Douglas, A.E., 1998. Nutritional interactions in insect-microbial symbioses: Aphids and their symbiotic bacteria Buchnera. Annual Review of Entomology, 17-37.

Douglas, A.E., 1998. Nutritional interactions in insect-microbial symbioses: Aphids and their symbiotic bacteria Buchnera. Annual Review of Entomology 43, 17-37.

Douglas, A.E., Francois, C., Minto, L.B., 2006. Facultative 'secondary' bacterial symbionts and the nutrition of the pea aphid, Acyrthosiphon pisum. Physiological Entomology 31, 262-269.

Douglas, A.E., Francois, C.L.M.J., Minto, L.B., 2006. Facultative 'secondary' bacterial symbionts and the nutrition of the pea aphid, Acyrthosiphon pisum. Physiological Entomology 31, 262-269.

Douglas, A.E., Price, D.R.G., Minto, L.B., Jones, E., Pescod, K.V., Francois, C., Pritchard, J., Boonham, N., 2006. Sweet problems: insect traits defining the limits to 
dietary sugar utilisation by the pea aphid, Acyrthosiphon pisum. Journal of Experimental Biology 209, 1395-1403.

Downing, N., 1978. Short Communications: Measurements of the Osmotic Concentrations of Stylet Sap, Haemolymph and Honeydew from an Aphid Under Osmotic Stress. Journal of Experimental Biology 77, 247-250.

Eastop, V.F., Balckmann, R.L., 2007. Taxonomic issues. Aphids as crop pests (ed. by H.F. Van Emden \& R. Harrington) CABI publishing, UK.

Eleftherianos, I., Vamvatsikos, P., Ward, D., Gravanis, F., 2006. Changes in the levels of plant total phenols and free amino acids induced by two cereal aphids and effects on aphid fecundity. Journal of Applied Entomology 130, 15-19.

Fares, M.A., Barrio, E., Sabater-Mun?oz, B., Moya, A., 2002. The evolution of the heat-shock protein GroEL from Buchnera, the primary endosymbiont of aphids, is governed by positive selection. Molecular Biology and Evolution 19, 1162-1170.

Fares, M.A., Moya, A., Barrio, E., 2004. GroEL and the maintenance of bacterial endosymbiosis. Trends in Genetics 20, 413-416.

Felsenstein, J., 1985. Confidence limits on phylogenies: An approach using the bootstrap. Evolution 39, 783-791.

Ferrari, J., Darby, A.C., Daniell, T.J., Godfray, H.C.J., Douglas, A.E., 2004. Linking the bacterial community in pea aphids with host-plant use and natural enemy resistance. Ecological Entomology 29, 60-65.

Figueroa, C.C., Simon, J.C., Le Gallic, J.F., Prunier-Leterme, N., Briones, L.M., Dedryver, C.A., Niemeyer, H.M., 2005. Genetic structure and clonal diversity of an introduced pest in Chile, the cereal aphid Sitobion avenae. Heredity 95, 24-33.

Filichkin, S.A., Brumfield, S., Filichkin, T.P., Young, M.J., 1997. In vitro interactions of the aphid endosymbiotic SymL chaperonin with barley yellow dwarf virus. Journal of Virology 71, 569-577.

Fisher, D.B.F. (Ed.), 2000. Long distance transport. American Society of Plant Physiologists, Rockville, MD.

Fukatsu, T., Ishikawa, H., 1993. Occurrence of chaperonin 60 and chaperonin 10 in primary and secondary bacterial symbionts of aphids: Implications for the evolution of an endosymbiotic system in aphids. Journal of Molecular Evolution 36, 568-577. 
Fukatsu, T., Ishikawa, H., 1998. Differential immunohistochemical visualization of the primary and secondary intracellular symbiotic bacteria of aphids. Applied Entomology and Zoology 33, 321-326.

Fukatsu, T., Nikoh, N., Kawai, R., Koga, R., 2000. The secondary endosymbiotic bacterium of the pea aphid Acyrthosiphon pisum (Insecta: Homoptera). Applied and Environmental Microbiology 66, 2748-2758.

Fukatsu, T., Tsuchida, T., Nikoh, N., Koga, R., 2001. Spiroplasma Symbiont of the Pea Aphid, Acyrthosiphon pisum (Insecta: Homoptera). Applied and Environmental Microbiology 67, 1284-1291.

Fukatsu, T., Watanabe, K., Sekiguchi, Y., 1998. Specific detection of intracellular symbiotic bacteria of aphids by oligonucleotide-probed in situ hybridization. Applied Entomology and Zoology 33, 461-472.

Funk, D.J., Wernegreen, J.J., Moran, N.A., 2001. Intraspecific variation in symbiont genomes: Bottlenecks and the aphid-Buchnera association. Genetics 157, 477-489.

Geiger, D.R., Servaites, J.C., 1994. Diurnal Regulation of Photosynthetic Carbon Metabolism in C3 Plants. Annual Review of Plant Physiology and Plant Molecular Biology 45, 235-256.

Goldstein, J., Pollitt, N.S., Inouye, M., 1990. Major cold shock protein of Escherichia coli. Proceedings of the National Academy of Sciences of the United States of America 87, 283-287.

Goodwin, T.W., 1986. Metabolism, Nutrition, and Function of Carotenoids. Annual Review of Nutrition 6, 273-297.

Grenier, A.M., Nardon, C., Rahbe, Y., 1994. Observations on the micro-organisms occurring in the gut of the pea aphid Acyrthosiphon pisum. Entomologia Experimentalis et Applicata 70, 91-96.

Haack, L., Simon, J.C., Gauthier, J.P., Plantegenest, M., Dedryver, C.A., 2000. Evidence for predominant clones in a cyclically parthenogenetic organism provided by combined demographic and genetic analyses. Molecular Ecology 9, 2055-2066.

Haack, L., Simon, J.C., Gauthier, J.P., Plantegenest, M., Dedryver, C.A., 2000. Evidence for predominant clones in a cyclically parthenogenetic organism provided by combined demographic and genetic analyses. Molecular Ecology 9, 2055-2066. 
HALL, T.A., 1999. BIOEDIT : A USER- FRIENDLY BIOLOGICAL SEQUENCE ALIGNMENT EDITOR AND ANALYSIS PROGRAM FOR WINDOWS 95/98/NT. NUCLEIC ACIDS SYMPOSIUM SERIES 41, 95-98.

Harmon, J.P., Losey, J.E., Ives, A.R., 1998. The role of vision and color in the close proximity foraging behavior of four coccinellid species. Oecologia 115, 287-292.

Hassan, A.K.M., Moriya, S., Baumann, P., Yoshikawa, H., Ogasawara, N., 1996. Structure of the dnaA region of the endosymbiont, Buchnera aphidicola, of aphid Schizaphis graminum. DNA Research 3, 415-419.

Hausmann, A., Sandmann, G., 2000. A Single Five-Step Desaturase Is Involved in the Carotenoid Biosynthesis Pathway to [beta]-Carotene and Torulene in Neurospora crassa. Fungal Genetics and Biology 30, 147-153.

Helden, A.J., Dixon, A.F.G., 2002. Life-cycle variation in the aphid Sitobion avenae: Costs and benefits of male production. Ecological Entomology 27, 692-701.

Houk, E.J., Griffiths, G.W., 1980. Intracellular symbiotes of the Homoptera. Annual Review of Entomology 25, 161-187.

Huang, C.-Y., Lee, C.-Y., Wu, H.-C., Kuo, M.-H., Lai, C.-Y., 2008. Interactions of Chaperonin with a Weakly Active Anthranilate Synthase from the Aphid Endosymbiont Buchnera aphidicola. Microbial Ecology 56, 696-703.

Jarosik, V., Honek, A., Tichopad, A., 2003. Comparison of field population growths of three cereal aphid species on winter wheat. Plant-Protection-Science 39, 61-64.

Jenkins, R.L., 1991. Colour and Symbionts of Aphids. PhD Thesis, University of East Anglia, U.K.

Jenkins, R.L., Loxdale, H.D., Brookes, C.P., Dixon, A.F.G., 1999. The major carotenoid pigments of the grain aphid, Sitobion avenae (F.) (Hemiptera: Aphididae). Physiological Entomology 24, 171-178.

Kehr, J., Hustiak, F., Walz, C., Willmitzer, L., Fisahn, J., 1998. Transgenic plants changed in carbon allocation pattern display a shift in diurnal growth pattern. The Plant Journal 16, 497-503.

Kerepesi, I., Galiba, G., 2000. Osmotic and Salt Stress induced alteration in carbohydrate content in wheat seedlings. Crop Science 40, 482-487. 
Kimura, M., 1980. A simple method for estimating evolutionary rate of base substitutions through comparative studies of nucleotide sequences. Journal of Molecular Evolution 16, 111-120.

Knight, J.D., Bale, J.S., Franks, F., Mathias, S.F., Baust, J.G., 1986. Insect cold hardiness: supercooling points and pre-freeze mortality. Cryoletters 7, 194-203.

Leitner, M., Boland, W., Mith, fer, A., 2005. Direct and indirect defences induced by piercing-sucking and chewing herbivores in Medicago truncatula. New Phytologist 167, 597-606.

Leonardo, T.E., 2004. Removal of a specialization-associated symbiont does not affect aphid fitness. Ecol. Lett. 7, 461-468.

Leonardo, T.E., Muiru, G.T., 2003. Facultative symbionts are associated with host plant specialization in pea aphid populations. Proceedings of the Royal Society B: Biological Sciences 270.

Leonardo, T.E., Muiru, G.T., 2003. Facultative symbionts are associated with host plant specialization in pea aphid populations. Proc. R. Soc. Lond. Ser. B-Biol. Sci. 270, S209-S212.

Llewellyn, K.S., Loxdale, H.D., Harrington, R., Brookes, C.P., Clark, S.J., Sunnucks, P., 2003. Migration and genetic structure of the grain aphid (Sitobion avenae) in Britain relates to climate and clonal fluctuation as revealed using microsatellites. Molecular Ecology 12, 21-34.

Loxdale, H.D., 2008. The nature and reality of the aphid clone: Genetic variation, adaptation and evolution. Agricultural and Forest Entomology 10, 81-90.

Loxdale, H.D., Lushai, G., 2007. Population genetic issues : The unfoldingstory using molecular markers. Aphids as crop pests (ed. by H.F. Van Emden \& R. Harrington) CABI publishing, UK.

Lushai, G., Markovitch, O., Loxdale, H.D., 2002. Host-based genotype variation in insects revisited. Bulletin of Entomological Research 92, 159-164.

Markkula, M., Myllymäki, S., 1963. Biological studies on cereal aphids, Rhopolosiphum padi (L.), Macrosiphum avenae (F.) and Acyrthosiphum dirhodum (Wlk.) (Hom., Aphididae). Annales Agriculturae Fenniae 2, 33-43. 
Markkula, M., Pulliainen, E., 1965. The effect of temperature on the lengths of the life periods of the english grain aphid Macrosiphum avenae (F.) (Hom., Aphididae) and on the number and colour of its progeny. Annales Entomologia Fennica 31, 39-45.

Markkula, M., Rautapää, J., 1967. The effect of light and temperature on the colour of the english grain aphid Macrosiphum avenae (F.) (Hom., Aphididae). Annales Entomologia Fennica 33, 1-13.

Massey, F.P., Ennos, A.R., Hartley, S.E., 2006. Silica in grasses as a defence against insect herbivores: Contrasting effects on folivores and a phloem feeder. Journal of Animal Ecology 75, 595-603.

Mayland, H.F., Shewmaker, G.F., Harrison, P.A., Chatterton, N.J., 2001. Nonstructural carbohydrate in tall fescue cultivars; relationship to animal preference. Agronomy Journal 92, 1203-1206.

Míka, V., Kubáň, V., Klejdus, B., Odstrčilová, V., Nerušil, P., 2005. Phenolic compounds as chemical markers of low taxonomiclevels in the family Poaceae. Plant Soil and Environment 51, 506-512.

Miller, L.A., Moorby, J.M., Davis, D.R., Humphreys, M.O., Scollan, N.D., MacRae, J.C., Theodorou, M.K., 2001. Increased concentration of water - soluble carbohydrate in perennial ryegrass (Lolium perenne L.): milk production from late-lactation dairy cows. Grass and Forage Science 56, 383-394

Mira, A., Moran, N.A., 2002. Estimating population size and transmission bottlenecks in maternally transmitted endosymbiotic bacteria. Microbial Ecology 44, 137143.

Montllor, C.A., Maxmen, A., Purcell, A.H., 2002. Facultative bacterial endosymbionts benefit pea aphids Acyrthosiphon pisum under heat stress. Ecological Entomology 27, 189-195.

Moran, N.A., 1992. The evolution of aphid life cycles. Annual review of entomology. Vol. 37, 321-348.

Moran, N.A., 1996. Accelerated evolution and Muller's rachet in endosymbiotic bacteria. Proceedings of the National Academy of Sciences of the United States of America 93, 2873-2878.

Moran, N.A., Baumann, P., Van Dohlen, C., 1994. Use of DNA sequences to reconstruct the history of the association between members of the sternorrhyncha 
(Homoptera) and their bacterial endosymbionts. European Journal of Entomology 91, 7983.

Moran, N.A., McCutcheon, J.P., Nakabachi, A., 2008. Genomics and Evolution of Heritable Bacterial Symbionts. Annual Review of Genetics 42, 165-190.

Moran, N.A., Von Dohlen, C.D., Baumann, P., 1995. Faster evolutionary rates in endosymbiotic bacteria than in cospeciating insect hosts. Journal of Molecular Evolution 41, 727-731.

Müller, F.P., 1961. Stabilität und veränderlichkeit der färbung bei blattläusen. Archiv der Freunde der Naturgeschichte in Mecklenburg (Rostock) 7, 228-239.

Muyzer, G., 1999. DGGE/TGGE a method for identifying genes from natural ecosystems. Current Opinion in Microbiology 2, 317-322.

Muyzer, G., De Waal, E.C., Uitterlinden, A.G., 1993. Profiling of complex microbial populations by denaturing gradient gel electrophoresis analysis of polymerase chain reaction-amplified genes coding for 16S rRNA. Applied and Environmental Microbiology 59, 695-700.

Nakashima, K., Kanamaru, K., Mizuno, T., Horikoshi, K., 1996. A novel member of the cspA family of genes that is induced by cold shock in Escherichia coli. JOURNAL OF BACTERIOLOGY 178, 2994-2997.

Nei, M., Kumar, S., 2000. Molecular Evolution and Phylogenetics. Oxford University Press, New York.

Nübel, U., Engelen, B., Felske, A., Snaidr, J., Wieshuber, A., Amman, R.I., Ludwig, W., Backhaus, H., 1996. Sequence heterogeneities of genes encoding 16S rRNAs in Paenibacillus polymyxa detected by temperature gradient gel electrophoresis. Journal of Bacteriology 178, 5636-5643.

Ohtaka, C., Ishikawa, H., 1991. Effects of heat treatment on the symbiotic system of an aphid mycetocyte. Symbiosis 11, 19-30.

Ohtaka, C., Nakamura, H., Ishikawa, H., 1992. Structures of chaperonins from an intracellular symbiont and their functional expression in Escherichia coli groE mutants. Journal of Bacteriology 174, 869-1874.

Ohtaka, C., Nakamura, H., Ishikawa, H., 1992. Structures of chaperonins from an intracellular symbiont and their functional expression in Escherichia coli groE mutants. pp. 1869-1874. 
Oliver, K.M., Moran, N.A., Hunter, M.S., 2005. Variation in resistance to parasitism in aphids is due to symbionts not host genotype. Proceedings of the National Academy of Sciences of the United States of America 102, 12795-12800.

Oliver, K.M., Moran, N.A., Hunter, M.S., 2005. Variation in resistance to parasitism in aphids is due to symbionts not host genotype. Proceedings of the National Academy of Sciences of the United States of America 102, 12795-12800.

Oliver, K.M., Russell, J.A., Morant, N.A., Hunter, M.S., 2003. Facultative bacterial symbionts in aphids confer resistance to parasitic wasps. Proceedings of the National Academy of Sciences of the United States of America 100, 1803-1807.

Ono, M., Swanson, J.J., Field, L.M., Devonshire, A.L., Siegfried, B.D., 1999 Amplification and methylation of an esterase gene associated with insecticide-resistance in greenbugs, Schizaphis graminum (Rondani) (Homoptera: Aphididae). Insect biochemistry and molecular biology 29, 1065-1073.

Ortiz-Rivas, B., Moya, A., Martínez-Torres, D., 2004. Molecular systematics of aphids (Homoptera: Aphididae): New insights from the long-wavelength opsin gene. Molecular Phylogenetics and Evolution 30, 24-37.

Papura, D., Simon, J.C., Halkett, F., Delmotte, F., Le Gallic, J.F., Dedryver, C.A., 2003. Predominance of sexual reproduction in Romanian populations of the aphid Sitobion avenae inferred from phenotypic and genetic structure. Heredity 90, 397-404.

Pérez-Brocal, V., Gil, R., Ramos, S., Lamelas, A., Postigo, M., Michelena, J.M., Silva, F.J., Moya, A., Latorre, A., 2006 A small microbial genome: the end of a long symbiotic relationship? Science $314,312-313$.

Phillips, W.J., 1919. Macrosiphum granarium , the English grain aphid. Journal of agricultural research $7,463-480$.

Porter, D.R., Burd, J.D., Shufran, K.A., Webster, J.A., Teetes, G.L., 1997. Greenbug (Homoptera: Aphididae) biotypes: selected by resistant cultivars or preadapted opportunists?

Journal of economic entomology 90, $1055-1065$.

Powell, S.J., Bale, J.S., 2004. Cold shock injury and ecological costs of rapid cold hardening in the grain aphid Sitobion avenae (Hemiptera: Aphididae). Journal of insect physiology

$50,277-284$. 
Powell, S.J., Bale, J.S., 2005. Low temperature acclimated populations of the grain aphid Sitobion avenae retain ability to rapidly cold harden with enhanced fitness. Journal of Experimental Biology 208, 2615-2620.

Price, D.R.G., Karley, A.J., Ashford, D.A., Isaacs, H.V., Pownall, M.E., Wilkinson, H.S., Gatehouse, J.A., Douglas, A.E., 2007. Molecular characterisation of a candidate gut sucrase in the pea aphid, Acyrthosiphon pisum. Insect Biochemistry and Molecular Biology 37, 307-317.

Reimer, L., 2004. Clonal diversity and population genetic structure of the grain aphid Sitobion avenae (F.) in central Europe. PhD thesis, University of Goettingen.

Reimer, L., 2004. Clonal diversity and population genetic structure of the grain aphid Sitobion avenae (F.) in central Europe. PhD thesis, University of Goettingen.

Reimer, L., 2005. Clonal diversity and population genetic structure of the grain aphid Sitobion avenae (F.) in central Europe. PhD thesis, University of Goettingen.

Reynolds, T.L., Crawford, R.L., 1997. Effects of light on the accumulation of abscisic acid and expression of an early cysteine-labeled metallothionein gene in microspores of Triticum aestivum during induced embryogenic development. Plant Cell Reports 16, 458-463.

Rhodes, J., Croghan, P., Dixon, A., 1996. Uptake, excretion and respiration of sucrose and amino acids in the pea aphid Acyrthosiphon pisum. The Journal of Experimental Biology 199, 1269-1276.

Rhodes, J.D., Croghan, P.C., Dixon, A.F.G., 1997. Dietary sucrose and oligosaccharide synthesis in relation to osmoregulation in the pea aphid, Acyrthoslphon pisum. Physiological Entomology 22, 373-379.

Rossello-Mora, R., Amann, R., 2001. The species concept for prokaryotes. FEMS Microbiology Reviews 25, 39-67.

Russell, J.A., Latorre, A., Sabater-Muñoz, B., Moya, A., Moran, N.A., 2003. Sidestepping secondary symbionts: Widespread horizontal transfer across and beyond the Aphidoidea. Molecular Ecology 12, 1061-1075.

Russell, J.A., Moran, N.A., 2006. Costs and benefits of symbiont infection in aphids: Variation among symbionts and across temperatures. Proceedings of the Royal Society B: Biological Sciences 273, 603-610. 
Russell, J.A., Moran, N.A., 2006. Costs and benefits of symbiont infection in aphids: Variation among symbionts and across temperatures. Proceedings of the Royal Society B: Biological Sciences 273, 603-610.

SAMBROOK, J., FRITSCH, E.F., MANIATIS, T., 1989. Molecular cloning: a laboratory manual. Cold Spring Habor Laboratory Press, New York.

Sanada, Y., Takai, T., Yamada, T., 2004. Genetic variation in water -soluble carbohydrate concentration in diverse cultivars of Dactylis glomerata L. during vegetative growth. Australian Journal of agricultural Research 55, 1183-1187.

Sandström, J.P., Russell, J.A., White, J.P., Moran, N.A., 2001. Independent origins and horizontal transfer of bacterial symbionts of aphids. Molecular Ecology 10, 217-228.

Saxena, R.C., Barrion, A.A., 1987. Biotypes of insect pests of agricultural crops. Insect Science and its Application 8, 453-458.

Scarborough, C.L., Ferrari, J., Godfray, H.C.J., 2005. Aphid protected from pathogen by endosymbiont. Science 310, 1781 .

Scarborough, C.L., Ferrari, J., Godfray, H.C.J., 2005. Ecology: Aphid protected from pathogen by endosymbiont. Science 310, 1781 .

Shigenobu, S., Watanabe, H., Hattori, M., Sakaki, Y., Ishikawa, H., 2000. Genome sequence of the endocellular bacterial symbiont of aphids Buchnera sp. APS. Nature 407, 81-86.

Shigenobu, S., Watanabe, H., Hattori, M., Sakaki, Y., Ishikawa, H., 2000. Genome sequence of the endocellular bacterial symbiont of aphids Buchnera sp. APS. Nature 407, 81-86.

Short, J.M., Fernandez, J.M., Sorge, J.A., Huse, W.D., 1988. AZap: a bacteriophage $\lambda$ expression vector with in vivo excision properties. Nucleic Acids Research 16, 75837600 .

Sigma-Plot, 2006. Release 10.0. Systat Software, Inc., 1735, Technology Drive, Ste 430 San Jose, CA 95110.

Simon, J.C., Baumann, S., Sunnucks, P., Hebert, P.D.N., Pierre, J.S., Le Gallic, J.F., Dedryver, C.A., 1999. Reproductive mode and population genetic structure of the cereal aphid Sitobion avenae studied using phenotypic and microsatellite markers. Molecular Ecology Notes 8, 531-545. 
Smith, K.F., Reed, K.F.M., Foot, J.Z., 1997. An assessment of the relative importance of specific traits for the genetic improvement of nutritive value in dairy pasture. Grass and Forage Science 52, 167-175.

Stackebrandt, E., Frederiksen, W., Garrity, G.M., Grimont, P.A.D., Kämpfer, P., Maiden, M.C.J., Nesme, X., Rosséllo-Mora, R., Swings, J., Trüper, H.G., Vauterin, L., Ward, A.C., Whitman, W.B., 2002. Report of the ad hoc committee for the re-evaluation of the species definition in bacteriology. International Journal of Systematic and Evolutionary Microbiology 52, 1043-1047.

Sunnucks, P., De Barro, P.J., Lushai, G., Maclean, N., Hales, D., 1997. Genetic structure of an aphid studied using microsatellites: Cyclic parthenogenesis, differentiated lineages and host specialization. Molecular Ecology 6, 1059-1073.

Sunnucks, P., England, P.R., Taylor, A.C., Hales, D.F., 1996. Microsatellite and chromosome evolution of parthenogenetic Sitobion aphids in Australia. Genetics 144, 747756.

SYSTAT, 2004. Release 11.00.01, Systat Software, Inc., 1735, Technology Drive, Ste 430 San Jose, CA 95110.

SYSTAT, 2007. Release 12.01.02, Systat Software, Inc., 1735, Technology Drive, Ste 430 San Jose, CA 95110.

Tamas, I., Klasson, L., Canbäck, B., Näslund, A.K., Eriksson, A.S., Wernegreen, J.J., Sandström, J., Moran, N., Andersson, S.G., 2002. 50 million years of genomic stasis in endosymbiotic bacteria. Science 296, 2376-2379.

Tamura, K., Dudley, J., Nei, M., Kumar, S., 2007. MEGA4: Molecular Evolutionary Genetics Analysis (MEGA) software version 4.0. Molecular Biology and Evolution 24, 1596-1599.

Thao, M.L., Moran, N.A., Abbot, P., Brennan, E.B., Burckhardt, D.H., Baumann, P., 2000. Cospeciation of Psyllids and Their Primary Prokaryotic Endosymbionts. pp. 28982905.

Thompson, J.D., Gibson, T.J., Plewniak, F., Jeanmougin, F., Higgins, D.G., 1997. The CLUSTAL_X windows interface: flexible strategies for multiple sequence alignment aided by quality analysis tools. Nucleic Acids Research 25, 4876-4882. 
Tosh, C.R., Vamvatsikos, P.G., Hardie, J., 2004. A highly viable cross between Aphis fabae (Homoptera: Aphididae) clones with different plant preference. Environmental Entomology 33, 1081-1087.

Tsuchida, T., Koga, R., Fukatsu, T., 2004. Host Plant Specialization Governed by Facultative Symbiont. Science 303, 1989.

Tsuchida, T., Koga, R., Fukatsu, T., 2004. Host plant specialization governed by facultative symbiont. Science 303, 1989-1989.

Tsuchida, T., Koga, R., Shibao, H., Matsumoto, T., Fukatsu, T., 2002. Diversity and geographic distribution of secondary endosymbiotic bacteria in natural populations of the pea aphid, Acyrthosiphon pisum. Molecular Ecology 11, 2123-2135.

Urbanska, A., Freddy Tjallingii, W., Dixon, A.F.G., Leszczynski, B., 1998. Phenol oxidising enzymes in the grain aphid's saliva. Entomologia Experimentalis et Applicata 86, 197-203.

Van Den Heuvel, J.F.J.M., Hummelen, H., Verbeek, M., Dullemans, A.M., Van Der Wilk, F., 1997. Characteristics of Acyrthosiphon pisum Virus, a Newly Identified Virus Infecting the Pea Aphid. Journal of Invertebrate Pathology 70, 169-176.

Van den Heuvel, J.F.J.M., Verbeek, M., Van der Wilk, F., 1994. Endosymbiotic bacteria associated with circulative transmission of potato leafroll virus by Myzus persicae. Journal of General Virology 75, 2559-2565.

Via, S., 1999. Reproductive isolation between sympatric races of pea aphids. I. Gene flow restriction and habitat choice. Evolution 53, 1446-1457.

Vialatte, A., Dedryver, C.A., Simon, J.C., Galman, M., Plantegenest, M., 2005. Limited genetic exchanges between populations of an insect pest living on uncultivated and related cultivated host plants. Proceedings of the Royal Society B: Biological Sciences 272, 1075-1082.

Vickerman, G.P., Wratten, S.D., 1979. The biology and pest status of cereal aphids (Hemiptera: Aphididae) in Europe: a review. Bulletin of Entomological Research 69, 1-32.

Wangai, A.W., Plumb, R.T., VAN Emden, H.F., 2000. Effects of Sowing Date and Insecticides on Cereal Aphid Populations and Barley Yellow Dwarf Virus on Barley in Kenya. Journal of Phytopathology 148, 33. 
Watt, A.D., Dixon, A.F., 1981. The role of cereal growth stages and crowding in the induction of alatae in Sitobion avenae and its consequences for population growth. Ecological Entomology 6, 441-447.

Weatherwax, S.C., Ong, M.S., Degenhardt, J., Bray, E.A., Tobin, E.M., 1996. The interaction of light and abscisic acid in the regulation of plant gene expression. Plant Physiology 111, 363-370.

Weber, G., 1985. On the ecological genetics of Sitobion avenae (F.) (Hemiptera, Aphididae). Journal of Applied Entomology 100, 100-108.

Weisgraber, K.H., Lousberg, R.J.J.C., Weiss, U., 1971. The chemical basis of the color dimorphism of an aphid, Macrosiphum liriodendri (monell), and a locust, Amblycorypha sp. Novel carotenoids. Experientia 27, 1017-1018.

Weisser, W.W., Braendle, C., 2001. Body colour and genetic variation in winged morph production in the pea aphid. Entomologia Experimentalis et Applicata 99, 217-223.

Wernegreen, J.J., Richardson, A.O., Moran, N.A., 2001. Parallel acceleration of evolutionary rates in symbiont genes underlying host nutrition. Molecular Phylogenetics and Evolution 19, 479-485.

Wilkinson, T., Ashford, D., Pritchard, J., Douglas, A., 1997. Honeydew sugars and osmoregulation in the pea aphid Acyrthosiphon pisum. The Journal of Experimental Biology 200, 2137-2143.

Wilson, A.C.C., Massonnet, B., Simon, J.C., Prunier-Leterme, N., Dolatti, L., Llewellyn, K.S., Figueroa, C.C., Ramirez, C.C., Blackman, R.L., Estoup, A., Sunnucks, P., 2004. Cross-species amplification of microsatellite loci in aphids: Assessment and application. Molecular Ecology Notes 4, 104-109.

Wilson, A.C.C., Sunnucks, P., Hales, D.F., 1997. Random loss of X chromosome at male determination in an aphid, Sitobion near fragariae, detected using an X-linked polymorphic microsatellite marker. Genetical Research 69, 233-236.

Wilson, A.C.C., Sunnucks, P., Hales, D.F., 2003. Heritable genetic variation and potential for adaptive evolution in asexual aphids (Aphidoidea). Biological Journal of the Linnean Society $79,115-135$.

Winter, H., Lohaus, G., Heldt, H.W., 1992. Phloem Transport of Amino Acids in Relation to their Cytosolic Levels in Barley Leaves. Plant Physiology 99, 996-1004. 


\section{Acknowledgments}

I would like to thanks my supervisors for scientific support and the Syrian ministry of high education for financing my residence in Germany during my study.

We thank Mr. Yasuharu Sanada from National Agricultural Research Center- Hokkaido Region for supplying us with cocksfoot cultivars. 


\section{Publication}

Alkhedir H, Vidal S (2006) Clonal performance, fitness and host adaptability of grain aphid Sitobion avenae F. clones in central Germany. Mitteilungen Biologischer Bundesanstalt für Land- und Forstwirtschaft, 400: 226-227.

Alkhedir H, Vidal S (2006) Water soluble carbohydrate (WSC) proportions in cocksfoot grass cultivars trigger host specialisation in grain aphid clones (Sitobion avenae F.). Mitteilungen Biologischer Bundesanstalt für Land- und Forstwirtschaft, 400: 230.

Alkhedir H, Vidal S (2006) The effect of light intensity on the color morph formation and performance in the grain aphid Sitobion avenae F. Mitteilungen Biologischer Bundesanstalt für Land- und Forstwirtschaft, 400: 230.

Alkhedir H, Vidal S, (2007) Diversity of bacterial symbionts in clones of the English Grain Aphid Sitobion avenae F. (Insecta: Homoptera) and host plant performance - Ber. nat.med. Verein Innsbruck, Suppl.17,8.

Alkhedir H, Karlovsky P and Vidal S (2008) Molecular characterisation of Sitobion avenae $\mathrm{F}$. clones and their interaction with different host plants. Mitteilungen aus dem Julius Kühn-Institut,417:223.

Alkhedir H, Karlovsky P and Vidal S (2008) Molecular characterization of primary and secondary endo symbiotic bacteria of the grain aphid Sitobion avenae F. . Mitteilungen aus dem Julius Kühn-Institut,417:391. 


\section{Curriculum Vitae}

Hussein Alkhedir

Born 1974 in Albab - Syria

Address agricultural Entomology

University of Goettingen

Grisebach Strasse 6

37077 Goettingen

Germany

E-mail halkhed@gwdg.de

\section{Educational history}

1992 Baccalaureate in the science branch (Albab - Aleppo- Syria)

1998 Diploma in Agricultural Sciences (plant protection) at University Aleppo- Syria 1999-2001 scientific assistant at department of plant protection -Aleppo University

Since 2002 scientific assistant at department of Entomology -University Goettingen

2005 Master in Agricultural Sciences (Phytomedicine) at George-August- University in institute of plant pathology and plant protection

Since 2005 PhD student at Department for Crop Sciences - Entomological Section in Georg-August-University of Göttingen

2008 Doctor degree in Agricultural science at University Goettinegen 